COO-1624-14

\title{
RECOMBINATION STATISTICS FOR THE NEUTRON-INDUCED BASE CURRENT COMPONENT
}

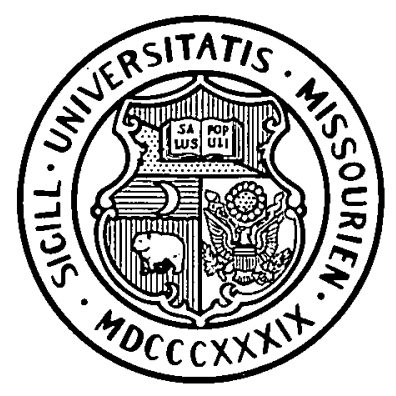

M. C. Chow

\author{
University of Missouri - Rolla \\ Space Sciences Research Center \\ Electronics Research \\ Rolla, Missouri 65401
}




\section{DISCLAIMER}

This report was prepared as an account of work sponsored by an agency of the United States Government. Neither the United States Government nor any agency Thereof, nor any of their employees, makes any warranty, express or implied, or assumes any legal liability or responsibility for the accuracy, completeness, or usefulness of any information, apparatus, product, or process disclosed, or represents that its use would not infringe privately owned rights. Reference herein to any specific commercial product, process, or service by trade name, trademark, manufacturer, or otherwise does not necessarily constitute or imply its endorsement, recommendation, or favoring by the United States Government or any agency thereof. The views and opinions of authors expressed herein do not necessarily state or reflect those of the United States Government or any agency thereof. 


\section{DISCLAIMER}

Portions of this document may be illegible in electronic image products. Images are produced from the best available original document. 
RECOMBINATION STATISTIES FOR THE NEUTRON-INDUCED

BASE CURRENT COMPONENT

by

MING-CHWAN CHOW

A DISSERTATION

Presented to the Faculty of the Graduate School of the UNIVERSITY OF MISSOURI - ROLLA

In Partial Fulfilment of the Requirements for the Degree DOCTOR OF PHILOSOPHY

IN

ELECTRICAL ENGINEERING

Rolla, Missouri

1968
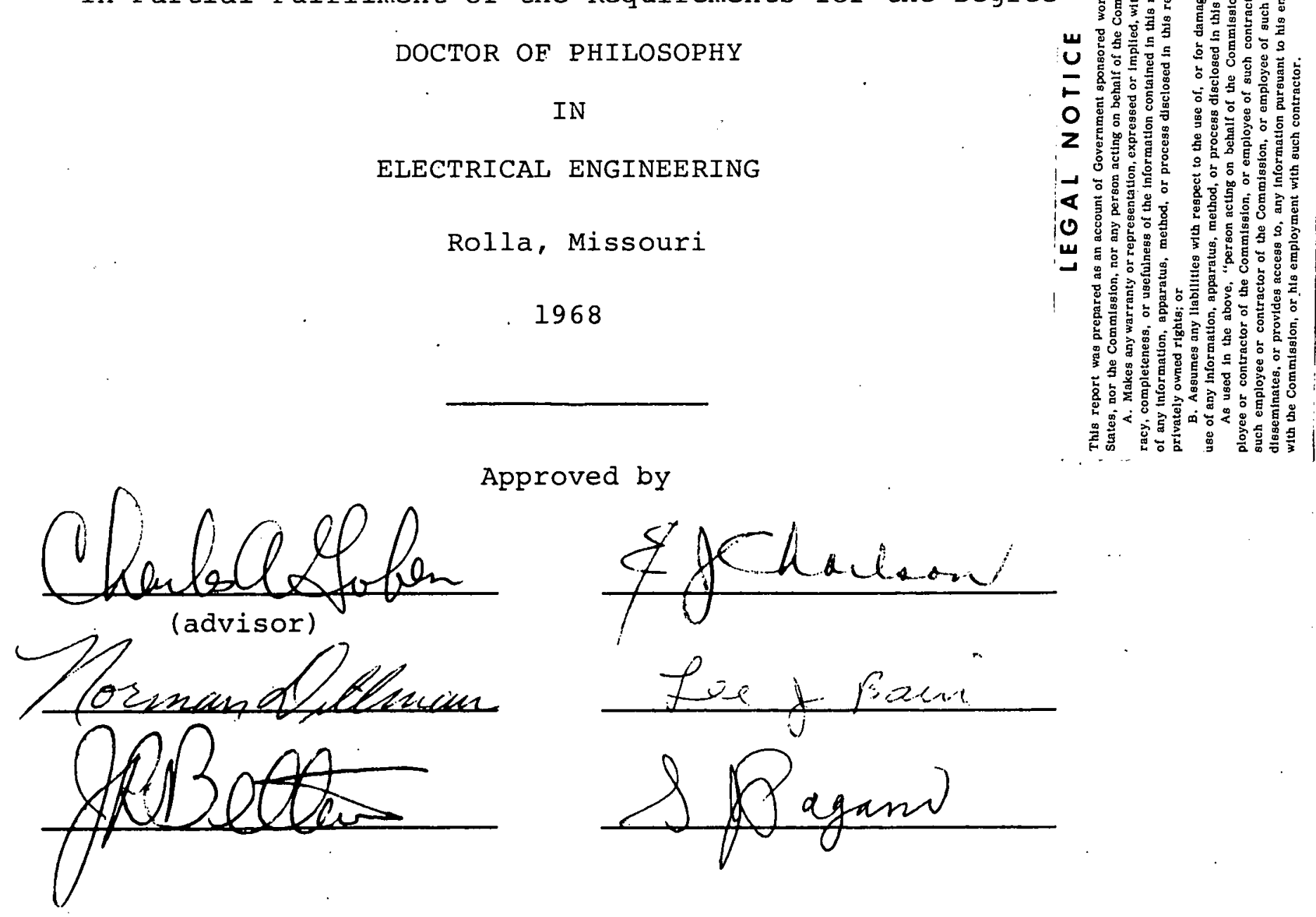

Approved by
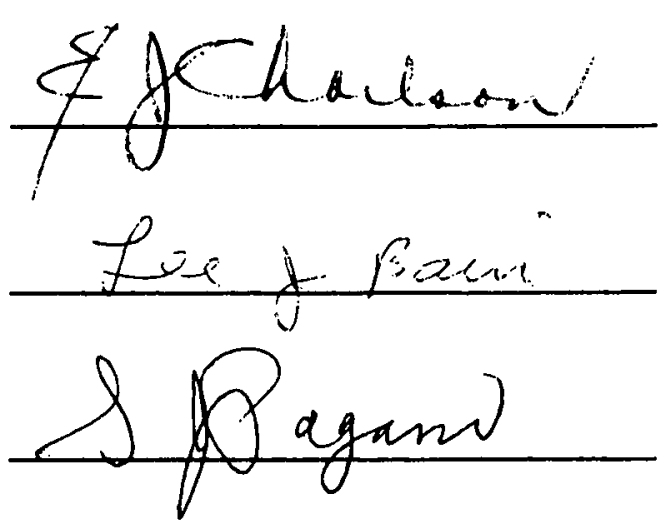


\section{ABSTRACT}

In 1964 Goben reported a neutron-induced base current component with an emitter-to-base voltage dependence of $\exp \left(\mathrm{qV}_{\mathrm{BE}} / \mathrm{nkT}\right)$. The reciprocal slope term, $\mathrm{n}$, was observed to increase with decreasing temperature. The room temperature value of $\mathrm{n}$ is about 1.5. The exact nature of the recombination statistics for this neutron-induced base current has not been previously studied.

Since neutron radiation introduces deep energy defect levels into the silicon bandgap, the neutron-induced current component, in this work, was assumed to have the same nature as that suggested by Sah, Noyce, and shockley for recombination-generation in silicon via non-radiation-induced deep levels in the bulk space-charge region. The electrical properties of a defect state is known, from Shockley-Read-Hall statistics, to be primarily characterized by the following four parameters: the defect concentration, $\mathrm{N}_{\mathrm{R}}\left(\mathrm{cm}^{-3}\right)$; the defect energy, $E_{R}(e V)$; and the capture cross-sections for electrons and holes, $\sigma_{\mathrm{n}}$ and $\sigma_{\mathrm{p}}\left(\mathrm{cm}^{-2}\right)$, respectively.

In order to investigate the recombination statistics for the neutron-induced current component, several transistor parameters were studied. From capacitance-voltage measurements, the impurity profiles for silicon $p-n$ junction transistors were determined. The determination of impurity distribution was repeated at various neutron fluences. The carrier removal coefficients for holes and electrons were calculated as $\mathrm{k}_{\mathrm{p}}=1.8 \times 10^{8} \times \mathrm{N}_{\mathrm{o}}^{0.442}$, and 
$\mathrm{k}_{\mathrm{n}}=4.0 \times 10^{8} \times \mathrm{N}_{\mathrm{o}}^{0.444}$, respectively, where $\mathrm{N}_{\mathrm{o}}$ is the initial impurity concentration. A very detailed table of correction factors (needed for the impurity distribution determination of diffused junctions and junction devices from capacitance-voltage measurements) was developed and is presented in this paper.

The theoretical dependence of diffusion potential, $\mathrm{V}_{\mathrm{T}}{ }^{\prime}$ on neutron fluence has been developed and confirming experimental measurements have been made.

From a temperature study of transistor voltage-current characteristics, the activation energies of the neutroninduced defect levels were calculated: $0.23 \mathrm{eV}$ in the emitter-base space-charge region and $0.35 \mathrm{eV}$ in the "neutral" base region. This paper presents a recombination statistical model for the neutron-induced base current component which has been proved of bulk origin and must be attributed to recombination in the bulk emitter-base space-charge region. A single dominant energy level, $0.23 \mathrm{eV}$, was assumed and used in the statistical model fitting. This assumption was proved to be valid, for low to moderate neutron fluences, from the predicted and observed $n$ values.

Minority carrier lifetime measurements were made at various neutron fluences. The lifetime radiation damage factors were calculated, $2.3 \times 10^{-7}\left(\mathrm{nvt}^{-1}-\mathrm{sec}^{-1}\right)$ for electrons and $8.5 \times 10^{-9}\left(\mathrm{nvt}^{-1}-\mathrm{sec}^{-1}\right)$ for holes. The capture cross-sections for holes and electrons were determined, $1.8 \times 10^{-16}\left(\mathrm{~cm}^{-2}\right)$ and $8.1 \times 10^{-15}\left(\mathrm{~cm}^{-2}\right)$, respectively. 
These capture cross-sections are in good agreement with those of Messenger, Spratt, Walters and Landis. This implies that minority carrier lifetime measurements give good results in the determination of capture cross-sections if high accurate lifetime measurements are available.

This paper presents a derivation of the recombination statistical model for the neutron-induced base current component. The derivation was based on the assumptions: 1) the current equation for the induced current component developed by Goben is valid; 2) the Shockley-Read-Hall statistics for holes and electrons are applicable; and 3) the recombination statistics derived by Sah, Noyce and Shockley, for sites in the bulk space-charge region are valid. Several examples were presented to emphasize accuracy of this derived model for predictions. This paper shows that the recombination process may be described by a mathematical model, recombination statistics which depend on the diffusion potential, the junction voltage, the activation energy, and the capture cross-sections for holes and electrons. This paper also shows that the statistical model will predict the correct value for $\mathrm{n}$ when the model is accurately fitted to the physical process. Temperature dependence of this reciprocal slope term was involved explicitly in the statistics model. Examples are presented to illustrate the utility of such a recombination statistical model in predicting the base current for $\mathrm{p}-\mathrm{n}$ junction transistors with considerable accuracy . 
TABLE OF CONTENTS

Page

ABSTRACT

LIST OF FIGURES • • • • • • • • • • • • • • • • • • • vi v vi

LIST OF TABLES • • • • • • • • • • • • • • • • • • • vii

LIST OF ILLUSTRATIONS FOR APPENDICES • • • • • • • • • viii

I. INTRODUCTION $\cdot$ •

II. DETERMINATION OF IMPURITY DISTRIBUTION, CONCENTRATION OF NEUTRON-INDUCED DEFECT CENTERS, DIFFUSION POTENTIAL, AND FERMI ENERGY FROM $\mathrm{C}-\mathrm{V}$

MEASUREMENTS

A. Impurity Distribution in a Junction Diode •. • 8

B. A Computer Program for the Determination of

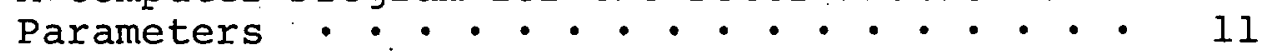

C. Impurity Profile of Epitaxial-Planar

Transistors . • • • • • • • • • • • 18

D. The Concentration of Neutron-Induced Defect

Centers $\cdot \cdot \cdot \cdot \cdot \cdot \cdot \cdot \cdot \cdot \cdot \cdot \cdot \cdot \cdot \cdot \cdot \cdot 19$

E. The Dependence of the Diffusion Potential

on Neutron Fluence . • • • • • • • • • 26

F. Determination of Fermi Energy Level • • • • 29

III. ACTIVATION ENERGY OF NEUTRON-INDUCED DEFECT

LEVEL • • • • • • • • • • • • • • • • • 34

A. Theoretical Consideration ' - . • . . 34

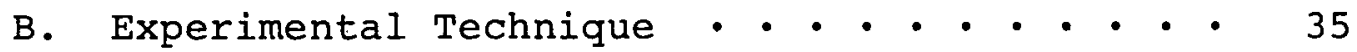

IV. MINORITY CARRIER LIFETIMES, CAPTURE CROSS-

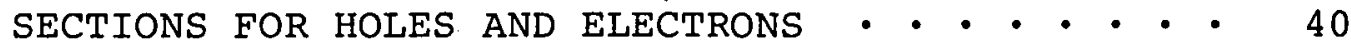

A. Minority Carrier Lifetimes . . . . . . . 40

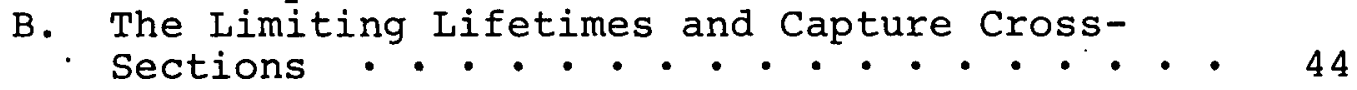

V. RECOMBINATION STATISTICS - MODEL FITTING • • • 49

A. Shockley-Read-Hall Recombination Statistics - 49

B. Sah-Noyce-Shockley Theory of Junction Space-

Charge Recombination-Generation Current • • 52

C. The Expression of the Reciprocal Slope Term

for the Neutron-Induced Base Current

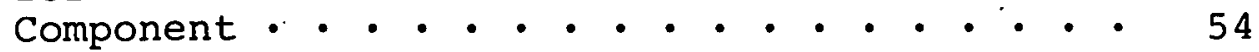

D. Temperature Dependence of the Reciprocal

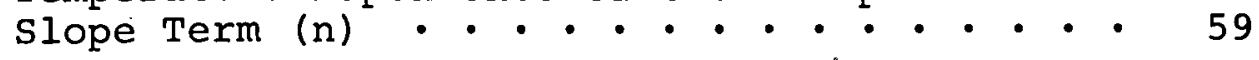


Page

VI. SUMMARY AND DISCUSSION • • • • • • • • • • 66

BIBLIOGRAPHY • • • • • • • • • • • • • • • 70

ACKNOWLEDGEMENTS • • • • • • • • • • • • • • 75

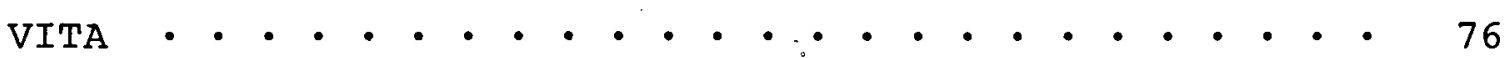

APPENDIX A: AUTOMATIC DATA ACQUISITION SYSTEM AND

DATA REDUCTION TECHNIQUES • $\cdot$. $\cdot$ • $\cdot$ Al

1. General Description . . . . . . Al

2. Cyclic Operation •. • . . . . . . A7

APPENDIX B: CAPACITANCE-VOLTAGE MEASURING SYSTEMS • $\quad$ BI

APPENDIX C: MINORITY CARRIER LIFETIME MEASUREMENT • • Cl

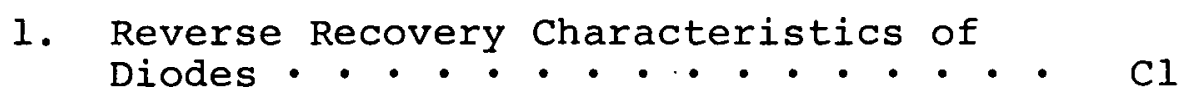

2. The Effective Lifetime of Minority

Carriers • $\cdot \cdot \cdot \cdot \cdot \cdot \cdot \cdot \cdot \cdot \cdot \cdot \cdot \quad c 3$

3. Minority Carrier Lifetimes in the Base and Collector Regions of a Junction

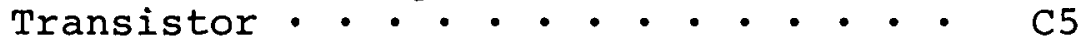

APPENDIX D: NUCLEAR REACTOR FACILITY AND IRRADIATION

PROBLEMS • • • • • • • • • • • • • • • DI

1. Nuclear Reactor Facility • . • . • D1

2. Irradiation Problems •. • . • . . D4

APPENDIX E: HISTORY OF THE RESEARCH IN THIS AREA • • E 1

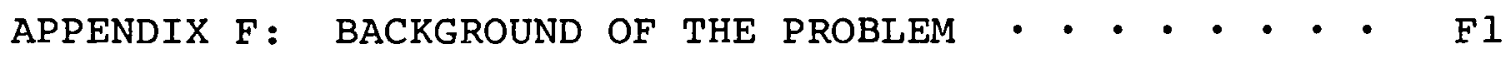

APPENDIX G: A SHORT REVIEW OF STATISTICS REGRESSION

MODELS - IEAST-SQUARES FITTING • • • • • GI

1. Least-Squares Fitting to Linear Re-

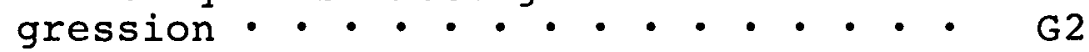

2. Non-Linear Estimation •. . . • . G3

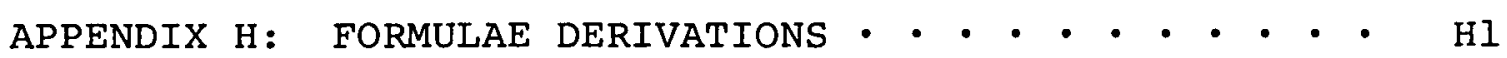

1. General Consideration of Minority Carrier Lifetimes • • • • • • • • • HI

2. The Limiting Lifetimes and the Capture Probabilities of the Centers for Holes

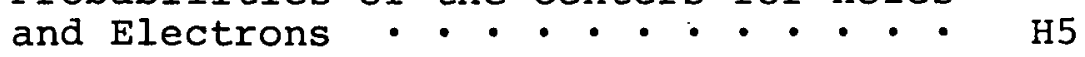


Figure

Page

II-1. Impurity profile and depletion layer characteristics for diffused junctions. . . . 10

II-2. Typical epitaxial-planar transistor impurity

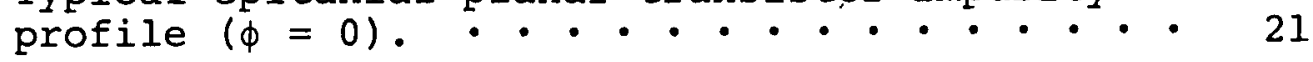

II-3. Epitaxial-planar transistor impurity profile at various fluences (Device SF2523 \#40). • • • 22

II-4. Dependence of carrier removal coefficient on initial carrier concentration. $\cdot$ - • • • • • 25

II-5. Dependence of the diffusion potential on neutron fluence at $300^{\circ} \mathrm{K}$ (Device SF2523\#40). • 28

III-1. Schematic V-I data different temperatures. • • 36

III-2. I-T characteristics used for activation

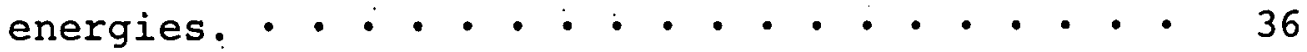

IV-1. Minority carrier lifetime in base versus neutron fluence (at $300^{\circ} \mathrm{K}$ ). . . . . . . 45

IV-2. Minority carrier lifetime in collector versus neutron fluence (at $\left.300^{\circ} \mathrm{K}\right) . . \cdot$. . . . . . 46

V-1. Four basic recombination-generation processes through recombination centers. . . . . . . 50

V-2, Predicted and observed base current versus emitter-base bias (Device SF2523 \#40). • • • 61

V-3. Predicted and observed base current versus emitter-base bias (Device SF2524 \#68). • • • • 62

V-4. Predicted and observed base current versus emitter-base bias (Device 2N914 \#7). • . . . .

$\mathrm{V}-5$. Predicted and observed temperature dependence of the reciprocal slope term, $n$, for $n-p-n$ silicon transistors. 


\section{LIST OF TABLES}

Tabie

Page

I-1. Identified junction transistor base current

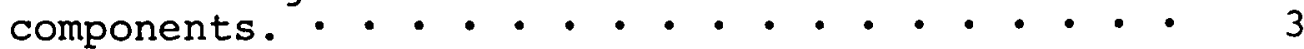

II-1. Correction factors for diffused junctions. • - 12

II-2. Parameters for impurity distribution (Device

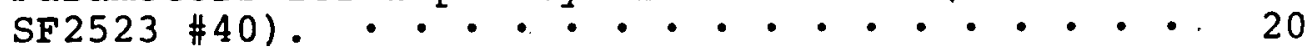

II-3. Defect concentrations for Device SF2523 \#40 • 24

II-4. Diffusion potential at various neutron fluences $\left(\mathrm{T}=300^{\circ} \mathrm{K}\right) \cdot \cdot \cdot \cdot \cdot \cdot \cdot \cdot \cdot \cdot \cdot \cdot 30$

II-5. Dependence of Fermi energy on doping levels ( $\mathrm{Si}, 300^{\circ} \mathrm{K}$ ).

II-6. Fermi energies for Device SF2523 \#40 at various fluences $\left(T=300^{\circ} \mathrm{K}\right) . \cdot \cdot \cdot \cdot \cdot \cdot \cdot \cdot \cdot \cdot \cdot \cdot \cdot 33$

III-1. Values of $E_{R}$ for nine $n-p-n$ Si epitaxial-planar

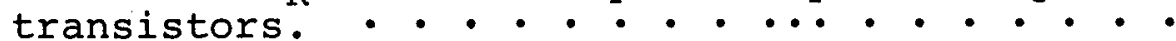

III-2. Activation energies for three different $V_{B E}$ (Device SF2523\#40, at $\phi=5.3 \times 10^{14}$ nvt).

III-3. Activation energies at various neutron fluences

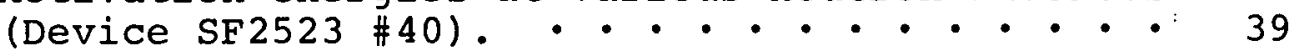

IV-1. Values of $\tau_{E B}, \tau_{B C}, \tau_{B}$ and $\tau_{C}$ (at $\left.\phi=0.0\right) . \cdot .43$

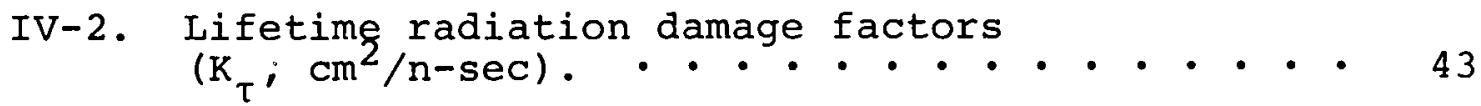
IV-3. Limiting lifetimes at $300^{\circ} \mathrm{K}$. • • • • • • • 47 IV-4. Capture cross-sections for holes and electrons. 48 
A-1. Block diagram of the Automatic Data Acquisition System. $\cdot \cdot \cdot \cdot \cdot \cdot \cdot \cdot \cdot \cdot \cdot \cdot \cdot \cdot \cdot \cdot \cdot \cdot \cdot \cdot \cdot A$ A2

A-2. Photograph of initiation of the system for a typical data run. $\cdot \bullet^{\cdot} \cdot \cdot \cdot \cdot \cdot \cdot \cdot \cdot \cdot \cdot \cdot \cdot \cdot$ A3

A-3. Photograph of sample holder in its mounting, the heat sink standing behind the devices. $\cdot$. A4

A-4. Base current measurement circuit. . • . . . . - A8

A-5. Collector current measurement circuit. . . • • A8

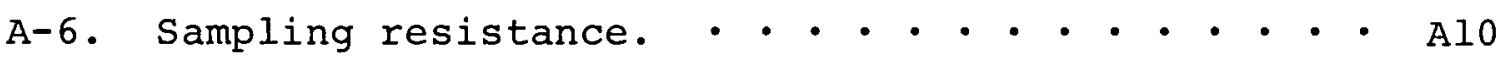

B-1. Capacitance-voltage measurement system. • • • • B3

B-2. Capacitance-voltage system block diagram. • • - B5

C-1. Typical display of diode reverse recovery . . . .

C-2. Tangent line for calculating the voltage decay

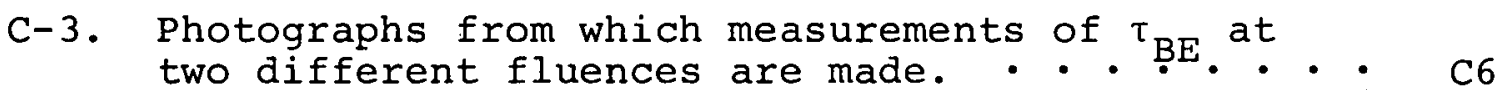

D-1. Table of technical data for the UMR Research

D-2. Core configuration 31-T. • • • • • • • • • • • D3

D-3. Photograph of sample holder. • • • • • • • • D5 


\section{INTRODUCTION}

The statistics of the recombination of holes and electrons in semiconductors was first derived by shockley and Read $^{1-3}$. The derivation was based on the assumption that the recombination-generation occurs through the mechanism of recombination centers or traps. Four basic processes were assumed to be involved in this recombination-generation through the recombination centers: 1) hole capture; 2) hole emission; 3) electron capture; and 4) electron emission ${ }^{1,2,4}$. Based on Shockley-Read-Hall Statistics ${ }^{1,2,4}$, Sah et al. 5,6 have developed a theory of $\mathrm{p}-\mathrm{n}$ junctions taking into account the recombination-generation of the carriers in the spacecharge (transition) region. It has been observed, for some types of junctions, that the measured current-voltage characteristics deviate from the ideal case of the diffusion model ${ }^{1-3}$. Sah, Noyce and Shockley ${ }^{5}$ showed that the current caused by recombination-generation in the space-charge region of a p-n junction accounts for the observed characteristics. Their model not only accounts for the nonsaturable reverse current, but also predicts an apparent exp ( $q V / n k T)$ dependence of the forward current in a $\mathrm{p}-\mathrm{n}$ junction. Some other important conclusions have been made ${ }^{5}$ the emitter efficiency of silicon transistors will increase with emitter current; the energy levels of the most effective recombination centers are within a few $\mathrm{kT}$ of the intrinsic Fermi level.

In a junction transistor, the collector current varies 
with emitter-base voltage as $\exp \left(\mathrm{qV}_{\mathrm{BE}} / \mathrm{kT}\right)$, while the base current is composed of several components and varies with $\mathrm{V}_{\mathrm{BE}}$ as $\exp \left(\mathrm{qV}_{\mathrm{BE}} / \mathrm{nkT}\right)$ with different values of $\mathrm{n}$; these are listed in Table I-l. In order to study the nuclear radiation effects on silicon $\mathrm{p}-\mathrm{n}$ junction transistors, the last component in Table I-1 was considered throughout this investigation. This component was identified by Goben ${ }^{8-12}$ and has the following expression ${ }^{13}$

$$
\mathrm{I}_{\mathrm{BN}}=\mathrm{K}_{\mathrm{V}} \cdot \mathrm{A}_{\mathrm{E}} \cdot \mathrm{x}_{\mathrm{m}}\left(\mathrm{V}_{\mathrm{BE}}\right) \cdot \phi \cdot \exp \left(\mathrm{qV}_{\mathrm{BE}} / \mathrm{nkT}\right),(1-1)
$$

where $\mathrm{x}_{\mathrm{m}}\left(\mathrm{V}_{\mathrm{BE}}\right)=$ depletion layer width $(\mathrm{cm})$,

$\mathrm{I}_{\mathrm{BN}}=$ neutron-induced base current component (amp), $\mathrm{K}_{\mathrm{V}}=$ damage constant (amp/ $\left.\mathrm{cm}^{3} / \mathrm{nvt}\right)$, $\mathrm{A}_{\mathrm{E}}=$ effective emitter area $\left(\mathrm{cm}^{2}\right)$. $\phi=$ neutron fluence (nvt), $q=$ electron charge $\left(1.6 \times 10^{-19} \mathrm{coul}\right)$, $\mathrm{V}_{\mathrm{BE}}=$ emitter-base voltage (volt), $\mathrm{n} \simeq 1.5$ at $\mathrm{T}=300^{\circ} \mathrm{K}$, $k=$ Boltzmann's constant, $\mathrm{T}=$ temperature $\left({ }^{\circ} \mathrm{K}\right)$.

One important limitation of transistors operated in a neutron environment is the decrease in transistor current gain observed upon exposure to neutron irradiation. The reduction in current gain results from the degradation of minority lifetime in the base region (i.e., to the resultant reduction of the base recombination term ${ }^{14-18}$, and the reduction in the emitter efficiency ${ }^{8-12}$. In Goben's work ${ }^{8-12}$, 
Table I-1. Identified junction transistor base current components.

\begin{tabular}{|c|c|}
\hline $\begin{array}{c}\text { Voltage } \\
\text { Dependence }\end{array}$ & Current Component/Description, Identifier. \\
\hline $\exp (q V / k T)$ & $\begin{array}{l}\text { Bulk recombination-generation, which follows } \\
\text { the ideal diffusion theory given by shockley }{ }^{1} \\
\text { for uniform base transistors and extended to } \\
\text { the general case by Moll and Ross }{ }^{7} \text {. }\end{array}$ \\
\hline $\exp (q V / 2 k T)$ & $\begin{array}{l}\text { Bulk recombination-generation in the space- } \\
\text { charge region which dominates the base cur- } \\
\text { rent at low current densities }{ }^{5} \text {. }\end{array}$ \\
\hline $\begin{array}{c}\exp (q V / n k T) \\
n \simeq 1.5\end{array}$ & $\begin{array}{l}\text { Surface recombination-generation in the } \\
\text { space-charge region } 2,6,7 \text {. }\end{array}$ \\
\hline $\begin{array}{l}\exp (q V / m k T) \\
2 \leq m \leq 4\end{array}$ & $\begin{array}{l}\text { Surface channel, } m \text { of values larger than } 4 \\
\text { have been noted for large charge } 3,5-7 \text {. }\end{array}$ \\
\hline $\begin{array}{c}\exp (\mathrm{qV} / \mathrm{nkT}) \\
\mathrm{n} \simeq 1.5\end{array}$ & $\begin{array}{l}\text { Bulk recombination-generation in the bulk } \\
\text { space-charge region, when the transistor is } \\
\text { exposed to neutron irradiation } 8-12 \text {. }\end{array}$ \\
\hline
\end{tabular}

it was shown that the emitter efficiency is indeed a very sharply decreasing function of neutron fluence and is responsible for a large fraction of the neutron degradation of transistor current gain. Transistors provide a definite advantage over semiconductor bulk materials for studying radiation effects since they permit measurement of base lifetime in the range from several hundred microseconds down to the nanosecond range, whereas determination of lifetime by photoconductivity in bars of semiconductor material is in general limited to the range greater than one microsecond. 
The reciprocal slope term, $\mathrm{n}$, in $\exp \left(\mathrm{qV}_{\mathrm{BE}} / \mathrm{nkT}\right)$ was observed ${ }^{8-12}$ to increase with decreasing temperature from 1.5 at room temperature to $1.6 \sim 1.7$ at $-50^{\circ} \mathrm{C}$ and to decrease with increasing temperature to 1.3 at $100^{\circ} \mathrm{C}$. In the work by Aukerman, Millea and $\operatorname{MCColl}^{19}$, it was shown that $\mathrm{n}$ varies with temperature as

$$
\mathrm{n}=1+\frac{1}{\mathrm{bkT}}
$$

where $b$ had the value of $70 \sim 80 \mathrm{ev}^{-1}$ for GaAs $\mathrm{p}-\mathrm{n}$ junction transistors with a doping level of $2 \times 10^{17}\left(\mathrm{~cm}^{-3}\right)$. This indicates that $\mathrm{n}$ is not a universal constant and suggests the possibility that $n$ may depend upon some fundamental parameters.

The defects produced by neutron radiation have the following effects 20 on the electrical characteristics of the crystal:

1. Majority carriers are trapped at the defect centers and cannot contribute to the conductivity. This trapping increases the resistivity of both $\mathrm{n}-$ and p- type crystals. Whether the resistivity increases equally in the $\mathrm{n}$ - and $\mathrm{p}$ - type materials depends on the location (energy levels) and number of traps in the particular material.

2. Increased scattering of the free carriers results in a decrease in mobility, which increases the resistivity even more. 
3. Excess carriers recombine sooner, resulting in a shorter diffusion length and a higher recombination rate.

4. The emergence of the neutron-induced component of base current reduces the emitter efficiency and thereby causes the degradation of transistor current gain.

It can be expected that the dominant effect ${ }^{8}$ causing changes in transistor parameters is the decrease in minority carrier lifetime and degradation of the emitter efficiency. second order effects will be caused by the radiation-induced centers acting as deep lying traps as discussed previously. At higher exposure levels, more defects are available to scatter free carriers, causing a decrease in the carrier mobilities.

In a word, most electrical effects of radiation damage in semiconductors arise from the introduction of defect states into the forbidden band. From the recombination statistics developed by Shockley, Read and Hall (SRH) ${ }^{1-4}$, one knows that the electrical properties of a defect state may be largely described by four parameters: the defect concentration $\left(\mathrm{N}_{\mathrm{R}^{\prime}} \mathrm{cm}^{-3}\right)$; the defect energy $\left(\mathrm{E}_{\mathrm{R}^{\prime}} \mathrm{eV}\right)$; and two. cross sections, the hole capture cross section $\left(\sigma_{\mathrm{p}}, \mathrm{cm}^{-2}\right.$ ) and the electron capture cross section $\left(\sigma_{n^{\prime}} \mathrm{cm}^{-2}\right)$. The recombination process may be described by a mathematical model, recombination statistics, and these recombination statistics, which depend on the above mentioned parameters, will predict 
the correct value for $\mathrm{n}$ when the model is accurately fitted to the physical process. This paper presents the study of the recombination statistics of the neutron-induced base current component.

In order to study the recombination statistics for the neutron-induced base current component (i.e., for the reciprocal slope term, n) several parameters were investigated. Capacitance-voltage measurements led to the determination of impurity distribution ${ }^{21,22}$ which was then employed to calculate the concentration of neutron-induced defect levels, $\mathrm{N}_{\mathrm{R}^{\prime}}$, and the dependence of the diffusion potential $\left(\mathrm{V}_{T}\right)$ on neutron fluence. The activation energy, $E_{R^{\prime}}$ has been studied by several investigators, and the values determined were in good agreement with that presented here. ${ }^{23-27}$ The currenttemperature characteristics yielded ${ }^{1,28}$ an activation energy which was used in this investigation and had a value very close to the above-mentioned values $(0.23 \mathrm{eV})$.

The formulae for obtaining the limiting lifetimes, $\tau$ pr and ${ }^{n}$ from transistor lifetimes in various regions were derived in this work. The capture cross-sections for holes and electrons were then calculated from $N_{R^{\prime}} \tau_{p r}$ and $\tau_{n r}$. All these parameters were used in the construction of a statistical model for the reciprocal slope term, $n$, in $\exp \left(\mathrm{qV}_{\mathrm{BE}} / \mathrm{nkT}\right)$

Based on the model for the neutron-induced base current component developed by Goben ${ }^{8-12}$ and the recombination 
statistics in the space-charge region given by sah et al. 5,6 , this paper develops a recombination statistical model for the neutron-induced base current component. This model can be used for predicting the base current of any diffused junction transistors and may be extended to a more general model for other types of transistors. The dependence of the reciprocal slope term $(n)$ on temperature is implicitly included in the developed recombination statistical model. The exponential fall-off rate for the density states was also studied in this paper. 
II. DETERMINATION OF IMPURITY DISTRIBUTION, CONCENTRATION OF NEUTRON-INDUCED DEFECT CENTERS, DIFFUSION POTENTIAL, AND FERMI ENERGY FROM C-V MEASUREMENTS

\section{A. Impurity Distribution in a Junction Diode}

The basic idea ${ }^{21}$ used in the determination of the impurity distribution a $\mathrm{p}-\mathrm{n}$ junction is that the variation of the junction depletion layer width depends on the ionized impurity concentration at the edge of the depletion layer. The desired result was obtained from a double integration of Poisson's equation.

The analysis of impurity distribution determination has been derived 21 for a specified junction model, the "onesided" junction, under the following assumptions:

1. The junction is planar.

2. The impurity concentration is much higher on one side of the junction than on the other, the depletion layer extends only into the more lightly doped side of the junction.

3. The impurity atoms are completely ionized.

4. The applied potential appears entirely across the junction.

The results for some types of junctions have also been obtained ${ }^{21}$.

Under these assumptions, the net impurity concentration, $\mathrm{N}_{\mathrm{T}}$, at the edge of the depletion layer of the "one-sided" junction is given 21 by 


$$
\mathrm{N}_{\mathrm{T}}=\frac{2}{\mathrm{q} \varepsilon \mathrm{A}^{2}} \cdot\left[\frac{\mathrm{d}\left(\frac{1}{\mathrm{C}^{2}}\right)}{\mathrm{dV}}\right]^{-1},
$$

where $A=$ the junction area $\left(\mathrm{cm}^{2}\right)$,

$\mathrm{q}=$ electron charge $\left(1.6 \times 10^{-19}\right.$ coulomb),

$\varepsilon=$ semiconductor permittivity $(\mathrm{farad} / \mathrm{cm})$.

The impurity profile, $\mathrm{N}(\mathrm{x})$, was obtained from a series of capacitance-voltage (C-V) measurements, each of which yielded an impurity concentration value using equation $(2-1)$.

The assumption of a one-sided junction was not accurate for diffused junctions. Diffused junctions are characterized by several types of impurity distributions depending on the method employed for carrying out the diffusion. Two important types of diffused junctions are decribed briefly and are illustrated in Figure II-l.

1. For the case of diffusion from the gaseous vapor where the surface concentration is always constant, the impurity distribution is governed by the complementary error function,

$$
\begin{aligned}
N(x) & =N_{0} \cdot \operatorname{erfc}(x / \sqrt{4 D E})-N_{B C} \\
& =N_{0} \cdot \operatorname{erfC}\left(I_{E} x\right)-N_{B C^{\prime}}
\end{aligned}
$$

where,

$$
\begin{aligned}
\mathrm{N}_{0} & =\text { surface concentration }\left(\mathrm{cm}^{-3}\right), \\
\mathrm{N}_{\mathrm{BC}} & =\text { background concentration }\left(\mathrm{cm}^{-3}\right), \\
\mathrm{D} & =\text { impurity diffusion coefficient }\left(\mathrm{cm}^{2} / \mathrm{sec}\right),
\end{aligned}
$$




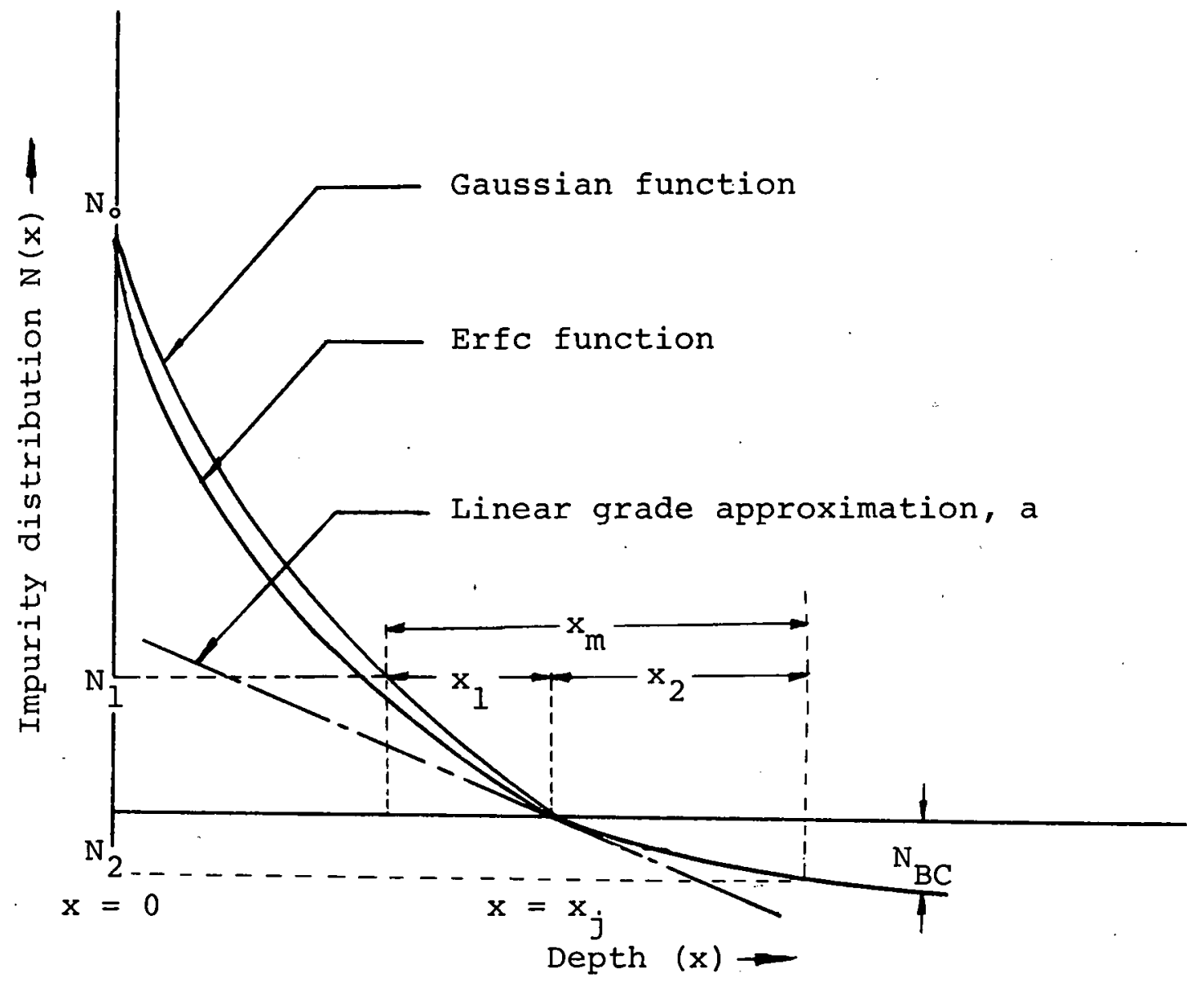

Figure II-1. Impurity profile and depletion layer characteristics for diffused junctions.

$$
\begin{aligned}
t & =\text { diffusion time (sec), } \\
\mathrm{L}_{\mathrm{E}} & =1 / / 4 \mathrm{Dt} .
\end{aligned}
$$

2. For the case of the diffusion which proceeds from a fixed concentration at the surface, one can obtain a Gaussian impurity distribution given by

$$
\begin{aligned}
\mathrm{N}(\mathrm{x}) & =\mathrm{N}_{0} \cdot \exp \left(-\mathrm{x}^{2} / 4 D t\right)-\mathrm{N}_{B C} \\
& =N_{0} \quad \exp \left(-\mathrm{L}_{B}^{2} \mathrm{x}^{2}\right)-\mathrm{N}_{B C}
\end{aligned}
$$


The impurity distribution in the vicinity of a diffused junction can usually be approximated by either equation (2-2) or equation (2-3) or a combination of the two equations. It has been shown ${ }^{21}$ that the impurity concentrations at the opposite edges of the depletion layer are related to the equivalent impurity concentration for the "one-sided" junction by

$$
\frac{1}{\mathrm{~N}_{\mathrm{T}}}=\frac{1}{\mathrm{~N}_{1}}+\frac{1}{\mathrm{~N}_{2}}
$$

where $\mathrm{N}_{1}, \mathrm{~N}_{2}=$ impurity concentrations at the depletion layer edges of a diffused junction at a specified voltage, $\mathrm{N}_{\mathrm{T}}=$ concentration given by equation $(2-1)$ for the "one-sided" junction with the same voltage.

In order to determine $\mathrm{N}_{1}$ and $\mathrm{N}_{2}$, the curves developed by Lawrence and Warner 21,29 for the division of the depletion layer width, $x_{m}$, between the widths of the two sides, $x_{1}$ and $\mathbf{x}_{2}$, in a diffused junction and the correction factors prepared by Hilibrand and Gold ${ }^{21}$ were used (The author has prepared a more complete table of these correction factors, see Table II-1).

\section{B. A Computer Program for the Determination of Parameters}

Schottky ${ }^{30}$ pointed out that the impurity distribution of junction devices could be determined from the dependence of transition capacitance on junction voltage. For abrupt 
Table II-1. Correction factors for diffused junctions.

\begin{tabular}{|c|c|c|c|c|c|c|c|c|}
\hline $\mathrm{Xl} / \mathrm{XM}$ & $\mathrm{N} 1 / \mathrm{NT}$ & $\mathrm{N} 2 / \mathrm{NT}$ & $\mathrm{Xl} / \mathrm{XM}$ & $\mathrm{N} 1 / \mathrm{NT}$ & $\mathrm{N} 2 / \mathrm{NT}$ & $\mathrm{Xl} / \mathrm{XM}$ & $\mathrm{N} I / \mathrm{NT}$ & $\mathrm{N} 2 / \mathrm{NT}$ \\
\hline 0.500 & $2.000 \mathrm{C}$ & 2.0000 & 0.499 & 2.0069 & 1.9931 & 0.498 & 2.0139 & 1.9863 \\
\hline 0.497 & 2.0210 & 1.9794 & 0.496 & 2.0282 & 1.9725 & 0.495 & 2.0355 & 1.9657 \\
\hline 0.494 & 2.0430 & 1.9588 & 0.493 & 2.0505 & 1.9519 & 0.492 & 2.0581 & 1.9451 \\
\hline 0.491 & 2.0658 & 1.9382 & 0.490 & 2.0737 & 1.9314 & 0.489 & 2.0817 & 1.9245 \\
\hline 0.488 & 2.0898 & 1.9176 & 0.487 & 2.0980 & 1.9108 & 0.486 & 2.1063 & 1.9039 \\
\hline 0.485 & 2.1148 & 1.8970 & 0.484 & 2.1234 & 1.8902 & 0.483 & 2.1321 & 1.8833 \\
\hline 0.482 & 2.1410 & 1.8764 & 0.481 & 2.1500 & 1.8696 & 0.480 & 2.1591 & 1.8627 \\
\hline 0.479 & 2.1684 & 1.8558 & 0.478 & 2.1779 & 1.8490 & 0.477 & 2.1875 & 1.8421 \\
\hline 0.476 & 2.1972 & 1.8353 & 0.475 & 2.2072 & 1.8284 & 0.474 & 2.2172 & 1.8215 \\
\hline 0.473 & 2.2275 & 1.8147 & 0.472 & 2.2379 & 1.8078 & 0.471 & 2.2485 & 1.8009 \\
\hline 0.470 & 2.2593 & 1.7941 & 0.469 & 2.2703 & 1.7872 & 0.468 & 2.2815 & 1.7803 \\
\hline 0.467 & 2.2929 & 1.7735 & 0.466 & 2.3044 & 1.7666 & 0.465 & 2.3162 & 1.7597 \\
\hline 0.464 & 2.3282 & 1.7529 & 0.463 & 2.3404 & 1.7460 & 0.462 & 2.3529 & 1.7392 \\
\hline 0.461 & 2.3656 & 1.7323 & 0.460 & 2.3785 & 1.7254 & 0.459 & 2.3917 & 1.7186 \\
\hline 0.458 & 2.4051 & 1.7117 & 0.457 & 2.4188 & $1: 7048$ & 0.456 & 2.4327 & 1.6980 \\
\hline 0.455 & 2.4470 & 1.6911 & 0.454 & 2.4615 & 1.6842 & 0.453 & 2.4763 & 1.6774 \\
\hline 0.452 & 2.4914 & 1.6705 & 0.451 & 2.5068 & 1.6636 & 0.450 & 2.5225 & 1.6568 \\
\hline 0.449 & 2.5325 & 1.6525 & 0.448 & 2.5427 & 1.6482 & 0.447 & 2.5529 & 1.6439 \\
\hline 0.446 & 2.5633 & 1.6397 & 0.445 & 2.5739 & 1.6354 & 0.444 & 2.5846 & 1.6311 \\
\hline 0.443 & 2.5954 & 1.6268 & 0.442 & 2.6064 & 1.6225 & 0.441 & 2.6175 & 1.6182 \\
\hline 0.440 & 2.6288 & 1.6139 & 0.439 & 2.6403 & 1.6097 & 0.438 & 2.6519 & 1.6054 \\
\hline 0.437 & 2.6637 & 1.6011 & 0.436 & 2.6756 & 1.5968 & 0.435 & 2.6877 & 1.5925 \\
\hline 0.434 & 2.7000 & 1.5882 & 0.433 & 2.7125 & 1.5839 & 0.432 & 2.7252 & 1.5796 \\
\hline 0.431 & 2.7380 & 1.5754 & 0.430 & 2.7511 & 1.5711 & 0.429 & 2.7643 & 1.5668 \\
\hline 0.428 & 2.7778 & 1.5625 & 0.427 & 2.7914 & 1.5582 & 0.426 & 2.8053 & 1.5539 \\
\hline 0.425 & 2.8194 & 1.5496 & 0.424 & 2.8337 & 1.5454 & 0.423 & 2.8482 & 1.5411 \\
\hline 0.422 & 2.8629 & 1.5368 & 0.421 & 2.8779 & 1.5325 & 0.420 & 2.8932 & 1.5282 \\
\hline 0.419 & 2.9087 & 1.5239 & 0.418 & 2.9244 & 1.5196 & 0.417 & 2.9404 & 1.5154 \\
\hline 0.416 & 2.9567 & 1.5111 & 0.415 & 2.9732 & 1.5068 & 0.414 & 2.9901 & 1.5025 \\
\hline 0.413 & 3.0072 & 1.4982 & 0.412 & 3.0246 & 1.4939 & 0.411 & 3.0423 & 1.4896 \\
\hline 0.410 & 3.0604 & 1.4854 & 0.409 & 3.0787 & 1.4811 & 0.408 & 3.0974 & 1.4768 \\
\hline
\end{tabular}


Table II-l. Continued.

\begin{tabular}{|c|c|c|c|c|c|c|c|c|}
\hline $\mathrm{Xl} / \mathrm{XM}$ & $\mathrm{N} 1 / \mathrm{NT}$ & $\mathrm{N} 2 / \mathrm{NT}$ & $\mathrm{Xl} / \mathrm{XM}$ & $\mathrm{N} 1 / \mathrm{NT}$ & $\mathrm{N} 2 / \mathrm{NT}$ & $\mathrm{Xl} / \mathrm{XM}$ & $\mathrm{N} 1 / \mathrm{NT}$ & $\mathrm{N} 2 / \mathrm{NT}$ \\
\hline 0.407 & 3.1164 & 1.4725 & 0.406 & 3.1358 & 1.4682 & 0.405 & 3.1555 & 1.4639 \\
\hline $0: 404$ & 3.1756 & 1.4596 & 0.403 & 3.1961 & 1.4553 & 0.402 & 3.2170 & 1.4511 \\
\hline 0.401 & 3.2383 & 1.4468 & 0.400 & 3.2599 & 1.4425 & 0.399 & 3.2733 & 1.4399 \\
\hline 0.398 & 3.2868 & 1.4373 & 0.397 & 3.3004 & 1.4347 & 0.396 & 3.3143 & 1.4321 \\
\hline 0.395 & 3.3283 & 1.4295 & 0.394 & 3.3425 & 1.4269 & 0.393 & 3.3568 & 1.4243 \\
\hline 0.392 & 3.3714 & 1.4217 & 0.391 & 3.3861 & 1.4191 & 0.390 & 3.4010 & 1.4165 \\
\hline 0.389 & 3.4161 & 1.4139 & 0.388 & 3.4313 & 1.4113 & 0.387 & 3.4468 & 1.4087 \\
\hline 0.386 & 3.4625 & 1.4061 & 0.385 & 3.4783 & 1.4035 & 0.384 & 3.4944 & 1.4009 \\
\hline 0.383 & 3.5107 & 1.3983 & 0.382 & 3.5272 & 1.3957 & 0.381 & 3.5439 & 1.3931 \\
\hline 0.380 & 3.5608 & 1.3905 & 0.379 & 3.5780 & 1.3879 & 0.378 & 3.5954 & 1.3853 \\
\hline 0.377 & 3.6130 & 1.3827 & 0.376 & 3.6309 & 1.3801 & 0.375 & 3.6490 & 1.3775 \\
\hline 0.374 & 3.6674 & 1.3749 & 0.373 & 3.6860 & 1.3723 & 0.372 & 3.7049 & 1.3697 \\
\hline 0.371 & 3.7241 & 1.3671 & 0.370 & 3.7435 & 1.3645 & 0.369 & 3.7632 & 1.3619 \\
\hline 0.368 & 3.7832 & 1.3593 & 0.367 & 3.8035 & 1.3567 & 0.366 & 3.8241 & 1.3541 \\
\hline 0.365 & 3.8450 & 1.3515 & 0.364 & 3.8662 & 1.3489 & 0.363 & 3.8877 & 1.3463 \\
\hline 0.362 & 3.9096 & 1.3437 & 0.361 & 3.9317 & 1.3411 & 0.360 & 3.9543 & 1.3385 \\
\hline 0.359 & 3.9771 & 1.3359 & 0.358 & 4.0003 & 1.3333 & 0.357 & 4.0239 & 1.3307 \\
\hline 0.356 & 4.0479 & 1.3281 & 0.355 & 4.0723 & 1.3255 & 0.354 & 4.0970 & 1.3229 \\
\hline 0.353 & 4.1221 & 1.3203 & 0.352 & 4.1477 & 1.3177 & 0.351 & 4.1737 & 1.3151 \\
\hline 0.350 & 4.2000 & 1.3125 & 0.349 & 4.2200 & 1.3106 & 0.348 & 4.2402 & 1.3086 \\
\hline 0.347 & 4.2607 & 1.3067 & 0.346 & 4.2815 & 1.3147 & 0.345 & 4.3025 & 1.3028 \\
\hline 0.344 & 4.3238 & 1.3009 & 0.343 & 4.3454 & 1.2989 & 0.342 & 4.3672 & 1.2970 \\
\hline 0.341 & 4.3894 & 1.2950 & 0.340 & 4.4118 & 1.2931 & 0.339 & 4.4346 & 1.2912 \\
\hline 0.338 & 4.4576 & 1.2892 & 0.337 & 4.4809 & 1.2873 & 0.336 & 4.5046 & 1.2853 \\
\hline 0.335 & 4.5286 & 1.2834 & 0.334 & 4.5529 & 1.2815 & 0.333 & 4.5776 & 1.2795 \\
\hline 0.332 & 4.6026 & 1.2776 & 0.331 & 4.6280 & 1.2756 & 0.330 & 4.6537 & 1.2737 \\
\hline 0.329 & 4.6797 & 1.2718 & 0.328 & 4.7062 & 1.2698 & 0.327 & 4.7330 & 1.2679 \\
\hline 0.326 & 4.7603 & 1.2659 & 0.325 & 4.7879 & 1.2640 & 0.324 & 4.8160 & 1.2621 \\
\hline 0.323 & 4.8444 & 1.2601 & 0.322 & 4.8733 & 1.2582 & 0.321 & 4.9026 & 1.2562 \\
\hline 0.320 & 4.9324 & 1.2543 & 0.319 & 4.9626 & 1.2524 & 0.318 & 4.9933 & 1.2504 \\
\hline 0.317 & 5.0245 & 1.2485 & 0.316 & 5.0562 & 1.2465 & 0.315 & 5.0884 & 1.2446 \\
\hline
\end{tabular}


Table II-l. Continued.

\begin{tabular}{|c|c|c|c|c|c|c|c|c|}
\hline $\mathrm{Xl} / \mathrm{XM}$ & $\mathrm{N} 1 / \mathrm{NT}$ & $\mathrm{N} 2 / \mathrm{NT}$ & $\mathrm{X} 1 / \mathrm{XM}$ & $\mathrm{N} 1 / \mathrm{NT}$ & $\mathrm{N} 2 / \mathrm{NT}$ & $\mathrm{Xl} / \mathrm{XM}$ & $\mathrm{N} 1 / \mathrm{NT}$ & $\mathrm{N} 2 / \mathrm{NT}$ \\
\hline 0.314 & 5.1210 & 1.2427 & 0.313 & 5.1543 & 1.2407 & 0.312 & 5.1880 & 1.2388 \\
\hline 0.311 & 5.2223 & 1.2368 & 0.310 & 5.2572 & 1.2349 & 0.309 & 5.2927 & 1.2330 \\
\hline 0.308 & 5.3287 & 1.2310 & 0.307 & 5.3654 & 1.2291 & 0.306 & 5.4027 & 1.2271 \\
\hline 0.305 & 5.4406 & 1.2252 & 0.304 & 5.4792 & 1.2233 & 0.303 & 5.5184 & 1.2213 \\
\hline 0.302 & 5.5584 & 1.2194 & 0.301 & 5.5991 & 1.2174 & 0.300 & 5.6404 & 1.2155 \\
\hline 0.299 & 5.6726 & 1.2140 & 0.298 & 5.7053 & 1.2125 & 0.297 & 5.7384 & 1.2110 \\
\hline 0.296 & 5.7720 & 1.2096 & 0.295 & 5.8061 & 1.2081 & 0.294 & 5.8407 & 1.2066 \\
\hline 0.293 & 5.8757 & 1.2051 & 0.292 & 5.9113 & 1.2036 & 0.291 & 5.9474 & 1.2021 \\
\hline 0.290 & 5.9841 & 1.2006 & 0.289 & 6.0213 & 1.1992 & 0.288 & 6.0590 & 1.1977 \\
\hline 0.287 & 6.0974 & 1.1962 & 0.286 & 6.1363 & 1.1947 & 0.285 & 6.1758 & 1.1932 \\
\hline 0.284 & 6.2159 & 1.1917 & 0.283 & 6.2566 & 1.1902 & 0.282 & 6.2980 & 1.1888 \\
\hline 0.281 & 6.3401 & 1.1873 & 0.280 & 6.3828 & 1.1858 & 0.279 & 6.4262 & 1.1843 \\
\hline 0.278 & 6.4703 & 1.1828 & 0.277 & 6.5151 & 1.1813 & 0.276 & 6.5607 & 1.1798 \\
\hline 0.275 & 6.6070 & 1.1783 & 0.274 & 6.6542 & 1.1769 & 0.273 & 6.7021 & 1.1754 \\
\hline 0.272 & 6.7508 & 1.1739 & 0.271 & 6.8004 & 1.1724 & 0.270 & 6.8508 & 1.1709 \\
\hline 0.269 & 6.9021 & 1.1694 & 0.268 & 6.9543 & 1.1679 & 0.267 & 7.0075 & 1.1665 \\
\hline 0.266 & 7.0616 & 1.1650 & 0.265 & 7.1167 & 1.1635 & 0.264 & 7.1728 & 1.1620 \\
\hline 0.263 & 7.2300 & 1.1605 & 0.262 & 7.2882 & 1.1590 & 0.261 & 7.3475 & 1.1575 \\
\hline 0.260 & 7.4079 & 1.1561 & 0.259 & 7.4696 & 1.1546 & 0.258 & 7.5324 & 1.1531 \\
\hline 0.257 & 7.5964 & 1.1516 & 0.256 & 7.6617 & 1.1501 & 0.255 & 7.7283 & 1.1486 \\
\hline 0.254 & 7.7964 & 1.1471 & 0.253 & 7.8656 & 1.1457 & 0.252 & 7.9364 & 1.1442 \\
\hline 0.251 & 8.0086 & 1.1427 & 0.250 & 8.0822 & 1.1412 & 0.249 & 8.1257 & 1.1403 \\
\hline 0.248 & 8.1698 & 1.1395 & 0.247 & 8.2143 & 1.1386 & 0.246 & 8.2595 & 1.1378 \\
\hline 0.245 & 8.3052 & 1.1369 & 0.244 & 8.3514 & 1.1360 & 0.243 & 8.3984 & 1.1352 \\
\hline 0.242 & 8.4459 & 1.1343 & 0.241 & 8.4940 & 1.1334 & 0.240 & 8.5427 & 1.1326 \\
\hline 0.239 & 8.5920 & 1.1317 & 0.238 & 8.6421 & 1.1309 & 0.237 & 8.6928 & 1.1300 \\
\hline 0.236 & 8.7441 & 1.1291 & 0.235 & 8.7962 & 1.1283 & 0.234 & 8.8489 & 1.1274 \\
\hline 0.233 & 8.9024 & 1.1265 & 0.232 & 8.9566 & 1.1257 & 0.231 & 9.0116 & 1.1248 \\
\hline 0.230 & 9.0672 & 1.1240 & 0.229 & 9.1237 & 1.1231 & 0.228 & 9.1810 & 1.1222 \\
\hline 0.227 & 9.2391 & 1.1214 & 0.226 & 9.2981 & 1.1205 & 0.225 & 9.3579 & 1.1196 \\
\hline 0.224 & 9.4185 & 1.1188 & 0.223 & 9.4801 & 1.1179 & 0.222 & 9.5425 & 1.1171 \\
\hline
\end{tabular}


Table II-1. Continued.

\begin{tabular}{|c|c|c|c|c|c|c|c|c|}
\hline $\mathrm{XI} / \mathrm{XM}$ & $\mathrm{Nl} / \mathrm{NT}$ & $\mathrm{N} 2 / \mathrm{NT}$ & $\mathrm{Xl} / \mathrm{XM}$ & $\mathrm{N} 1 / \mathrm{NT}$ & $\mathrm{N} 2 / \mathrm{NT}$ & $\mathrm{Xl} / \mathrm{XM}$ & $\mathrm{N} 1 / \mathrm{NT}$ & $\mathrm{N} 2 / \mathrm{NT}$ \\
\hline 0.221 & 9.6059 & 1.1162 & 0.220 & 9.6701 & 1.1153 & 0.219 & 9.7354 & 1.1145 \\
\hline 0.218 & 9.8017 & 1.1136 & 0.217 & 9.8690 & 1.1128 & 0.216 & 9.9374 & 1.1119 \\
\hline 0.215 & 10.0068 & 1.1110 & 0.214 & 10.0772 & 1.1102 & 0.213 & 10.1488 & 1.1093 \\
\hline 0.212 & 10.2216 & 1.1084 & 0.211 & 10.2955 & 1.1076 & 0.210 & 10.3706 & 1.1067 \\
\hline 0.209 & 10.4468 & 1.1059 & 0.208 & 10.5244 & 1.1050 & 0.207 & 10.6032 & 1.1041 \\
\hline 0.206 & 10.6834 & 1.1033 & 0.205 & 10.7649 & 1.1024 & 0.204 & 10.8478 & 1.1015 \\
\hline 0.203 & 10.9321 & 1.1007 & 0.202 & 11.0179 & 1.0998 & 0.201 & 11.1052 & 1.0990 \\
\hline 0.200 & 11.1937 & 1.0981 & 0.199 & 11.2951 & 1.0971 & 0.198 & 11.3985 & 1.0962 \\
\hline 0.197 & 11.5040 & 1.0952 & 0.196 & 11.6117 & 1.0942 & 0.195 & 11.7216 & 1.0933 \\
\hline 0.194 & 11.8339 & 1.0923 & 0.193 & 11.9484 & 1.0913 & 0.192 & 12.0655 & 1.0904 \\
\hline 0.191 & 12.1850 & 1.0894 & 0.190 & 12.3072 & 1.0884 & 0.189 & 12.4321 & 1.0875 \\
\hline 0.188 & 12.5598 & 1.0865 & 0.187 & 12.6903 & 1.0855 & 0.186 & 12.8239 & 1.0856 \\
\hline 0.185 & 12.9605 & 1.0836 & 0.184 & 13.1003 & 1.0826 & 0.183 & 13.2434 & 1.0817 \\
\hline 0.182 & 13.3900 & 1.0807 & 0.181 & 13.5401 & 1.0797 & 0.180 & 13.6939 & 1.0788 \\
\hline 0.179 & 13.8515 & 1.0778 & 0.178 & 14.0130 & 1.0768 & 0.177 & 14.1787 & 1.0759 \\
\hline 0.176 & 14.3486 & 1.0749 & 0.175 & 14.5230 & 1.0739 & 0.174 & 14.7020 & 1.0730 \\
\hline 0.173 & 14.8858 & 1.0720 & 0.172 & 15.0747 & 1.0710 & 0.171 & 15.2685 & 1.0701 \\
\hline 0.170 & 15.4679 & 1.0691 & 0.169 & 15.6730 & 1.0682 & 0.168 & 15.8840 & 1.0672 \\
\hline 0.167 & 16.1011 & 1.0662 & 0.166 & 16.3247 & 1.0653 & 0.165 & 16.5550 & 1.0643 \\
\hline 0.164 & 16.7923 & 1.0633 & 0.163 & 17.0369 & 1.0624 & 0.162 & 17.2893 & 1.0614 \\
\hline 0.161 & 17.5497 & 1.0604 & 0.160 & 17.8186 & 1.0595 & 0.159 & 18.0964 & 1.0585 \\
\hline 0.158 & 18.3835 & 1.0575 & 0.157 & 18.6805 & 1.0566 & 0.156 & 18.9877 & 1.0556 \\
\hline 0.155 & 19.3058 & 1.0546 & 0.154 & 19.6354 & 1.0537 & 0.153 & 19.9770 & 1.0527 \\
\hline 0.152 & 20.3314 & 1.0517 & 0.151 & 20.6993 & 1.0508 & 0.150 & 21.0804 & 1.0498 \\
\hline 0.149 & 21.2506 & 1.0494 & 0.148 & 21.4234 & 1.0490 & 0.147 & 21.5991 & 1.0485 \\
\hline 0.146 & 21.7783 & 1.0481 & 0.145 & 21.9602 & 1.0477 & 0.144 & 22.1453 & 1.0473 \\
\hline 0.143 & 22.3342 & 1.0469 & 0.142 & 22.5260 & 1.0465 & 0.141 & 22.7218 & 1.0460 \\
\hline 0.140 & 22.9207 & 1.0456 & 0.139 & 23.1232 & 1.0452 & 0.138 & 23.3301 & 1.0448 \\
\hline 0.137 & 23.5403 & 1.0444 & 0.136 & 23.7546 & 1.0439 & 0.135 & 23.9734 & 1.0435 \\
\hline 0.134 & 24.1960 & 1.0431 & 0.133 & 24.4230 & 1.0427 & 0.132 & 24.6549 & 1.0423 \\
\hline 0.131 & 24.8910 & 1.0419 & 0.130 & 25.1318 & 1.0414 & 0.129 & 25.3781 & 1.0410 \\
\hline
\end{tabular}


Table II-1. Continued.

\begin{tabular}{|c|c|c|c|c|c|c|c|c|}
\hline $\mathrm{X} I / \mathrm{XM}$ & $\mathrm{Nl} / \mathrm{NT}$ & $\mathrm{N} 2 / \mathrm{NT}$ & $\mathrm{XI} / \mathrm{XM}$ & $\mathrm{Nl} / \mathrm{NT}$ & $\mathrm{N} 2 / \mathrm{NT}$ & $\mathrm{XI} / \mathrm{XM}$ & $\mathrm{N} 1 / \mathrm{NT}$ & $\mathrm{N} 2 / \mathrm{NT}$ \\
\hline 0.128 & 25.6289 & 1.0406 & 0.127 & 25.8849 & 1.0402 & 0.126 & 26.1469 & 1.0389 \\
\hline 0.125 & 26.4138 & 1.0393 & 0.124 & 26.6865 & 1.0389 & 0.123 & 26.9658 & 1.0385 \\
\hline 0.122 & 27.2505 & 1.0381 & 0.121 & 27.5415 & 1.0377 & 0.120 & 27.8398 & 1.0373 \\
\hline 0.119 & 28.1441 & 1.0368 & 0.118 & 28.4554 & 1.0364 & 0.117 & 28.7746 & 1.0360 \\
\hline 0.116 & 29.1006 & 1.0356 & 0.115 & 29.4344 & 1.0352 & 0.114 & 29.7770 & 1.0347 \\
\hline 0.113 & 30.1271 & 1.0343 & 0.112 & 30.4859 & 1.0339 & 0.111 & 30.8544 & 1.0335 \\
\hline 0.110 & 31.2314 & 1.0331 & 0.109 & 31.6180 & 1.0327 & 0.108 & 32.0156 & 1.0322 \\
\hline 0.107 & 32.4227 & 1.0318 & 0.106 & 32.8406 & 1.0314 & 0.105 & 33.2708 & 1.0310 \\
\hline 0.104 & 33.7118 & 1.0310 & 0.103 & 34.1649 & 1.0302 & 0.102 & 34.6319 & 1.0297 \\
\hline 0.101 & 35.1111 & 1.0293 & 0.100 & 35.6030 & 1.0289 & 0.099 & 36.0354 & 1.0285 \\
\hline 0.098 & 36.4776 & 1.0282 & 0.097 & 36.9310 & 1.0278 & 0.096 & 37.3975 & 1.0275 \\
\hline 0.095 & 37.8749 & 1.0271 & 0.094 & 38.3651 & 1.0268 & 0.093 & 38.8698 & 1.0264 \\
\hline 0.092 & 39.3869 & 1.0261 & 0.091 & 39.9183 & 1.0257 & 0.090 & 40.4646 & 1.0253 \\
\hline 0.089 & 41.0281 & 1.0250 & 0.088 & 41.6063 & 1.0246 & 0.087 & 42.2014 & 1.0243 \\
\hline 0.086 & 42.8159 & 1.0239 & 0.085 & 43.4473 & 1.0236 & 0.084 & 44.0981 & 1.0232 \\
\hline 0.083 & 44.7691 & 1.0228 & 0.082 & 45.4632 & 1.0225 & 0.081 & 46.1778 & 1.0221 \\
\hline 0.080 & 46.9156 & 1.0218 & 0.079 & 47.6801 & 1.0214 & 0.078 & 48.4684 & 1.0211 \\
\hline 0.077 & 49.2835 & 1.0207 & 0.076 & 50.1297 & 1.0204 & 0.075 & 51.0036 & 1.0200 \\
\hline 0.074 & 51.9091 & 1.0197 & 0.073 & 52.8481 & 1.0193 & 0.072 & 53.8250 & 1.0189 \\
\hline 0.071 & 54.8366 & 1.0186 & 0.070 & 55.8878 & 1.0182 & 0.069 & 56.9838 & 1.0179 \\
\hline 0.068 & 58.1213 & 1.0175 & 0.067 & 59.3060 & 1.0172 & 0.066 & 60.5443 & 1.0168 \\
\hline 0.065 & 61.8329 & 1.0164 & 0.064 & 63.1785 & 1.0161 & 0.063 & 64.5847 & 1.0157 \\
\hline 0.062 & 66.0602 & 1.0154 & 0.061 & 67.6016 & 1.0150 & 0.060 & 69.2178 & 1.0147 \\
\hline 0.059 & 70.9190 & 1.0143 & 0.058 & 72.7024 & 1.0139 & 0.057 & 74.5791 & 1.0136 \\
\hline 0.056 & 76.5567 & 1.0132 & 0.055 & 78.6493 & 1.0129 & 0.054 & 80.8550 & 1.0125 \\
\hline 0.053 & 83.1897 & 1.0122 & 0.052 & 85.6718 & 1.0118 & 0.051 & 88.3013 & 1.0115 \\
\hline 0.050 & 91.0916 & 1.0111 & 0.049 & 92.9320 & 1.0109 & 0.048 & 94.8491 & 1.0107 \\
\hline 0.047 & 96.8479 & 1.0104 & 0.046 & 98.9337 & 1.0102 & 0.045 & 101.1027 & 1.0100 \\
\hline 0.044 & 103.3800 & 1.0098 & 0.043 & 105.7633 & 1.0095. & 0.042 & 108.2602 & 1.0093 \\
\hline 0.041 & 110.8676 & 1.0091 & 0.040 & 113.6169 & 1.0089 & 0.039 & 116.5074 & 1.0087 \\
\hline 0.038 & 119.5501 & 1.0084 & 0.037 & 122.7575 & 1.0082 & 0.036 & 126.1284 & 1.0080 \\
\hline
\end{tabular}


junctions, the proportionality of $1 / \mathrm{C}^{2}$ and the applied voltage has been used by Goldstein ${ }^{31}$, and of $1 / C^{3}$ and the applied voltage for linearly graded junctions has been described by McAfee et al. ${ }^{32}$, and Greenberg et al. ${ }^{33}$.

For the determination of the impurity distribution in junction diodes from capacitance-voltage measurements differentiation of the raw $\mathrm{C}-\mathrm{V}$ data is necessary. The precise $\mathrm{C}-\mathrm{V}$ data required for the impurity concentration determination were taken from the capacitance system consisting of a Micro Instruments 1201DS Capacitance Tester, Dymec 2901A and 2902A Master and Slave Scanner/Programmers, a Dymec 2401CM31 Digital Voltmeter, and a John Fluke 383B Voltage/Current Calibrator for supplying the precise bias. The raw $\mathrm{C}-\mathrm{V}$ data obtained from the capacitance system was smoothed by a digital computer.

A series of clusters ( 8 in this work) of six voltagecapacitance points, at one or two per cent intervals in capacitance, was taken to obtain a series of impurity concentration values for several depletion layer widths. It was assumed that the capacitance could be given by the following equation for the range covered by each cluster,

$$
C=\frac{K}{\left(-V+V_{T}\right)^{m}}
$$

and equation $(2-1)$ becomes

$$
\mathrm{N}_{\mathrm{T}}=\frac{\mathrm{K}^{2}}{\mathrm{~A}^{2} \mathrm{q} \varepsilon \mathrm{m}} \cdot\left(-\mathrm{V}_{\mathrm{a}}+\mathrm{V}_{\mathrm{T}}\right)^{1-2 \mathrm{~m}},
$$


and the location of the edge of the depletion layer, $x_{m} m$ is given by

$$
\mathrm{x}_{\mathrm{m}}=\frac{\mathrm{A \varepsilon}_{\mathrm{\varepsilon}}}{\mathrm{C}_{\mathrm{a}}}
$$

where $K, V_{T}, m=$ constants within each cluster,

$$
\begin{aligned}
\mathrm{N}_{\mathrm{T}}= & \text { impurity concentration for the "one-sided" } \\
& \text { junction, } \\
& 6 \\
\mathrm{~V}_{\mathrm{a}}= & { }_{\mathrm{i}}^{\mathrm{E}} \mathrm{v}_{\mathrm{i}} / 6, \text { average voltage of a cluster } \\
\mathrm{C}_{\mathrm{a}}= & \text { capacitance corresponding to } \mathrm{v}_{\mathrm{a}} .
\end{aligned}
$$

The capacitance-voltage data were used as the input of a computer program; a non-linear least-squares fit was used to obtain a best fit for the capacitance calculated from equation (2-5). The output of the computer program yielded following items :

1. the constants $\mathrm{K}, \mathrm{V}_{\mathrm{T}}$ and $\mathrm{m}$,

2. the average $\mathrm{V}_{\mathrm{a}}$ and $\mathrm{C}_{\mathrm{a}}$ for each cluster,

3. the impurity concentration $\mathrm{N}_{\mathrm{T}^{\prime}}$, and

4. the location of the edge of the depletion layer, $\mathrm{x}_{\mathrm{m}}$.

\section{Impurity Profile of Epitaxial-Planar Transistors}

In this work, it was assumed that the impurity distribution of epitaxial-planar transistors have depth dependence (x) of

$$
N(x)=N_{O E} \operatorname{erfc}\left(L_{E} x\right)-N_{O B} \exp \left(-L_{B}^{2} x^{2}\right)+N_{B C}
$$


where $\mathrm{N}_{\mathrm{BC}}$ = the background concentration,

$\mathrm{N}_{\mathrm{OE}}=$ the surface concentration for the emitter , diffusion,

$\mathrm{N}_{\mathrm{OB}}=$ the surface concentration for the base diffusion, $x=$ the depth (distance from the surface).

The technique which was used for the determination of the impurity concentration of a $\mathrm{p}-\mathrm{n}$ junction was employed for both the emitter-base and base-collector junctions. The impurity profile in the vicinity of metallurgical junctions was determined by forward biased capacitance measurements, and that in the normally "neutral regions" adjacent to junction depletion layers was determined by reverse biased capacitance measurements. The impurity concentration data obtained for region adjacent to the junctions were then used in the fitting of $\mathrm{N}(\mathrm{x})$ given by equation (2-8). Typical values of $\mathrm{N}_{\mathrm{OE}}=2.5 \times 10^{20} \mathrm{~cm}^{-3}, \mathrm{~N}_{\mathrm{OB}}=6.0 \times 10^{18} \mathrm{~cm}^{-3}, \mathrm{~N}_{\mathrm{BC}}=$ $1.1 \times 10^{16} \mathrm{~cm}^{-3}, \mathrm{~L}_{\mathrm{E}}=1.15 \times 10^{4} \mathrm{~cm}^{-1}$ and $\mathrm{L}_{\mathrm{B}}^{2}=0.69 \times 10^{8} \mathrm{~cm}^{-2}$ were obtained.

Table II-2 lists the values of $\mathrm{N}_{O E^{\prime}} \mathrm{N}_{O B^{\prime}} \mathrm{N}_{\mathrm{BC}^{\prime}} \mathrm{L}_{E}$ and $\mathrm{L}_{\mathrm{B}}{ }^{2}$ for Device SF2523 \#40 at different neutron fluences. A typical impurity profile for the same device is shown in Figure II-2. The impurity profiles at various neutron fluences for the device are illustrated in Figure II-3.

\section{The Concentration of Neutron-Induced Defect Centers}

The impurity distribution at various neutron fluences have been determined. The change in impurity concentration 
Table II-2. Parameters for impurity distribution (Device SF2523\#40).

\begin{tabular}{|c|c|c|c|c|c|}
\hline$\phi \quad(n v t)$ & $\begin{array}{c}{ }^{\mathrm{N}} \mathrm{OE} \\
\left(10^{20} \mathrm{~cm}^{-3}\right)\end{array}$ & $\begin{array}{c}{ }_{\mathrm{OB}} \\
\left(10^{18} \mathrm{~cm}^{-3}\right)\end{array}$ & $\begin{array}{c}\mathrm{N}_{\mathrm{BC}} \\
\left(10^{16} \mathrm{~cm}^{-3}\right)\end{array}$ & $\begin{array}{c}\mathrm{L}_{\mathrm{E}} \\
\left(10^{4} \mathrm{~cm}^{-1}\right) \\
\end{array}$ & $\begin{array}{c}\mathrm{L}_{\mathrm{B}}^{2} \\
\left(10^{7} \mathrm{~cm}^{-2}\right)\end{array}$ \\
\hline$\phi=0.0$ & 2.505 & 6.014 & 1.300 & 1.115 & 6.776 \\
\hline$\phi=1.0 \times 10^{12}$ & 2.505 & 6.001 & 1.299 & 1.115 & 6.777 \\
\hline$\phi=5.9 \times 10^{12}$ & 2.505 & 5.983 & 1.298 & 1.116 & 6.778 \\
\hline$\phi=1.2 \times 10^{13}$ & 2.505 & 5.947 & 1.292 & 1.117 & 6.779 \\
\hline$\phi=2.1 \times 10^{13}$ & 2.505 & 5.901 & 1.289 & 1.118 & 6.780 \\
\hline$\phi=3.9 \times 10^{13}$ & 2.504 & 5.858 & 1.285 & 1.118 & 6.782 \\
\hline$\phi=6.2 \times 10^{13}$ & 2.504 & 5.789 & 1.279 & 1.120 & 6.785 \\
\hline$\phi_{\phi}=8.3 \times 10^{13}$ & 2.503 & 5.738 & 1.272 & 1.121 & 6.787 \\
\hline$\phi=1.0 \times 10^{14}$ & 2.503 & 5.694 & 1.270 & 1.122 & 6.790 \\
\hline$\phi=1.8 \times 10^{14}$ & 2.502 & 5.651 & 1.242 & 1.123 & 6.793 \\
\hline$\phi=2.3 \times 10^{14}$ & 2.501 & 5.607 & 1.225 & 1.125 & 6.811 \\
\hline$\phi=2.9 \times 10^{14}$ & 2.500 & 5.545 & 1.211 & 1.126 & 6.815 \\
\hline$\phi=3.3 \times 10^{14}$ & 2.499 & 5.539 & 1.199 & 1.126 & 6.822 \\
\hline$\phi=4.1 \times 10^{14}$ & 2.498 & 5.532 & 1.175 & 1.127 & 6.851 \\
\hline$\phi=5.3 \times 10^{14}$ & 2.497 & 5.524 & 1.144 & 1.128 & 6,875 \\
\hline
\end{tabular}




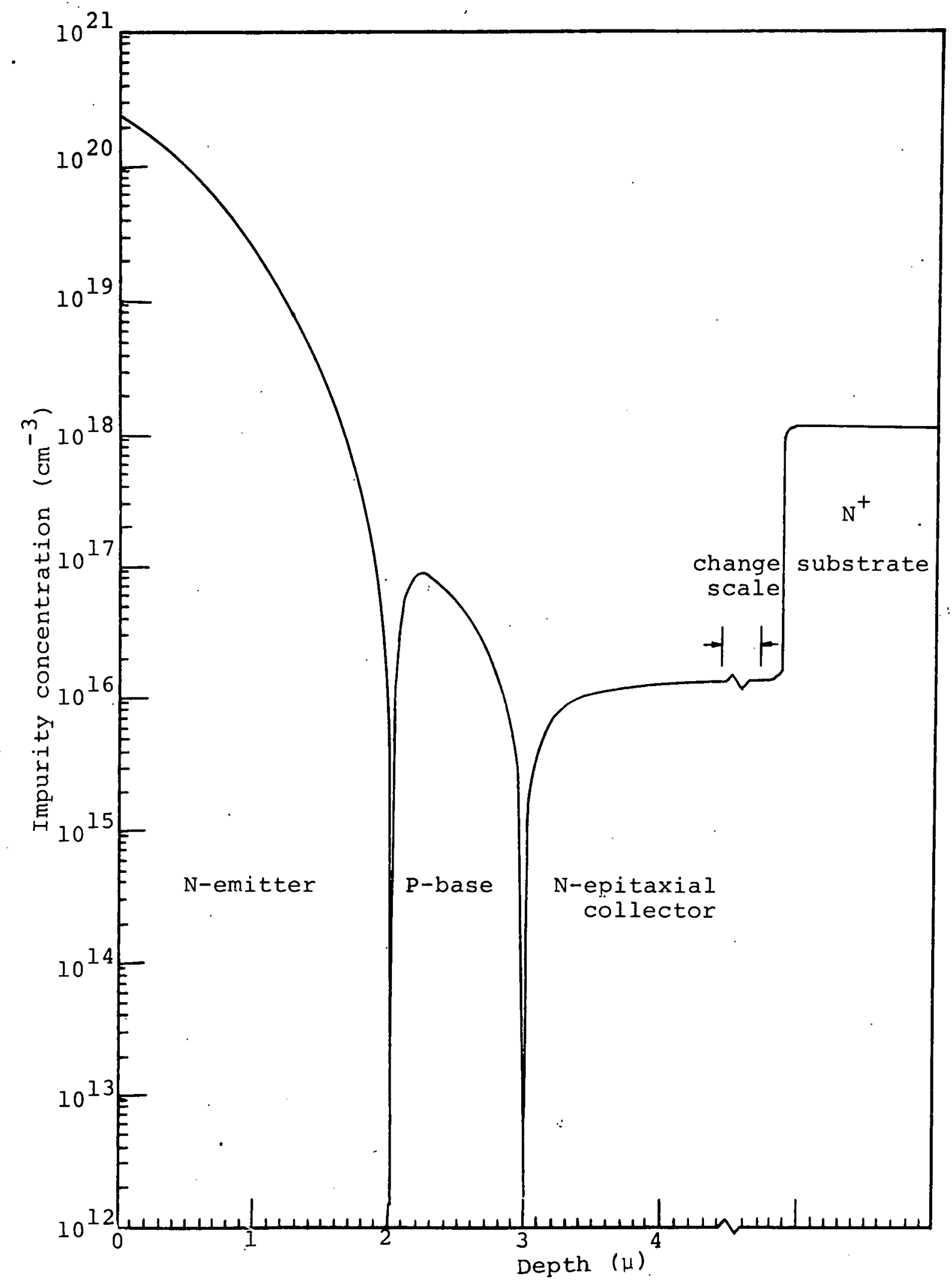

Figure II-2. Typical epitaxial-planar transistor impurity profile $(\phi=0)$. 


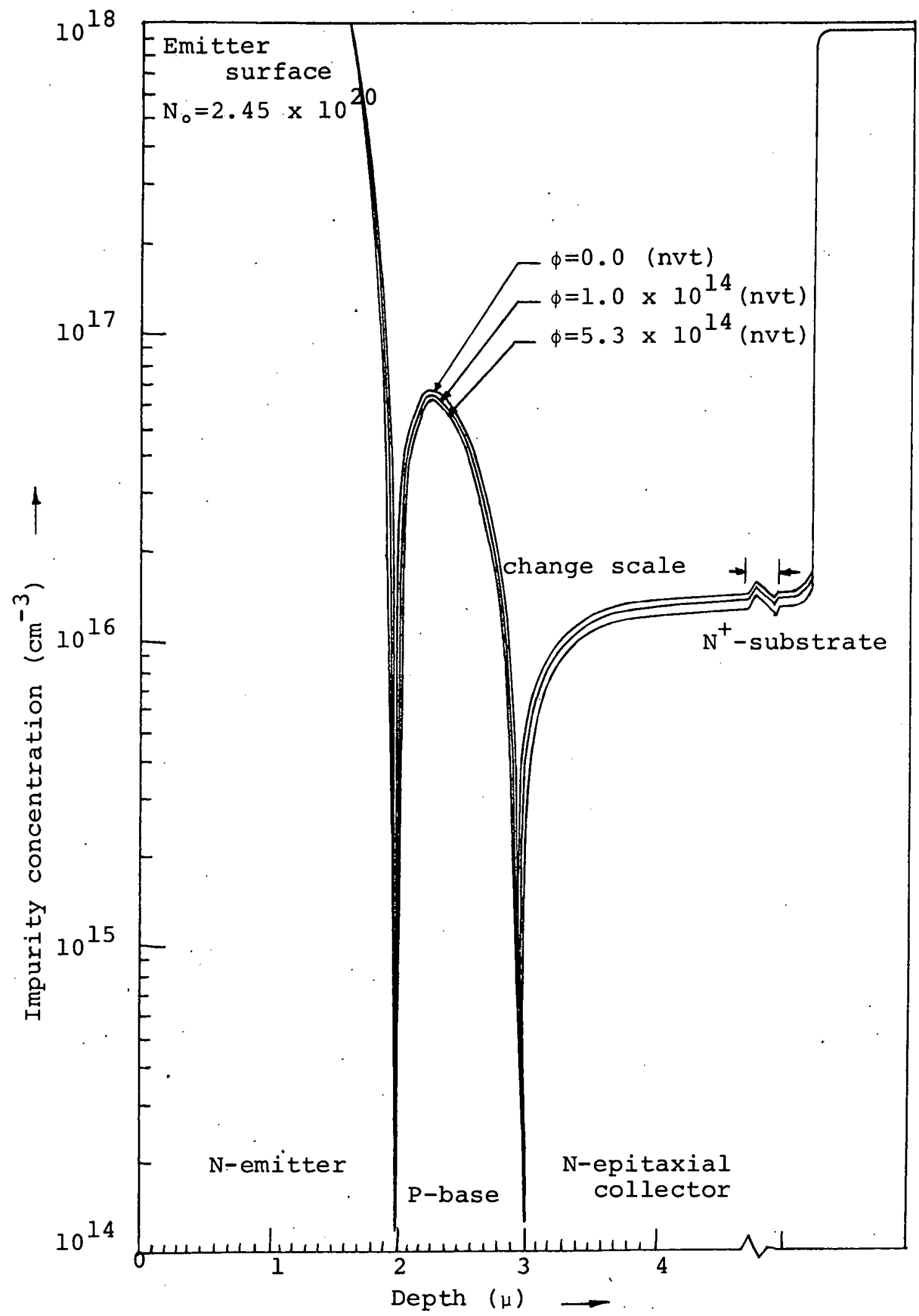

Figure II-3. Epitaxial-planar transistor impurity profile at various neutron fluences (Device SF2523 \#40). 
has the following empirical expression $34-37$

$$
\Delta N=N_{0}\left(1-e^{-\phi / k} n^{\prime} p^{\prime}\right.
$$

where $\mathrm{N}_{0}=$ pre-irradiated concentration $\left(\mathrm{cm}^{-3}\right)$,

$$
\begin{aligned}
\Delta \mathrm{N} & =\text { change in concentration }\left(\mathrm{cm}^{-3}\right), \\
\mathrm{N} & =\text { post-irradiated concentration }\left(\mathrm{cm}^{-3}\right)=\mathrm{N}_{0}-\Delta \mathrm{N}, \\
\phi= & \text { neutron fluence }(\mathrm{nvt}), \\
\mathrm{k}_{\mathrm{n}}, \mathrm{k}_{\mathrm{p}}= & \text { carrier removal coefficient }\left(\mathrm{cm}^{-2}\right) \text { for } \mathrm{n}-\text { and } \\
& \text { p- type carriers, respectively. }
\end{aligned}
$$

Figure II-4 shows the relationship between the carrier removal coefficients and the initial carrier concentrations. A straight line was tried to fit the experimental data. With this straight line fitting, then one can have $k_{n}=1.8 \times 10^{8} \times N_{0}^{0.442}$. Although a better model can be found to fit these data (as shown by the curve lines in Figure (I-4), it is not interesting to the author.

The concentration of the neutron-induced defect centers, $\mathrm{N}_{\mathrm{R}^{\prime}}$, has the empirical expression 38,39

$$
\begin{array}{ll}
N_{R} \approx \frac{\Delta N}{2} & \text { for } \mathrm{n} \text {-type material } \\
N_{R} \approx \frac{\Delta N}{3} & \text { for } \mathrm{p} \text {-type material }
\end{array}
$$

The defect concentrations for Device SF2523 \#40 are listed in Table II-3. Those defect concentrations were used in Chapter IV to determine the limiting lifetimes. 
Table II-3. Defect concentrations for Device SF2523 \#40.

\begin{tabular}{|c|c|c|c|}
\hline (nvt) & $\begin{array}{l}\text { Emitter } \\
\left(10^{15} \mathrm{~cm}^{-3}\right)\end{array}$ & $\begin{array}{c}\text { Base } \\
\left(10^{15} \mathrm{~cm}^{-3}\right)\end{array}$ & $\begin{array}{l}\text { Collector } \\
\left(10^{14} \mathrm{~cm}^{-3}\right)\end{array}$ \\
\hline$\phi=1.0 \times 10^{12}$. & 0.18 & 0.045 & 0.056 \\
\hline$\phi=5.9 \times 10^{12}$ & 0.203 & 0.051 & 0.067 \\
\hline$\phi=1.2 \times 10^{13}$ & 0.232 & 0.059 & 0.071 \\
\hline$\phi=2.1 \times 10^{13}$ & 0.278 & 0.069 & 0.082 \\
\hline$\phi=3.9 \times 10^{13}$ & 0.369 & 0.091 & 0.103 \\
\hline$\phi=6.2 \times 10^{13}$ & 0.488 & 0.122 & 0.145 \\
\hline$\phi=8.3 \times 10^{13}$ & 0.591 & 0.148 & 0.172 \\
\hline$\phi=1.0 \times 10^{14}$ & 0.695 & 0.173 & 0.189 \\
\hline$\phi=1.8 \times 10^{14}$ & 1.078 & 0.269 & 0.301 \\
\hline$\phi=2.3 \times 10^{14}$ & 1.343 & 0.348 & 0.392 \\
\hline$\phi=2.9 \times 10^{14}$ & 1.649 & 0.403 & 0.453 \\
\hline$\phi=3.3 \times 10^{14}$ & 1.844 & 0.473 & 0.541 \\
\hline$\phi=4.1 \times 10^{14}$ & 2.245 & 0.569 & 0.623 \\
\hline$\phi=5.3 \times 10^{14}$ & 2.828 & 0.708 & 0.801 \\
\hline
\end{tabular}




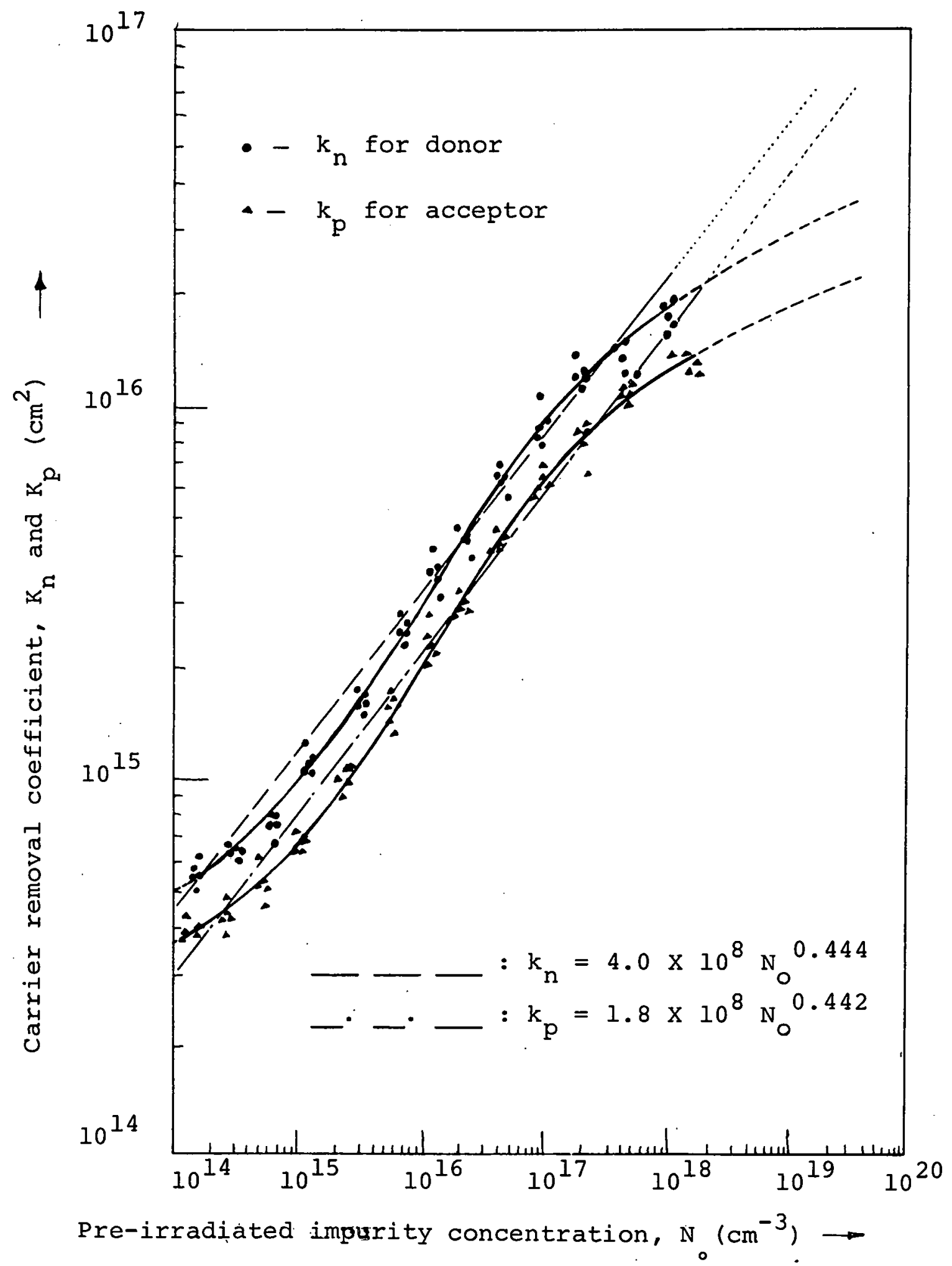

Figure II-4. Dependence of carrier removal coefficient on initial carrier concentration. 
E. The Dependence of the Diffusion Potential on Neutron Fluence

The dependence of diffusion potential on neutron fluence is given by 29

$$
V_{T}(\phi)=\frac{k T}{q} \cdot \log _{e} \frac{N_{A}(\phi) N_{D}(\phi)}{n_{i}^{2}(\phi)}
$$

where $\mathrm{n}_{i}=$ intrinsic carrier concentration, $\mathrm{N}_{\mathrm{A}}=$ hole concentration in a p-type semiconductor, $\mathrm{N}_{\mathrm{D}}=$ electron concentration in a n-type semiconductor. The dependence of hole and electron concentrations on neutron fluence are given, respectively, by the following empirical expressions,

$$
\begin{aligned}
& \mathrm{N}_{\mathrm{A}}(\phi)=\mathrm{N}_{\mathrm{AO}} \cdot \exp \left(-\mathrm{k}_{\mathrm{p}} \phi\right), \\
& \mathrm{N}_{\mathrm{D}}(\phi)=\mathrm{N}_{\mathrm{DO}} \cdot \exp \left(-\mathrm{k}_{\mathrm{n}} \phi\right),
\end{aligned}
$$

where $\mathrm{N}_{\mathrm{AO}}$ and $\mathrm{N}_{\mathrm{DO}}$ are the pre-irradiated concentrations, and $\mathrm{k}_{\mathrm{p}}$ and $\mathrm{k}_{\mathrm{n}}$ are the concentration damage constants for holes and electrons, respectively.

substituting equations (2-13) and (2-14) into (2-12) yields,

$$
V_{T}(\phi)=\frac{k T}{q}\left[\log _{e} \frac{N_{A O}{ }^{N V} D O}{n_{i}{ }^{2}(\phi)}-\left(k_{p}+k_{n}\right) \phi\right],
$$

The intrinsic carrier concentration, $\mathrm{n}_{i}$, was assumed to be independent of neutron fluence at the low to moderate 
fluences which were considered throughout this investigation. Finally, the dependence of the diffusion potential on neutron fluence is given by

$$
\mathrm{V}_{\mathrm{T}}=\mathrm{V}_{\mathrm{TO}}-\frac{\mathrm{kT}}{\mathrm{q}} \cdot \mathrm{K}_{\mathrm{d}} \cdot \phi_{,}
$$

where $\mathrm{V}_{\mathrm{TO}}=$ pre-irradiated diffusion potential,

$$
\mathrm{V}_{\mathrm{T}}=\text { post-irradiated diffusion potential, }
$$

$\mathrm{k}_{\mathrm{d}}=\mathrm{k}_{\mathrm{p}}+\mathrm{k}_{\mathrm{n}}=$ diffusion potential damage constant.

Therefore, from equation (2-16), the diffusion potential decreases as the neutron fluence increases (see Figure II-5).

Several methods have been used to find the diffusion potentials at various neutron fluences:

1. The emitter-base junction capacitance was measured using a Micro Instrument 1201DS Digital Capacitance Tester. The depletion layer width of a $p-n$ junction decreases with externally applied forward voltage. If currents and I-R drops were neglected and the applied voltage were increased to the diffusion potential, the depletion layer width would decrease to zero, and the junction capacitance would tend to infinity. The externally applied voltage which caused $C_{B E}$ to approach infinity (off scale reading on the Capacitance Tester) was assumed to be $V_{T}$.

2. The value of $\mathrm{V}_{\mathrm{T}}$ was automatically calculated by the computer program which was employed to determine $\mathrm{N}_{\mathrm{T}}$, $\mathrm{x}_{\mathrm{m}}, \mathrm{v}_{\mathrm{T}}, \mathrm{C}_{\mathrm{a}}$ etc. (refer to Section $\mathrm{C}$ of this Chapter). 


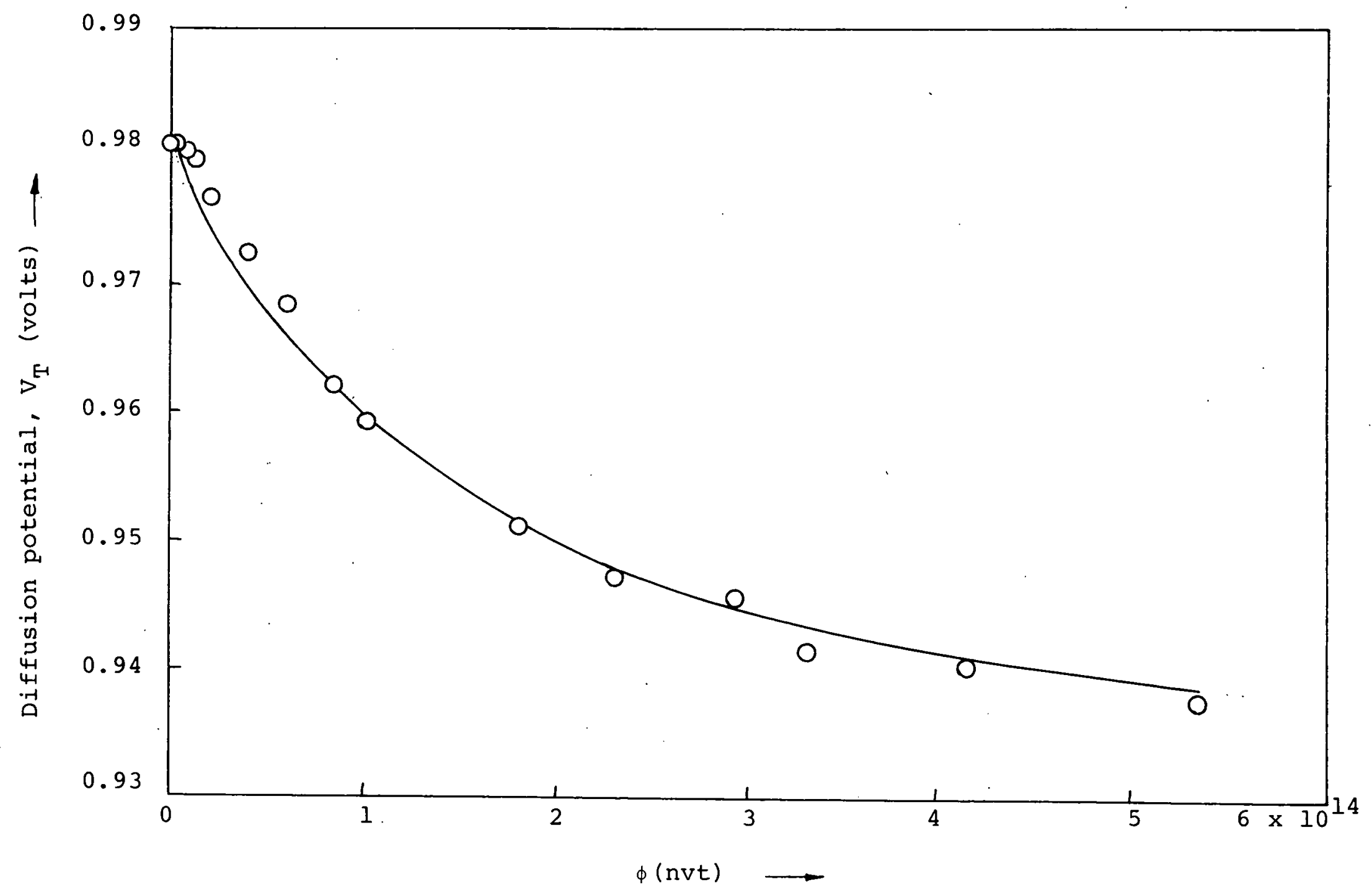

Figure II-5. Dependence of the diffusion potential on neutron fluence at $300^{\circ} \mathrm{K}$ (Device SF2523 \#40). 
3. By using the measured values of $\mathrm{N}_{\mathrm{AO}}, \mathrm{N}_{\mathrm{DO}}$ and the calculated $k_{p}$ and $k_{n}$ from Sections $C$ and $D$ in this Chapter, the values of $\mathrm{V}_{\mathrm{T}}$ were calculated from equation $(2-16)$.

Due to experimental error and the poor accuracy of off-scale reading of externally applied voltages, method 1 did not give good data values as was expected because of neglecting the I-R drops.: Methods 2 and 3 gave nearly identical results and the tabulated values of $V_{T}$ in Table II-4 are those obtained from methods 2 and 3 . These $v_{T}$ values were used in the statistical model fitting for the neutron-induced base current component in the later Chapters.

It is noted that the experimental data of $V_{T}$ as shown in Figure II-5 did not agree with equation (2-16), but the following model was found to be a good fit to the experimental $\mathrm{V}_{\mathrm{T}}$ data,

$$
\text { . } V_{T}=V_{T O} e^{-5.1} \times 10^{-15} \phi+0.935 \times\left(1-e^{-5.1 \times 10^{-15}} \phi\right) .
$$

The discrepance was due to the assumptions of equations $(2-13)$ and (2-14). A further study of $V_{T}$ is needed, but it is beyond the scope of this research.

\section{F. Determination of Fermi Energy Level}

The Fermi energy of a n-type and a p-type semiconductor are given, respectively, by the following two equations 40 
Table II-4. Diffusion potential at various neutron fluences $\left(T=300^{\circ} \mathrm{K}\right)$.

\begin{tabular}{|c|c|c|c|}
\hline $\begin{array}{l}\phi \\
(\text { nvt })\end{array} \underbrace{\text { Device }}_{\text {No. }}$ & SF $2523 \# 40$ & SF $2524 \# 68$ & $2 \mathrm{~N} 914 \# 7$ \\
\hline$\phi=0.0$ & 0.9804 & 0.9609 & 0.9646 \\
\hline$\phi=1.0 \times 10^{12}$ & 0.9804 & 0.9609 & 0.9646 \\
\hline$\phi=5.9 \times 10^{12}$ & 0.9791 & 0.9596 & 0.9633 \\
\hline$\phi=1.2 \times 10^{13}$ & 0.9785 & 0.9590 & 0.9627 \\
\hline$\phi=2.1 \times 10^{13}$ & 0.9765 & 0.9570 & 0.9607 \\
\hline$\phi=3.9 \times 10^{13}$ & 0.9726 & 0.9531 & 0.9568 \\
\hline$\phi=6.2 \times 10^{13}$ & 0.9672 & 0.9477 & 0.9514 \\
\hline$\phi=8.3 \times 10^{13}$ & 0.9625 & 0.9430 & 0.9467 \\
\hline$\phi .=1.0 \times 10^{14}$ & 0.9589 & 0.9394 & 0.9431 \\
\hline$\phi=1.8 \times 10^{14}$ & 0.9521 & 0.9326 & 0.9363 \\
\hline$\phi=2.3 \times 10^{14}$ & 0.9478 & 0.9283 & 0.9320 \\
\hline$\phi=2.9 \times 10^{14}$ & 0.9454 & 0.9259 & 0.9296 \\
\hline$\phi=3.3 \times 10^{14}$ & 0.9429 & 0.9234 & 0.9271 \\
\hline$\phi=4.1 \times 10^{14}$ & 0.9405 & 0.9210 & 0.9247 \\
\hline$\phi=5.3 \times 10^{14}$ & 0.9378 & 0.9183 & 0.9220 \\
\hline
\end{tabular}




$$
\begin{aligned}
& E_{F}=E_{i}+k T \cdot \log _{e}\left[\frac{N_{D}(1+Q N D)}{2 n_{i}}\right], \\
& E_{F}=E_{i}+k T \cdot \log _{e}\left[\frac{N_{A}(1+Q N A)}{2 n_{i}}\right],
\end{aligned}
$$

where $Q N D=\left[1+\left(2 n_{i} / N_{D}\right)^{2}\right]^{1 / 2}$,

$$
\begin{aligned}
\mathrm{QNA} & \left.=] 1+\left(2 \mathrm{n}_{i} / \mathrm{N}_{\mathrm{A}}\right)^{2}\right]^{1 / 2}, \\
\mathrm{E}_{i} & =\text { the intrinsic Fermi energy }(\mathrm{eV}),
\end{aligned}
$$$$
\mathrm{N}_{\mathrm{D}}=\text { n-type impurity density }\left(\mathrm{cm}^{-3}\right) \text {, }
$$$$
\mathrm{N}_{\mathrm{A}}=\text { p-type impurity density }\left(\mathrm{cm}^{-3}\right) \text {, }
$$$$
\mathrm{n}_{i}=\text { the intrinsic carrier concentration }\left(\mathrm{cm}^{-3}\right) \text {. }
$$

The dependence of the Fermi level on the doping level is listed in Table II-5. From the impurity concentration data obtained in Chapter II and used in Table II-5, the Fermi energies have been calculated. Table II-6 lists typical $E_{F}$ values for Device SF2523 \#40. These $E_{F}$ values were used in Chapter IV to calculate the limiting lifetimes which were needed in the construction of the desired statistical model. 
Table II-5. Dependence of Fermi energy on doping levels ( $\mathrm{Si}, 300^{\circ} \mathrm{K}$ ).

$N A, N D=$ impurity density of $p$ - and n-type crystals, EFN,EFP = the corresponding Fermi energies.

\begin{tabular}{|c|c|c|c|c|c|c|c|c|c|c|}
\hline $\mathrm{NA} O \mathrm{OR}$ & $\mathrm{ND}$ & EFN & EFP & NA OR & ND & EFN & EFP & NA OR ND & EFN & EFP \\
\hline $0.1 \mathrm{E}$ & 10 & 0.5509 & 0.5491 & $0.2 \mathrm{E}$ & 10 & 0.5517 & 0.5483 & $0.3 \mathrm{E} \quad 10$ & 0.5526 & 0.5474 \\
\hline $0.1 \mathrm{E}$ & 11 & 0.5585 & 0.5415 & $0.2 \mathrm{E}$ & 11 & 0.5662 & 0.5338 & $0.3 E \quad 11$ & 0.5728 & 0.5272 \\
\hline $0.1 \mathrm{E}$ & 13 & 0.6587 & 0.4413 & $0.2 \mathrm{E}$ & 13 & 0.6767 & 0.4233 & $0.3 \mathrm{E} 13$ & 0.6872 & 0.4128 \\
\hline $0.1 E]$ & 14 & 0.7183 & 0.3817 & $0.2 \mathrm{E}$ & 14 & 0.7363 & 0.3637 & $0.3 \mathrm{E} \quad 14$ & 0.7468 & 0.3532 \\
\hline $0.1 \mathrm{E}]$ & 15 & 0.7780 & 0.3220 & $0.2 \mathrm{E}$ & 15 & 0.7959 & 0.3041 & $0.3 E \quad 15$ & 0.8064 & 0.2936 \\
\hline $0.4 \mathrm{E}$ & 15 & 0.8138 & 0.2862 & $0.5 \mathrm{E}$ & 15 & 0.8196 & 0.2804 & $0.6 \mathrm{E} \quad 15$ & 0.8243 & 0.2757 \\
\hline $0.7 \mathrm{E}]$ & 15 & 0.8283 & 0.2717 & $0.8 \mathrm{E}$ & 15 & 0.8318 & 0.2682 & $0.9 \mathrm{E} \quad 15$ & 0.8348 & 0.2652 \\
\hline $0.1 E]$ & 16 & 0.8376 & 0.2624 & $0.2 \mathrm{E}$ & 16 & 0.8555 & 0.2445 & $0.3 \mathrm{E} 16$ & 0.8660 & 0.2340 \\
\hline $0.4 \mathrm{E}$ & 16 & 0.8735 & 0.2265 & $0.5 \mathrm{E}$ & 16 & 0.8792 & 0.2208 & $0.6 \mathrm{E} \quad 16$ & 0.8840 & 0.2160 \\
\hline $0.7 \mathrm{E}]$ & 16 & 0.8880 & 0.2120 & $0.8 \mathrm{E}$ & 16 & 0.8914 & 0.2086 & $0.9 \mathrm{E} 16$ & 0.8945 & 0.2055 \\
\hline $0.1 \mathrm{E}]$ & 17 & 0.8972 & 0.2028 & $0.2 \mathrm{E}$ & 17 & 0.9151 & 0.1849 & $0.3 \mathrm{E} 17$ & 0.9256 & 0.1744 \\
\hline $0.4 \mathrm{E}]$ & 17 & 0.9331 & 0.1669 & $0.5 \mathrm{E}$ & 17 & 0.9389 & 0.1611 & $0.6 \mathrm{E} \quad 17$ & 0.9436 & 0.1564 \\
\hline $0.7 \mathrm{E}$ & 17 & 0.9476 & 0.1524 & $0.8 \mathrm{E}$ & 17 & 0.9510 & 0.1490 & $0.9 \mathrm{E} \quad 17$ & 0.9541 & 0.1459 \\
\hline $0.1 \mathrm{E}]$ & 18 & 0.9568 & 0.1432 & $0.2 \mathrm{E}$ & 18 & 0.9747 & 0.1253 & $0.3 E 18$ & 0.9852 & 0.1148 \\
\hline $0.4 \mathrm{E}]$ & 18 & 0.9927 & 0.1073 & $0.5 \mathrm{E}$ & 18 & 0.9985 & 0.1015 & $0.6 \mathrm{E} \quad 18$ & 1.0032 & 0.0968 \\
\hline $0.7 \mathrm{E}$ & 18 & $1: .0072$ & 0.0928 & $0.8 \mathrm{E}$ & 18 & 1.0106 & 0.0894 & $0.9 \mathrm{E} 18$ & 1.0137 & 0.0863 \\
\hline $0.1 \mathrm{E}$ & 19 & 1.0164 & 0.0836 & $0.2 \mathrm{E}$ & 19 & 1.0344 & 0.0656 & $0.3 \mathrm{E} 19$ & 1.0449 & 0.0551 \\
\hline $0.4 \mathrm{E}$ & 19 & 1.0523 & 0.0477 & $0.5 \mathrm{E}$ & 19 & 1.0581 & 0.0419 & $0.6 \mathrm{E} \quad 19$ & 1.0628 & 0.0372 \\
\hline $0.7 \mathrm{E}]$ & 19 & 1.0668 & 0.0332 & $0.8 \mathrm{E}$ & 19 & 1.0702 & 0.0297 & $0.9 \mathrm{E} \quad 19$ & 1.0733 & 0.0267 \\
\hline $0.1 \mathrm{E} 2$ & 20 & 1.0760 & 0.0240 & $0.2 \mathrm{E}$ & 20 & 1.0940 & 0.0060 & $0.3 \mathrm{E} 20$ & $1.1045^{\circ}$ & -.0045 \\
\hline $0.4 \mathrm{E} 2$ & 20 & 1.1119 & -.0119 & $0.5 \mathrm{E}$ & 20 & 1.1177 & -.0177 & $0.6 \mathrm{E} 20$ & 1.1224 & -.0224 \\
\hline $0.7 \mathrm{E} 2$ & 20 & 1.1264 & -.0264 & $0.8 \mathrm{E}$ & 20 & 1.1299 & -.0299 & $0.9 \mathrm{E} 20$ & 1.1329 & -.0329 \\
\hline $0.1 \mathrm{E} 2$ & 21 & 1.1356 & -.0356 & $0.2 \mathrm{E}$ & 21 & 1.1536 & -.0536 & $0.3 E 21$ & 1.1641 & -.0641 \\
\hline $0.4 \mathrm{E} 2$ & 21 & 1.1715 & -.0715 & $0.5 \mathrm{E}$ & 21. & 1.1773 & -.0773 & $0.6 \mathrm{E} 21$ & 1.1820 & -.0820 \\
\hline $0.7 \mathrm{E} 2$ & 21 & 1.1860 & -.0860 & $0.8 \mathrm{E}$ & 21 & 1.1895 & -.0895 & $0.9 E 21$ & 1.1925 & -.0925 \\
\hline $0.1 \mathrm{E} 2$ & 22 & 1.1953 & -.0953 & $0.2 \mathrm{E}$ & 22 & 1.2132 & -.1132 & $0.3 \mathrm{E} 22$ & 1.2237 & -.1237 \\
\hline
\end{tabular}


Table II-6. Fermi energies for Device SF2523 \#40 at various fluences $\left(T=300^{\circ} \mathrm{K}\right)$.

\begin{tabular}{|c|c|c|c|}
\hline$\underset{(\text { nvt })}{\phi}$ & $\begin{array}{c}\text { Emitter } \\
(\mathrm{eV})\end{array}$ & $\begin{array}{l}\text { Base } \\
(\mathrm{eV})\end{array}$ & $\begin{array}{c}\text { Collector } \\
\text { (eV) }\end{array}$ \\
\hline$\phi=0.0$ & 1.12249 & 0.1570 & 0.9010 \\
\hline$\phi=1.0 \times 10^{12}$ & 1.12249 & 0.1570 & 0.9010 \\
\hline$\phi=5.9 \times 10^{12}$ & 1.12249 & 0.1570 & 0.9009 \\
\hline$\phi=1.2 \times 10^{13}$ & 1.12249 & 0.1571 & 0.9008 \\
\hline$\phi=2.1 \times 10^{13}$ & 1.12249 & 0.1572 & 0.9006 \\
\hline$\phi=3.9 \times 10^{13}$ & 1.12249 & 0.1573 & 0.9002 \\
\hline$\phi=6.2 \times 10^{13}$ & 1.12249 & 0.1575 & 0.8998 \\
\hline$\phi=8.3 \times 10^{13}$ & 1.12249 & 0.1577 & 0.8994 \\
\hline$\phi=1.0 \times 10^{14}$ & 1.12249 & 0.1579 & 0.8991 \\
\hline$\phi=1.8 \times 10^{14}$ & 1.12249 & 0.1585 & 0.8978 \\
\hline$\phi=2.3 \times 10^{14}$ & 1.12249 & 0.1589 & 0.8967 \\
\hline$\phi=2.9 \times 10^{14}$ & 1.12249 & 0.1593 & 0.8954 \\
\hline$\phi=3.3 \times 10^{14}$ & 1.12249 & 0.1597 & 0.8943 \\
\hline$\phi=4.1 \times 10^{14}$ & 1.12248 & 0.1603 & 0.8924 \\
\hline$\phi=5.3 \times 10^{14}$ & 1.12248 & 0.1612 & 0.8897 \\
\hline
\end{tabular}


III. ACTIVATION ENERGY OF NEUTRON-INDUCED DEFECT LEVEL

\section{A. Theoretical Consideration}

Sah, Noyce and Shockley ${ }^{5}$ pointed out that the thermal activation energy of recombination centers could be obtained from the slope of a plot of the logarithm of the reverse current as a function of the reciprocal of temperature at a constant reverse bias.

It has been shown ${ }^{8-12}$ that the dependence of the transistor current at a constant bias on the activation energy of the defect can be expressed as

$$
I=K \cdot T \cdot \exp \left(-E_{R} / k T\right)
$$

where $I=$ transistor current (amp),

$$
\begin{aligned}
\mathrm{K} & =\text { proportional constant }\left(\operatorname{amp} /{ }^{\circ} \mathrm{K}\right), \\
\mathrm{T} & =\text { temperature }\left({ }^{\circ} \mathrm{K}\right), \\
\mathrm{K} & =\text { Boltzmann's constant }\left(8.62 \times 10^{-5} \mathrm{eV} /{ }^{\circ} \mathrm{K}\right), \\
\mathrm{E}_{\mathrm{R}} & =\text { activation energy }(\mathrm{eV}) .
\end{aligned}
$$

Taking the logarithm of both sides of equation (3-1), one obtains

$$
\log _{e} I=\log _{e} K+\log _{e} T-E_{R} / k T
$$

If two sets of (I, T) data i.e., $\left(I_{1}, T_{1}\right)$ and $\left(I_{2}, T_{2}\right)$, are substituted into equation (3-2), the following is obtained

$$
\log _{e} I_{1}=\log _{e} K+\log _{e} T_{1}-E_{R} / k T_{1}
$$




$$
\log _{e} I_{2}=\log _{e} K+\log _{e} T_{2}-E_{R} / k T_{2}
$$

Subtracting equation (3-3) from equation (3-4),

$$
\log _{e}\left(\frac{I_{2}}{I_{1}}\right)=\log _{e}\left(\frac{T_{2}}{T_{1}}\right)-\left(\frac{E R}{k}\right)\left(\frac{1}{T_{2}}-\frac{1}{T_{1}}\right)
$$

Equation (3-5) is the basic equation used throughout this investigation to obtain the values of the activation energy, $E_{R^{\prime}}$ which was employed in building the recombination statistics for the neutron-induced base current component.

\section{B. Experimental Technique}

The Automatic Data Acquisition System 41,42 was used to measure the base and the collector currents at constant emitter-to-base bias for a specified temperature and repeated for some other temperatures. The temperatures used in this work were $-60^{\circ} \mathrm{C},-50^{\circ} \mathrm{C},-40^{\circ} \mathrm{C},-30^{\circ} \mathrm{C},-20^{\circ} \mathrm{C},-10^{\circ} \mathrm{C}$, $0^{\circ} \mathrm{C}, 10^{\circ} \mathrm{C}, 20^{\circ} \mathrm{C}$ and $27^{\circ} \mathrm{C}$. From the I-V data for different temperatures (see Figure III-I), $\log (\mathrm{I})$ versus $10^{3} / \mathrm{T}$ has been plotted (see Figure III-2) by machine (Calcomp Model 556 Plotter), where $10^{3} / \mathrm{T}$ was used, instead of $1 / \mathrm{T}$, for scaling purposes.

A computer program using a least-squares fitting technique was employed to find the best-fit of $\log \left(I_{B}\right)$ vs $10^{3} / \mathrm{T}$ as shown in Figure III-2. If one chooses $10^{\circ} \mathrm{C}$ increment in temperatures, equation (3-4) can be rewritten, for $\mathrm{T}>200^{\circ} \mathrm{K}$, after some algebra, as 


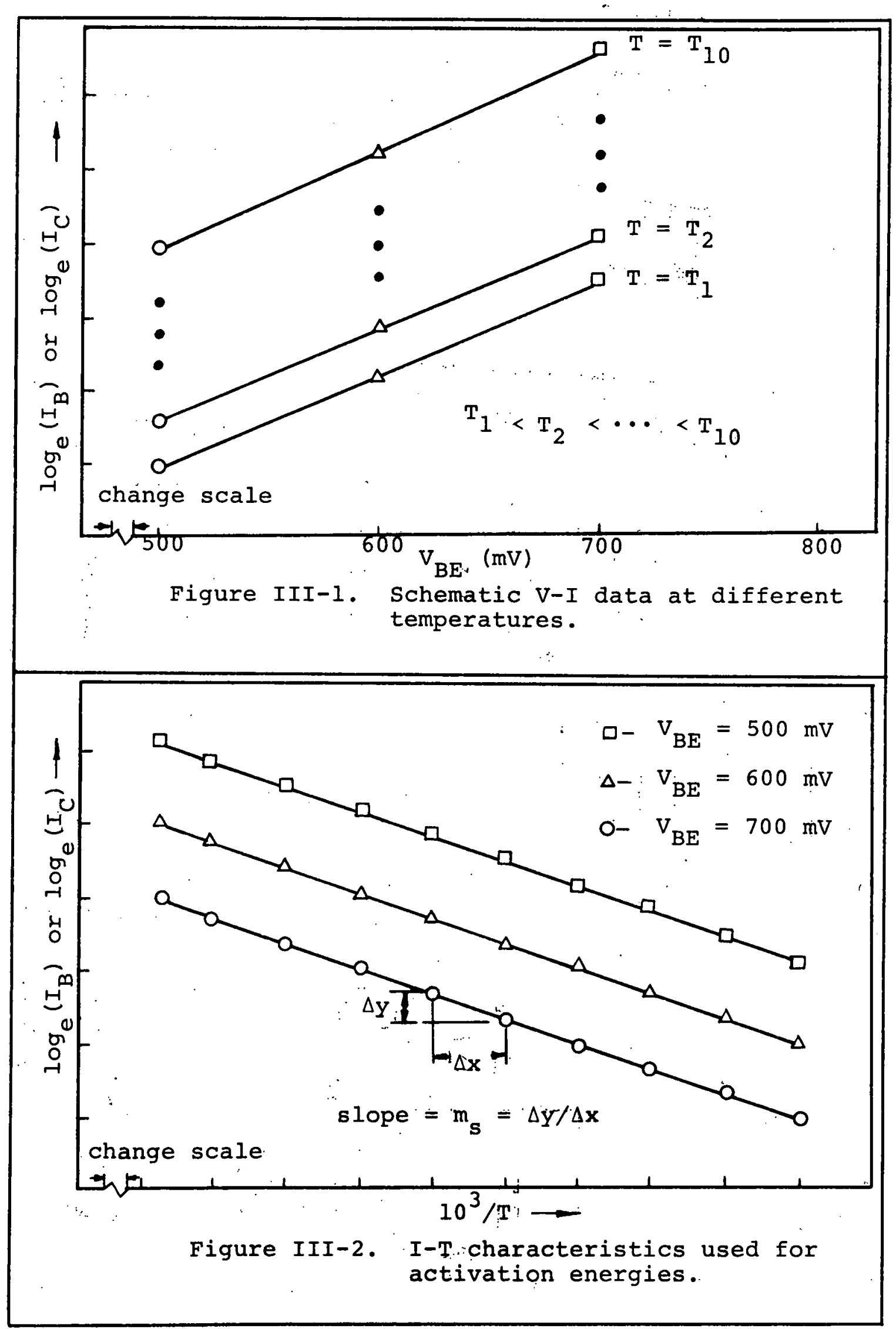




$$
E_{R}=0.1987 \cdot m_{s}-0.021(e V) \text {, }
$$

where $m_{s}$ is the slope of the plotted curve (Figure III-2). Equation (3-6) was employed throughout this work to obtain the activation energy, $E_{R^{\prime}}$ which was required for the statistical model. The nine epitaxial-planar transistors used in this investigation have the $E_{R}$ values listed in Table III-1. The activation energy inferred from this process is similar to that reported ${ }^{23-25}$ for neutral vacancy and interstitial annealing.

The $\log \left(I_{B}\right)$ versus $10^{3} / T$ curve was obtained for a specified emitter-to-base bias, $\mathrm{V}_{\mathrm{BE}}$. The same process was repeated for three different values of $\mathrm{V}_{\mathrm{BE}}$. The slight difference in the three values of $E_{R}$ shows that $E_{R}$ is independent of $V_{B E}$ at low to moderate neutron fluences. The three different chosen values of $\mathrm{V}_{\mathrm{BE}}$ are $500 \mathrm{mv}, 600 \mathrm{mv}, 700 \mathrm{mv}$. Table III-2 is an example of $E_{R}$ values, at $\phi=5.3 \times 10^{14} \mathrm{nvt}$, for three $\mathrm{V}_{\mathrm{BE}}$ 's.

Moreover, from Table III-3 in which the activation energies for Device SF2523 \#40 at four different neutron fluences are listed, it may said, (since all those numbers are very close to $0.235 \mathrm{eV}$ ), that the dominant activation energy of the neutron-induced defect levels is independent of neutron fluence at low to moderate fluences. 
Table III-1. Values of $\mathrm{E}_{\mathrm{R}}$. for nine $\mathrm{n}-\mathrm{p}-\mathrm{n}$ Si epitaxial-planar transistors.

\begin{tabular}{|c|c|c|c|c|c|c|c|c|c|}
\hline (nvt) & $\begin{array}{c}\text { SF2523 } \\
\text { \#40 } \\
(\mathrm{eV})\end{array}$ & $\begin{array}{c}\text { SF2523 } \\
\# 46 \\
(\mathrm{eV})\end{array}$ & $\begin{array}{c}\text { SF2523 } \\
\# 47 \\
(\mathrm{eV})\end{array}$ & $\begin{array}{c}\text { SF25:23 } \\
\# 48 \\
(\mathrm{eV})\end{array}$ & $\begin{array}{c}\text { SF2524 } \\
\# 62 \\
(\mathrm{eV})\end{array}$ & $\begin{array}{c}\text { SF2524 } \\
\# 68 \\
(e V)\end{array}$ & $\begin{array}{c}2 \mathrm{~N} 914 \\
\# 4 \\
(\mathrm{eV})\end{array}$ & $\begin{array}{r}2 N 914 \\
\quad \# 5 \\
(\mathrm{eV})\end{array}$ & $\begin{array}{c}210914 \\
\# 7 \\
(\mathrm{ev})\end{array}$ \\
\hline$\phi=1.0 \times 10^{12}$ & 0.235 & 0.229 & 0.236 & 0.230 & 0.235 & 0.232 & 0.236 & 0.234 & 0.233 \\
\hline$\phi=5.9 \times 10^{12}$ & 0.236 & 0.231 & 0.234 & 0.229 & 0.230 & 0.231 & 0.229 & 0.231 & 0.236 \\
\hline$\phi=1.2 \times 10^{13}$ & 0.234 & 0.233 & 0.238 & 0.233 & 0.234 & 0.235 & 0.231 & 0.228 & 0.231 \\
\hline$\phi=2.1 \times 10^{13}$ & 0.229 & 0.236 & 0.231 & 0.231 & 0.238 & 0.233 & 0.235 & 0.235 & 0.229 \\
\hline$\phi=3.9 \times 10^{13}$ & 0.237 & 0.232 & 0.236 & 0.232 & 0.235 & 0.229 & 0.237 & 0.234 & 0.234 \\
\hline$\phi=6.2 \times 10^{13}$ & 0.238 & 0.234 & 0.234 & 0.234 & 0.237 & 0.230 & 0.231 & 0.230 & 0.233 \\
\hline$\phi=8.3 \times 10^{13}$ & 0.234 & 0.229 & 0.230 & 0.236 & 0.231 & 0.234 & 0.228 & 0.229 & 0.238 \\
\hline$\phi=1.0 \times 10^{14}$ & 0.233 & 0.230 & 0.236 & 0.232 & 0.229 & 0.237 & 0.236 & 0.228 & 0.237 \\
\hline$\phi=1.8 \times 10^{14}$ & 0.230 & 0.231 & 0.233 & 0.235 & 0.232 & 0.234 & 0.230 & 0.231 & 0.234 \\
\hline$\phi=2.3 \times 10^{14}$ & 0.232 & 0.235 & 0.232 & 0.228 & 0.236 & 0.238 & 0.234 & 0.234 & 0.235 \\
\hline$\phi=2.9 \times 10^{14}$ & 0.231 & 0.232 & 0.234 & 0.234 & 0.232 & 0.232 & 0.233 & 0.237 & 0.229 \\
\hline$\phi=3.3 \times 10^{14}$ & 0.236 & 0.233 & 0.229 & 0.236 & 0.234 & 0.231 & 0.235 & 0.233 & 0.230 \\
\hline$\phi=4.1 \times 10^{14}$ & 0.229 & 0.232 & 0.238 & 0.235 & 0.238 & 0.236 & 0.229 & 0.230 & 0.231 \\
\hline$\phi=5.3 \times 10^{14}$ & 0.235 & 0.235 & 0.237 & 0.231 & 0.235 & 0.229 & 0.232 & 0.234 & 0.235 \\
\hline
\end{tabular}


Table III-2. Activation energies for three different $V_{B E}$ (Device SF2523\#40, at $\phi=5.3 \times 10^{14} \mathrm{nvt}$ )

\begin{tabular}{|c|c|c|c|}
\hline$v_{B E}(m v)$ & 500 & 600 & 700 \\
\hline$E_{R}(\mathrm{ev})$ & 0.234 & 0.237 & 0.235 \\
\hline
\end{tabular}

Table III-3. Activation energies at various neutron fluences (Device SF2523 \#40).

\begin{tabular}{|c|c|c|c|c|}
\hline$\phi \quad(n v t)$ & $1.0 \times 10^{12}$ & $6.2 \times 10^{13}$ & $2.3 \times 10^{14}$ & $5.3 \times 10^{14}$ \\
\hline$E_{R}(\mathrm{ev})$ & 0.235 & 0.238 & 0.232 & 0.235 \\
\hline
\end{tabular}


IV. MINORITY CARRIER LIFETIMES, CAPTURE CROSSSECTIONS FOR HOLES AND ELECTRONS

\section{A. Minority Carrier Lifetimes}

When a small density of excess carriers is injected, the density decreases with time proportionally as $e^{-t / \tau}$ and when $t$ equals $\tau$, the carriers have decayed to $1 /$ e of the original value. Thus, $\tau$ is referred to as the lifetime of the carriers and is an inverse measure of the recombination rate.

Prior to Goben's $\mathrm{s}^{8-12}$ work, the decrease in transistor gain observed upon exposure to neutron radiation had been attributed primarily to the neutron-induced reduction in minority carrier lifetime in the region ${ }^{43-47}$. Landis ${ }^{48}$ points out that measurement of minority carrier lifetime as a function of radiation fluence is probably the most sensitive of all radiation damage techniques, and that it can be made to give good values for the recombination cross sections $\left(\sigma_{n}\right.$ and $\sigma_{p}$ ) of radiation-induced defect levels.

The expression for minority carrier lifetime, the relationships of limiting lifetimes ( $\tau_{n r}$ and $\tau_{p r}$ ) with base region and collector region minority carriers lifetimes and other parameters have been derived in detail. They are summarized, for convenience, as follows:

The lifetime expression is

$$
\tau=\frac{\tau_{p r}\left(n+n_{r}\right)+\tau_{n r}\left(p+p_{r}\right)}{n+p},
$$


and the relationships for the limiting lifetimes are

$$
\begin{aligned}
& \tau_{\mathrm{pr}}=1 / \mathrm{N}_{\mathrm{R}} \mathrm{C}_{\mathrm{P}} ; \quad \tau_{\mathrm{nr}}=1 / \mathrm{N}_{\mathrm{R}} \mathrm{C}_{\mathrm{n}}, \\
& \tau_{\mathrm{C}} \simeq \tau_{\mathrm{pr}}\left[1+\exp \left(\frac{\mathrm{E}_{\mathrm{R}}-\mathrm{E}_{\mathrm{F}}}{\mathrm{kT}}\right)\right], \\
& \tau_{\mathrm{B}} \simeq \tau_{\mathrm{nr}}+\tau_{\mathrm{pr}} \cdot \exp \left(\frac{\mathrm{E}_{\mathrm{R}}+\mathrm{E}_{\mathrm{F}}-2 \mathrm{E}_{i}}{\mathrm{kT}}\right),
\end{aligned}
$$

where $\mathrm{p}_{r}, \mathrm{n}_{r}=$ the hole and electron concentrations that would exist of the the Fermi level coincided with the energy level $E_{R}$ of the centers, $\tau_{p r}{ }^{\prime} \tau_{n r}=$ lifetimes of holes and electrons in highly $n-$ type and p-type materials, respectively, $\tau_{B}=$ base region minority carriers lifetime, $\tau_{C}=$ collector region minority carriers lifetime, $\mathrm{N}_{\mathrm{R}}=$ concentration of defect centers, $E_{i}=$ intrinsic Fermi energy.

Transistor risetime measurements and diode storage time measurements have been made by using a Tektronix 555 Oscilloscope with Tektronix Type $\mathrm{R}$ risetime and Type $\mathrm{S}$ recovery time plug-in units. From the measured time constants associated with the $\mathrm{p}-\mathrm{n}$ junction devices, the minority carrier lifetime in the various regions of the device were calculated. That is, the values of $\tau_{B E}$ and $\tau_{B C}$ were aalculated using data from risetime and storage time measurement ${ }^{49}$ and from these, the base and collector region lifetimes were calculated. They are given by 


$$
\begin{aligned}
& \tau_{B} \simeq \tau_{E B}, \\
& \tau_{C} \simeq \frac{\tau_{E B}-\tau_{B C}}{\tau_{E B} \cdot \tau_{B C}},
\end{aligned}
$$

from which the minority carriers lifetimes in both base and collector regions are obtainable.

The pre-irradiation values of $\tau_{E B}, \tau_{B C}{ }^{\prime} \tau_{B}$ and $\tau_{C}$ for the nine devices used in this work are listed in Table IV-I. Those values were obtained from the fitting:curves for the observed data by a least-squares fitting.

The empirical expression 50,51 for the relationship of minority carrier lifetime with neutron fluence can be written, for.low to:moderate fluences, as:

$$
\frac{1}{\tau}=\frac{1}{\tau_{0}}+K_{\tau} \cdot \phi
$$

$$
\text { where } \begin{aligned}
\tau_{0} & =\text { pre-irradiation minority carrier lifetime, } \\
\tau & =\text { post-irradiation minority carrier lifetime, } \\
\mathrm{K}_{\tau} & =\text { minority carrier lifetime radiation damage factor, } \\
\phi & =\text { neutron fluence. }
\end{aligned}
$$

Equation (4-7) has been tried for the best fit of the lifetime fluence data in this work. This paper found that equation (4-7) gave a good fit for the data at low to moderate fluence levels ( $\left.\phi<7.0 \times 10^{14} \mathrm{nvt}\right)$.

The minority carriers lifetime radiation damage factors of the devices used in this investigation are listed in Table IV-2. 
Table IV-1. Values of $\tau_{E B}, \tau_{B C}, \tau_{B}$ and $\tau_{C}(a t=0.0)$

\begin{tabular}{|c|c|c|c|c|c|}
\hline Device & & $\tau_{\text {EB }}(n s)$ & $\tau^{\tau_{B C}} \quad(n s)$ & ${ }^{\tau}{ }_{B}(n s)$ & ${ }^{\tau}{ }_{C}(\mu s)$ \\
\hline \multirow[t]{4}{*}{ SF 2523} & $\# 40$ & 122 & 115 & 122 & 1.93 \\
\hline & $\# 46$ & 123 & 117 & 123 & 2.28 \\
\hline & $\# 47$ & 123 & 119 & 123 & 3.56 \\
\hline & $\# 48$ & 130 & 123 & 130 & 2.24 \\
\hline \multirow[t]{2}{*}{ SF 2524} & $\# 62$ & $1 \cdot 37$ & 121 & 137 & 1.03 \\
\hline & $\# 68$ & 144 & 126 & 144 & 0.98 \\
\hline \multirow[t]{3}{*}{$2 N 914$} & $\# 4$ & 87 & 79 & 87 & 0.87 \\
\hline & $\# 5$ & 90 & 82 & 90 & 0.98 \\
\hline & \# 7 & 96 & 87 & 96 & 0.96 \\
\hline
\end{tabular}

Table IV-2. Lifetime radiation damage factors $\left(\mathrm{K}_{\tau}, \mathrm{cm}^{2} / \mathrm{n}-\mathrm{sec}\right)$.

\begin{tabular}{rcc} 
Devices & $K_{\tau}$ for $\tau_{B}\left(x 10^{-7}\right)$ & $K_{\tau}$ for $\tau_{C}\left(x 10^{-9}\right)$ \\
\hline SF2523\#40 & 2.31 & 4.52 \\
$\# 46$ & 2.29 & 5.37 \\
\#47 & 2.29 & 4.66 \\
SF2524 \#62 & 2.23 & 5.72 \\
\#68 & 2.71 & 8.58 \\
$\# 4$ & 2.62 & 8.02 \\
$\# 5$ & 2.11 & 12.6 \\
7 & 2.07 & 11.1 \\
& 1.82 & 11.2
\end{tabular}


Figures IV-1 and IV-2 show the dependence of minority carrier lifetimes on neutron fluence in the base and collector regions, respectively, for three devices. Curtis 51,52 reported the dependence of lifetimes on neutron fluence, his plot of $\tau$ vs $\phi$ has the same characteristics as those on this paper (see Figures IV-I and IV-2).

\section{B. The Limiting Lifetimes and Capture Cross-Sections}

Knowing the activation energy $E_{R}$ from Chapter III, the Fermi energy $E_{F}$ from Chapter II, and the minority carrier lifetimes calculated in Section $A$, one can obtain the limiting lifetimes by using equations (4-3) and (4-4). Table IV-3 shows the calculated $\tau_{p r}$ and $\tau_{n r}$ at various neutron fluences at $300^{\circ} \mathrm{K}$ for three devices.

The capture cross-sections for holes and electrons are given by the following equations 26,48 ,

$$
\begin{aligned}
& \sigma_{p}=\frac{c_{p}}{v_{p}}, \\
& \sigma_{n}=\frac{C_{n}}{v_{n}},
\end{aligned}
$$

where $\sigma_{p}, \sigma_{n}=$ capture cross-sections for holes and electrons,

$c_{p}, c_{n}=$ capture probabilities of the sites for holes and electrons,

$\mathrm{v}_{\mathrm{p}}, \mathrm{v}_{\mathrm{n}}=$ hole, electron thermal velocities.

The capture probabilities of the sites for holes and 


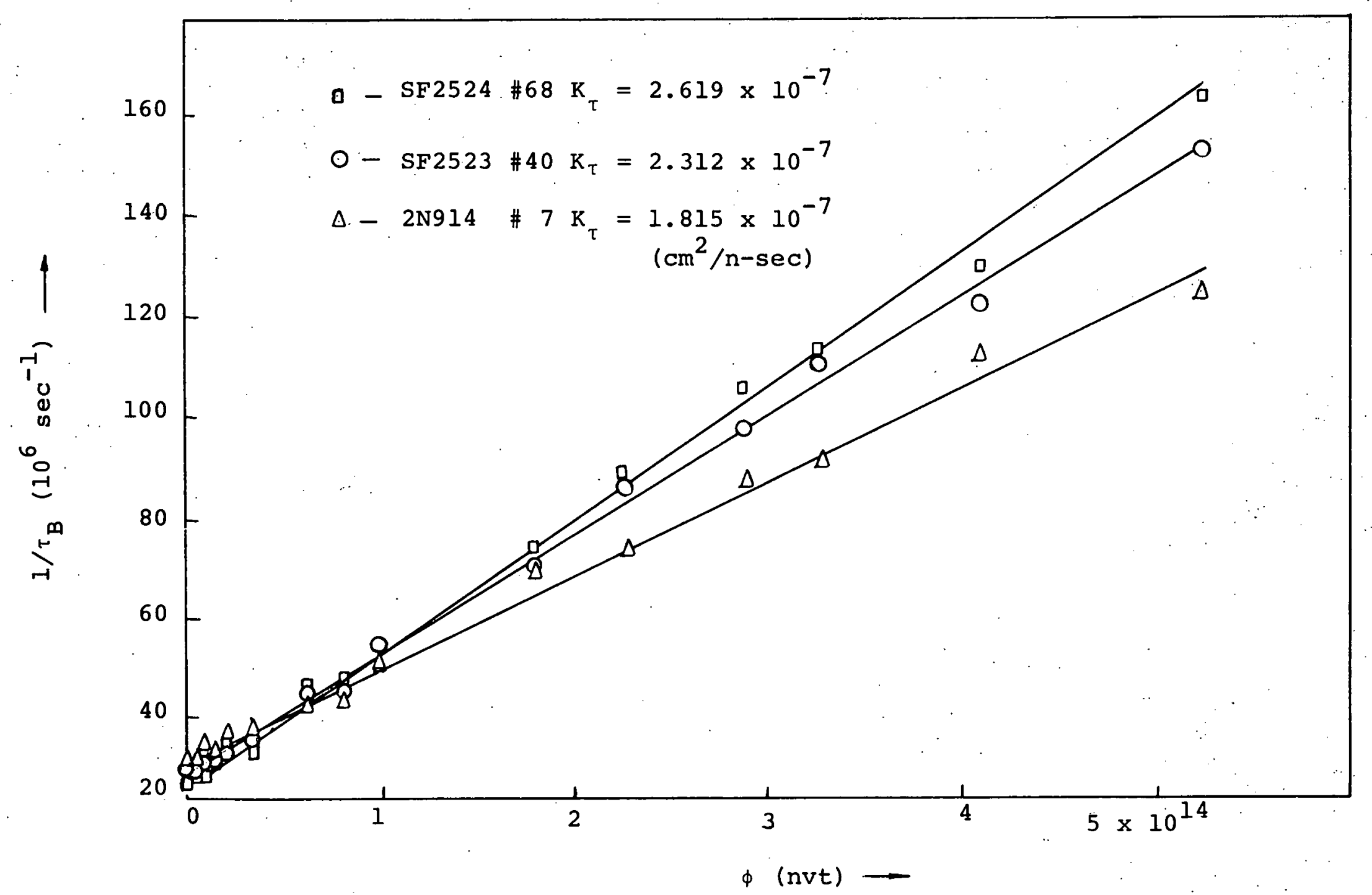

Figure IV-1. Minority carrier lifetime in base versus neutron fluence (at $300^{\circ} \mathrm{K}$ ). 


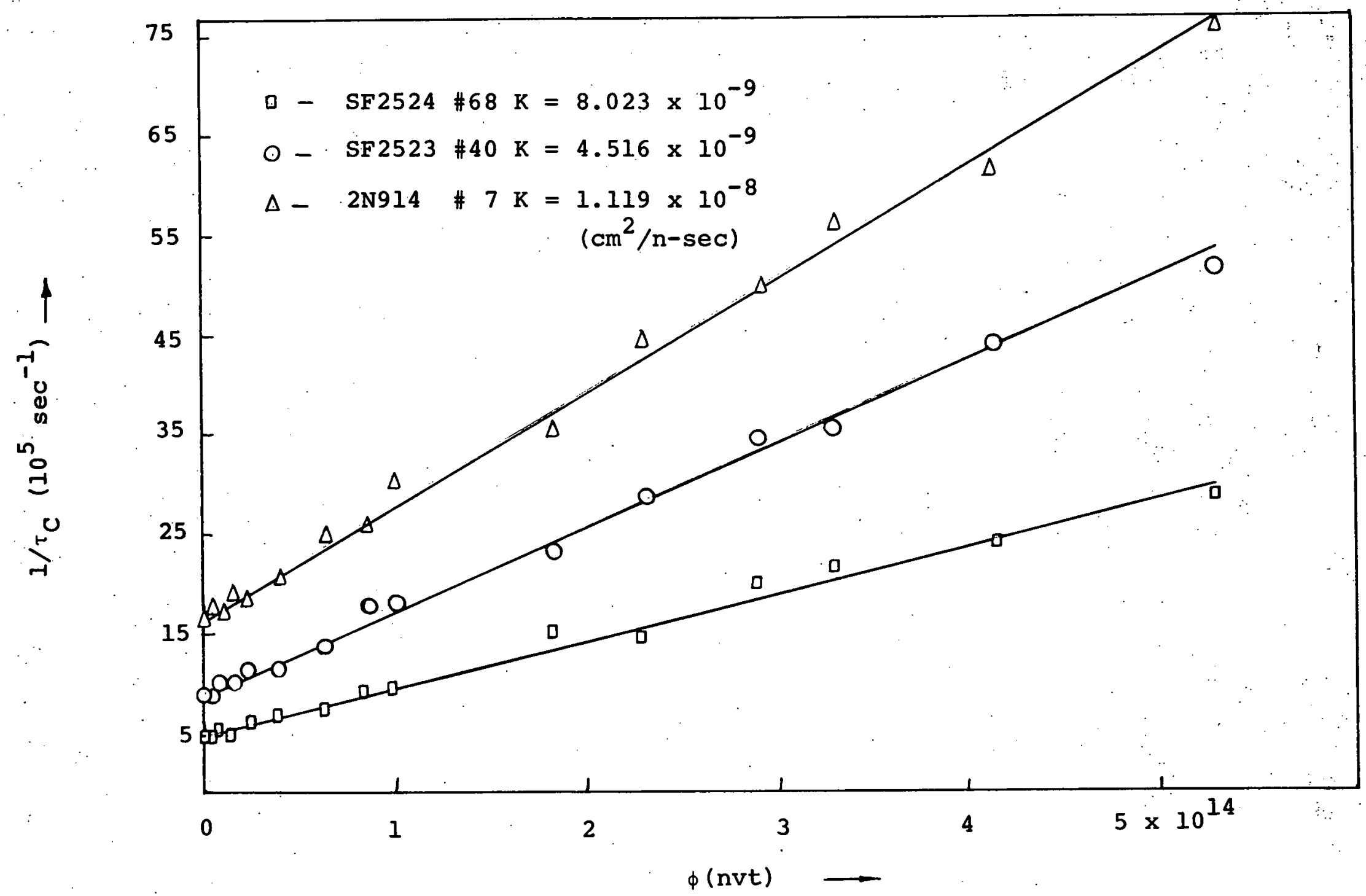

Figure IV-2. Minority carrier lifetime in collector versus neutron fluence (at $300^{\circ} \mathrm{K}$ ). 
Table IV-3. Limiting lifetimes at $300^{\circ} \mathrm{K}$.

\begin{tabular}{|c|c|c|c|c|c|c|}
\hline Device & SF 25 & $3 \# 40$ & SF 25: & \#68 & $2 \mathrm{~N}$ & $\# 7$ \\
\hline$\underset{\text { (nvt) }}{\phi}\left(10^{-7 \text { sec })}\right.$ & $\tau_{n r}$ & ${ }^{\tau}$ pr & ${ }^{\tau} n r$ & ${ }^{\tau}$ pr & $\tau_{n r}$ & $\tau_{p r}$ \\
\hline$\phi=1.0 \times 10^{12}$ & 1.209 & 19.061 & 1.394 & 10.508 & 0.945 & 9.668 \\
\hline$\phi=5.9 \times 10^{12}$ & 1.072 & 16.901 & 1.181 & 8.903 & 0.871 & 8.910 \\
\hline$\phi=1.2 \times 10^{13}$ & 0.938 & 14.787 & 1.003 & 7.563 & 0.798 & 8.164 \\
\hline$\phi=2.1 \times 10^{13}$ & 0.783 & 12.342 & 0.810 & 6.106 & 0.706 & 7.225 \\
\hline$\phi=3.9 \times 10^{13}$ & 0.591 & 9.316 & 0.591 & 4.454 & 0.57 .4 & 5.871 \\
\hline$\phi=6.2 \times 10^{13}$ & 0.446 & 7.032 & 0.430 & 3.243 & 0.460 & 4.706 \\
\hline$\phi=8.3 \times 10^{13}$ & 0.368 & 5.803 & 0.349 & 2.631 & 0.393 & 4.021 \\
\hline$\phi=1.0 \times 10^{14}$ & 0.313 & 4.933 & 0.294 & 2.217 & 0.342 & 3.498 \\
\hline$\phi=1.8 \times 10^{14}$ & 0.202 & 3.182 & 0.185 & 1.396 & 0.232 & 2.372 \\
\hline$\phi=2.3 \times 10^{14}$ & 0.162 & 2.554 & 0.147 & 1.107 & 0.190 & 1.944 \\
\hline$\phi=2.9 \times 10^{14}$ & 0.132 & 2.081 & 0.120 & 0.904 & 0.158 & 1.617 \\
\hline$\phi=3.3 \times 10^{14}$ & 0.118 & 1.860 & 0.107 & 0.807 & 0.142 & 1.452 \\
\hline$\phi=4.1 \times 10^{14}$ & 0.097 & 1.528 & 0.087 & 0.657 & 0.117 & 1.197 \\
\hline$\phi=5.3 \times 10^{14}$ & 0.077 & 1.213 & 0.069 & 0.521 & 0.094 & 0.961 \\
\hline
\end{tabular}


electrons were calculated by using equation (4-2) and the calculated $\mathrm{N}_{\mathrm{R}}$ from Chapter II and the values for $\tau$ pr and $\tau_{n r} \cdot$ The capture cross-sections for holes and electrons were then obtained by using equations (4-8) and (4-9), respectively: The thermal velocities for holes and electrons used in this work are $v_{p}=1.5 \times 10^{7}\left(\mathrm{~cm}-\mathrm{sec}^{-1}\right)$ and $v_{n}=2.0$ $x 10^{7}\left(\mathrm{~cm}^{\left.-\sec ^{-1}\right)}\right.$ which are given by Messenger ${ }^{26}$. Table IV-4 lists some typical values for $\sigma_{p}$ and $\sigma_{n}$ (for E-B spacecharge region only). Due to the accuracy of the lifetime measurements, only the first two digits of the data for the capture cross-sections are significant. The results show that $\sigma_{\ddot{p}}$ and $\sigma_{n}$ remain approximately constant at low to moderate neutron fluences.

Table IV-4. Capture cross-sections for holes and electrons.

\begin{tabular}{|c|c|c|c|c|c|c|}
\hline Device & SF 2523 & $\# 40$ & $S F 252$ & \#68 & 2 N914 & $\# 7$ \\
\hline $\begin{array}{c}\text { Capture } \\
\text { cross- } \\
\text { sections } \\
(\mathrm{nvt}) \backslash\left(\mathrm{cm}^{-2}\right)\end{array}$ & $\begin{array}{c}\sigma_{n} \\
\left(10^{-15}\right)\end{array}$ & $\begin{array}{c}{ }^{\sigma} \mathrm{p} \\
\left(10^{-16}\right)\end{array}$ & $\begin{array}{c}\sigma_{\mathrm{n}} \\
\left(10^{-15}\right)\end{array}$ & $\begin{array}{c}\sigma_{\mathrm{p}} \\
\left(10^{-16}\right)\end{array}$ & $\begin{array}{c}\sigma_{n} \\
\left(10^{-15}\right) \\
\end{array}$ & $\begin{array}{c}\sigma_{\mathrm{p}} \\
\left(10^{-16}\right)\end{array}$ \\
\hline$\phi=1.0 \times 10^{12}$ & 9.18 & 1.94 & 5.32 & 1.04 & 8.21 & 1.88 \\
\hline$\phi=3.9 \times 10^{13}$ & 9.28 & 1.93 & 5.29 & 1.06 & 8.18 & 1.84 \\
\hline$\phi=1.0 \times 10^{14}$ & 9.23 & 1.95 & 5.26 & 1.03 & 8.16 & 1.86 \\
\hline$\phi=5.3 \times 10^{14}$ & 9.17 & 1.94 & 5.24 & 1.05 & 8.17 & 1.89 \\
\hline
\end{tabular}




\section{RECOMBINATION STATISTICS - MODEL FITTING}

A. Shockley-Read-Hall Recombination Statistics ${ }^{1-4}$

The recombination-generation of hole-electron pairs in semiconductors may take place at certain types of recombination centers or traps. These recombination sites may be crystal lattice dislocations, impurity atoms located interstitially or substitutionally in the crystal lattice, or surface defects. Under steady state conditions a single energy level recombination center is largely described by three parameters ${ }^{3}$ : the capture cross-sections for holes and electrons, and the energy involved in these transitions.

There are four basic processes involved in the carrier recombination-generation through the recombination centers:

1. If center is occupied by a hole, an electron from the conduction band may drop into the center and recombine with the hole.

2. If center is occupied by a hole, the center may emit the hole into the valence band.

3. If center is occupied by an electron, the trapped electron may be emitted to the conduction band.

4. If the center is occupied by an electron, a valence band hole may move into the center and recombine with the trapped electron.

These processes are illustrated in Figure V-l.

The electron capture process is shown in Figure V-1 (a). The capture rate is given by 


$$
r_{n}=n \cdot N_{R} \cdot C_{n} \cdot f_{c p}
$$

where $\mathrm{f}_{\mathrm{Cp}}=$ fraction of centers occupied by holes,

$$
\begin{aligned}
\mathrm{N}_{\mathrm{R}} & =\text { center density, } \\
\mathrm{n} & =\text { density of electrons in the conduction band, } \\
& =\mathrm{N}_{C} \exp \left[\left(\mathrm{E}_{\mathrm{F}}-\mathrm{E}_{C}\right) / \mathrm{kT}\right] .
\end{aligned}
$$

The electron emission rate indicated in Figure $V-1$ (c) is given by

$$
e_{n}=\alpha \cdot f_{c^{\prime}}
$$

$$
\begin{aligned}
\text { where } f_{\mathrm{C}} & =I-f_{\mathrm{cp}} \\
& =\text { fraction of centers occupied by electrons, } \\
& =\text { a proportionality factor. }
\end{aligned}
$$

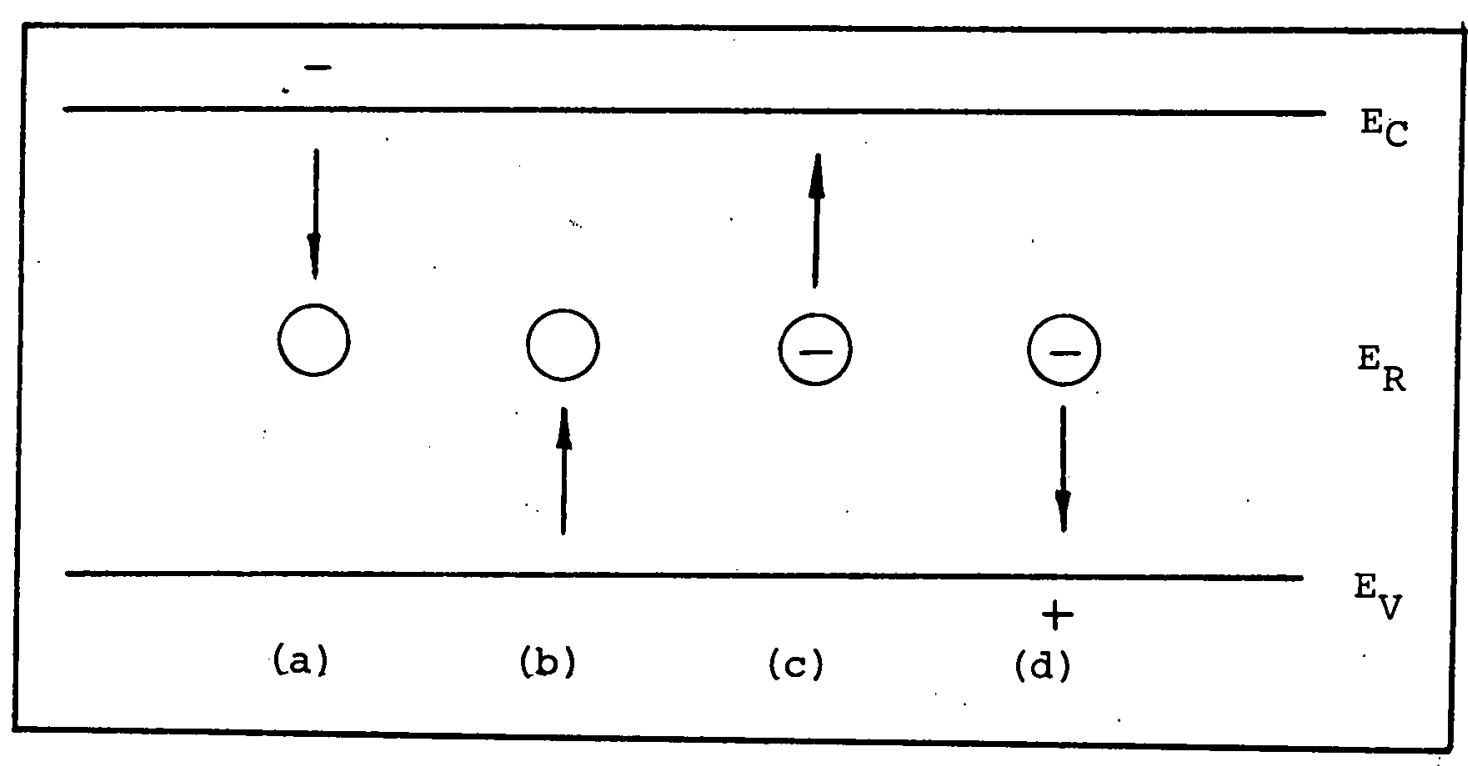

(a) electron capture; (b) hole emission; (c) electron emission; and (d) hole capture.

Figure V-1. Four basic recombination-generation processes through recombination centers. 


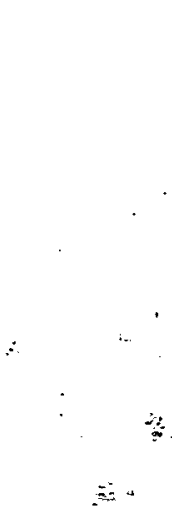


The number a includes the center density, the total number of empty electronics states in the conduction band and the probability of electron emission from the center. Under the condition of thermal equilibrium, the electron emission rate must be equal to the electron capture rate, i.e., equations $(5-1)$ and $(5-2)$ are equal. Thus, the Fermi level must be coincident with the energy level $E_{R}$ of the recombination center, and using 5

$$
f_{C}=\frac{1}{1+\exp \left(\frac{E_{R}-E_{F}}{k T}\right)},
$$

and equating $(5-1)$ and $(5-2)$, one obtains

$$
\alpha=\mathrm{n}_{\mathrm{r}} \cdot \mathrm{C}_{\mathrm{n}} \cdot \mathrm{N}_{\mathrm{R}^{\prime}}
$$

where $\mathrm{n}_{r}=$ electron density in the conduction band if $E_{R}$

$$
\begin{aligned}
& \text { equals } E_{F^{\prime}} \\
= & N_{C} \cdot \exp \left[-\left(E_{C}-E_{R}\right) / k T\right] .
\end{aligned}
$$

Therefore, the net capture rate for electrons by the centers under non-equilibrium conditions can be written as

$$
R_{n}=C_{n} N_{R}\left(n f_{c p}-n_{r} f_{C}\right)
$$

Similar procedures may be applied to the case of the hole; the net capture rate for holes is

$$
R_{p}=C_{p} N_{R}\left(p f_{c}-p_{r} f_{c p}\right)
$$


where $\mathrm{p}=$ hole density on the valence band,

$$
\begin{aligned}
& =N_{V} \cdot \exp \left[\left(E_{V}-E_{F}\right) / k T\right], \\
p_{r} & =\text { hole density in the valence band if } E_{F} \text { equals } E_{R^{\prime}} \\
& =N_{V} \cdot \exp \left[\left(E_{V}-E_{R}\right) / k T\right] .
\end{aligned}
$$

The net rate of recombination for non-equilibrium, but steady-state, conditions is obtained by equating (5-5) and $(5-6)$. This leads to

$$
\begin{aligned}
R & =R_{n}=R_{p} \\
& =\frac{p n-n_{i}{ }^{2}}{\tau_{p r}\left(n+n_{r}\right)+\tau_{n r}\left(p+p_{r}\right)},
\end{aligned}
$$

for the steady-state recombination rate for electrons and holes.

The result of these statistics can be applied to current carriers both in and outside the transition region of a $\mathrm{p}-\mathrm{n}$ junction.

B. Sah-Noyce-Shockley Theory of Junction Space-Charge Recombination-Generation Current ${ }^{5}$

Starting with the exact expression for the steady-state recombination rate of the carriers, as given by equation (5-7), one can obtain a completely theoretical relationship between the current and the applied voltage to the $p-n$ junction.

The following relationships are substituted in equation $(5-7)$ 


$$
\begin{aligned}
n & =n_{i} \cdot \exp \left[q\left(\psi-\phi_{n}\right) / k T\right], \\
p & =n_{i} \cdot \exp \left[q\left(\phi_{p}-\psi\right) / k T\right], \\
n_{r} & =n_{i} \cdot \exp \left[\left(E_{R}-E_{i}\right) / k T\right], \\
p_{r} & =n_{i} \cdot \exp \left[\left(E_{i}-E_{R}\right) / k T\right], \\
E_{i} & =\frac{E_{C}+E_{V}}{2}-\frac{k T}{2} \cdot \log _{e}\left(\frac{N_{C}}{N_{V}}\right)=-q \psi \cdot
\end{aligned}
$$

Equation (5-7) becomes, after substitution and simplification,

$$
R=\frac{n_{i}}{\left(\tau_{p r} \tau_{n r}\right)^{\frac{1}{2}}} \cdot \frac{\sinh \left[\frac{q\left(\phi_{p}-\phi_{n}\right)}{2 k T}\right]}{A A+B B}
$$

where

$$
\begin{aligned}
& \mathrm{AA}=\cosh \left[\frac{\mathrm{q}}{\mathrm{kT}}\left(\psi-\frac{\phi_{\mathrm{p}}+\phi_{\mathrm{n}}}{2}\right)+\frac{1}{2} \cdot \log _{\mathrm{e}}\left(\frac{\tau p r}{\tau \mathrm{pr}}\right)\right] \\
& \mathrm{BB}=\exp \left[-\frac{\mathrm{q}\left(\phi_{\mathrm{p}}-\phi_{\mathrm{n}}\right)}{2 \mathrm{kT}}\right] \cdot \cosh \left[\frac{E_{\mathrm{R}}-E_{i}}{\mathrm{kT}}+\frac{1}{2} \log _{\mathrm{e}}\left(\frac{{ }^{\tau} \mathrm{pr}}{\tau}\right)\right], \\
& \psi=\text { electrostatic potential, } \\
& \phi_{\mathrm{n}}=\text { quasi-Fermi electrostatic potential for } \\
& \phi_{\mathrm{p}}=\text { quasi-Fermi electrostatic potential for holes. }
\end{aligned}
$$

The recombination-generation current in the space- 
charge layer is obtained by integrating equation (5-8) over the entire space-charge layer. Consider the case of a one dimensional problem; the total recombination-generation current in the space-charge layer is given by

$$
I_{B N}=q A \int_{0}^{x_{m}} R \cdot d x
$$

where $A$ is the junction area, and the integration is taken over the space-charge layer.

The final expression for $I_{B N}$ is given in the Sah-NoyceShockley paper ${ }^{5}$ as

$$
I_{B N}=\frac{2 q n_{i} x_{m}}{(\tau p r \tau n r)^{\frac{3}{2}}} \cdot \frac{f(b) \cdot \sinh \left(q V_{B E} / 2 k T\right)}{q\left(V_{T}-V_{B E}\right) / k T}
$$

where

$$
f(b)=\int_{z_{1}}^{z_{2}}\left(\frac{d z}{z^{2}+2 b z+1}\right)
$$

$$
b=\exp \left(-\frac{q V_{B E}}{2 k T}\right) \cdot \cosh \left[\frac{E_{R}-E_{i}}{k T}+\frac{1}{2} \cdot \log _{e}\left(\frac{\tau_{p r}}{\tau_{n r}}\right)\right],
$$

$$
\mathrm{z}_{1,2}=\left(\frac{\tau p r}{\tau_{\mathrm{n} r}}\right)^{\frac{1}{2}} \cdot \exp \left[ \pm \frac{\mathrm{q}\left(\mathrm{V}_{\mathrm{T}}-\mathrm{V}_{\mathrm{BE}}\right)}{2 \mathrm{kT}}\right]
$$

\section{The Expression of the Reciprocal Slope Term for the}

\section{Neutron-Induced Base Current Component}

The neutron-induced base current is given ${ }^{13}$ by the following equation, 


$$
I_{B N}=K_{v} \cdot A_{E} \cdot \phi \cdot x_{m}\left(V_{B E}\right) \cdot \exp \left(q_{B E} / n k T\right),(5-14)
$$

where $\mathrm{K}_{\mathrm{v}}$ is a volume damage constant with the units of $\left(\operatorname{amp} / \mathrm{cm}^{3}\right) /\left(\right.$ neutron $\left./ \mathrm{cm}^{2}\right)$, and $\mathrm{x}_{\mathrm{m}}\left(\mathrm{V}_{\mathrm{BE}}\right)$ is the depletion layer width of the emitter-base junction. Note that equation (5-14) differs from the expression used in prior work ${ }^{8-12}$ by the inclusion of the depletion layer width [which causes equation $(5-14)$ to show a volume dependency $\left.\left(x_{m}\left(V_{B E}\right) \cdot A_{E}\right)\right]$ and the change of the area dependent damage constant $\left(\mathrm{K}_{1}\right)$ to a volume dependent constant. $\left(\mathrm{K}_{\mathrm{V}}\right)$. A value of $\mathrm{K}_{\mathrm{v}}$ was calculated as $3.3 \times 10^{-17}$ for $\mathrm{n}-\mathrm{p}-\mathrm{n}$ silicon junction transistors used in this investigation.

Taking the derivatives of the logarithm of $I_{B N}$ from both equation (5-10) and equation (5-14), one obtains

$$
\begin{aligned}
& \frac{d}{d V_{B E}}\left(\log _{e} I_{B N}\right)=\frac{I}{x_{m}} \cdot \frac{d x_{m}}{d V_{B E}}+\frac{q}{k T} \cdot \frac{1}{2} \cdot \operatorname{coth} \frac{q V_{B E}}{2 k T} \\
& +\frac{d}{d V_{B E}}\left[\log _{e} f(b)\right]+\frac{1}{V_{T}-V_{B E}} \\
& \frac{l}{n}=\frac{k T}{q}\left[\frac{d}{d V_{B E}}\left(\log _{e} I_{B N}\right)-\frac{1}{x_{m}} \cdot \frac{d x_{m}}{d V_{B E}}\right]
\end{aligned}
$$

Substituting equation (5-15) into (5-16), yields;

$$
\begin{aligned}
\frac{1}{\mathrm{n}}= & \frac{\mathrm{kT}}{\mathrm{q}}\left\{\frac{\mathrm{q}}{\mathrm{kT}} \cdot \frac{1}{2} \cdot \operatorname{coth}\left(\frac{\mathrm{qV}_{\mathrm{BE}}}{2 \mathrm{kT}}\right)+\frac{\mathrm{d}}{\mathrm{dV_{BE }}}\left[\log _{\mathrm{e}} \mathrm{f}(\mathrm{b})\right]\right. \\
& \left.+\frac{1}{\mathrm{~V}_{\mathrm{T}}-\mathrm{V}_{\mathrm{BE}}}\right\}
\end{aligned}
$$


or,

$$
\begin{aligned}
\frac{1}{n}= & \frac{1}{2} \cdot \operatorname{coth}\left(\frac{q V_{B E}}{2 k T}\right)+\frac{k T}{q} \cdot \frac{d}{d V_{B E}}\left[\log _{e} f(b)\right] \\
& +\frac{k T}{q} \cdot \frac{1}{V_{T}-V_{B E}} \cdot
\end{aligned}
$$

If the emitter-base bias $\left(\mathrm{V}_{\mathrm{BE}}\right)$ is larger than $150 \mathrm{mV}$ at room temperature, then $\left(\mathrm{qV}_{\mathrm{BE}} / 2 \mathrm{kT}\right)>4$ and $\operatorname{coth}\left(\mathrm{qV}_{\mathrm{BE}} / 2 \mathrm{kT}\right) \simeq 1$, and equation (5-18) becomes,

$$
\frac{1}{n}=\frac{1}{2}+\frac{k T}{q} \cdot \frac{1}{V_{T}-V_{B E}}+\frac{k T}{q} \cdot \frac{d}{d V_{B E}}\left[\log _{e} f(b)\right]
$$

where

$$
\begin{aligned}
& f(b)=\int_{z_{1}}^{z} \frac{1}{z^{2}+2 b z+1} \cdot d z \\
& b=\exp \left(-\frac{q V_{B E}}{2 k T}\right) \cdot \cosh \left[\frac{E_{R}-E_{i}}{k T}+\frac{1}{2} \cdot \log _{e}\left(\frac{{ }^{\tau} p r}{\tau}\right)\right] \\
& z_{1,2}={ }_{\left({ }^{\tau} \mathrm{pr} r\right.}{ }^{1 / 2 r}
\end{aligned}
$$

Bartholomew ${ }^{54}$ has derived an expression for $\mathrm{n}$ as in equation (5-19), but with a factor of $2 / 3$ in the $\left(\frac{k T}{q}\right)\left(\frac{1}{V_{T}-V_{B E}}\right)$ term. There are two reasons which cause the discrepancy in the expression. They are

1. Bartholomew didn't have the correct expression for the neutron-induced base current component as given by Goben 53 . 
That is, in equation (5-14), he neglected the fact that $x_{m}$ is a function of $\mathrm{V}_{\mathrm{BE}}$;

2. In his derivation, he used the expression for the depletion layer width $\mathrm{x}_{\mathrm{m}}$ as 29

$$
\mathrm{x}_{\mathrm{m}}=\left[\frac{12 \varepsilon}{\mathrm{q} a}\left(\mathrm{~V}_{\mathrm{T}}-\mathrm{V}_{\mathrm{BE}}\right)\right]^{1 / 3},
$$

where $\quad a=$ the impurity gradient.

Equation (5-23) is not always true for any kind of junction transistor, but if one uses a multivariate least squares fitting technique as in this paper, the final result is not affected by the form of junction. The author notes that upon combining equation $(5-15)$ and $(5-16)$ the result of his derivation for $\mathrm{n}$ is independent of junction width, $\mathrm{x}_{\mathrm{m}}$, or the type of junction. The integral given by $f(b)$ in equation $(5-20)$ is evaluated under three cases:

1. when $b<1$, it yields

$$
f(b)=\frac{1}{\sqrt{1-b^{2}}} \arctan \left[\frac{2 \sqrt{1-b^{2}} \cdot \sinh \frac{q\left(V_{T}-v_{B E}\right)}{2 k T}}{\left(\frac{{ }^{\tau} p r}{{ }^{T} n r}\right)^{1 / 2}+\left(\frac{{ }^{\tau} n r}{{ }^{\tau} p r}\right)^{1 / 2}+2 b \cdot \cosh \frac{q\left(V_{T}-V_{B E}\right)}{2 k T}}\right] .
$$

2. when $b=1$, it yields

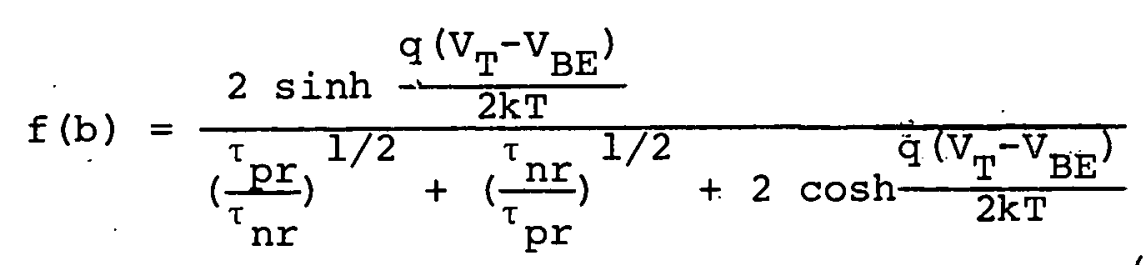


3. when $b>1$, it yields

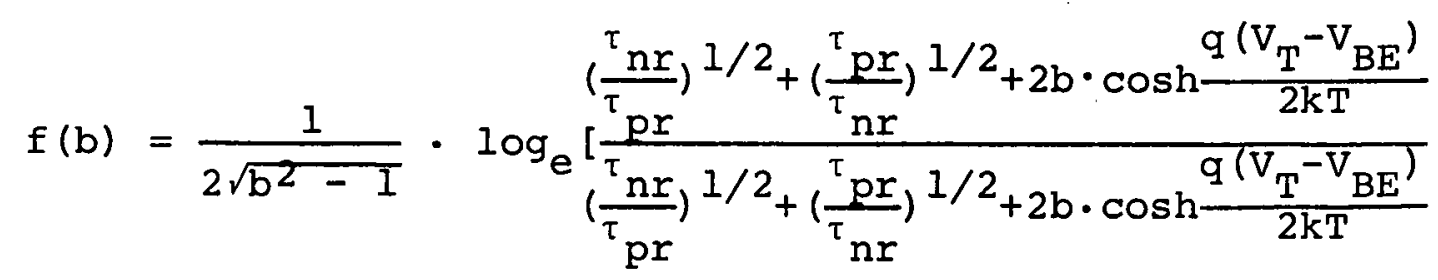

$$
\begin{aligned}
& +2 \sqrt{\mathrm{b}^{2}-1} \cdot \sinh \frac{\mathrm{q}\left(\mathrm{V}_{\mathrm{T}}-\mathrm{V}_{\mathrm{BE}}\right)}{2 \mathrm{kT}} \\
& {\left[-2 \sqrt{b^{2}-1} \cdot \sinh \frac{q\left(V_{T}-V_{B E}\right)}{2 k T}\right] \text {. }}
\end{aligned}
$$

Equation (5-19) is the theoretical recombination statistical model for the reciprocal slope term of the neutron-induced base current component. A multivariate least-squares fitting technique (reviewed in Appendix G) was used to construct a statistical model for the reciprocal slope term from equation (5-19) with equations $(5-20),(5-21)$ and $(5-22)$. The resulting statistical model is:

$$
\begin{aligned}
\frac{1}{n}= & 0.4107+\frac{k T}{q} \cdot \frac{1.21 \times 10^{-1}}{V_{T^{-}}-V_{B E}}+\frac{k T}{q} \cdot \frac{2.948}{E_{i}^{-E_{R}}} \\
& +6.34 \times 10^{-3} \log _{e}\left[\left(\frac{\sigma_{p}}{\sigma_{n}}\right)^{1 / 2}+\left(\frac{\sigma_{n}}{\sigma_{p}}\right) 1 / 2\right] .
\end{aligned}
$$

Equation $(5-27)$ is the recombination statistical model for the reciprocal slope term (n) which predicts the neutroninduced base current component for $n-p-n$ silicon transistors with considerable accuracy. 
In the prediction for the neutron-induced base current component, the following equation ${ }^{8-13}$ was used,

$$
I_{B N}=K_{v} \cdot A_{E} \cdot x_{m}\left(v_{B E}\right) \cdot \phi \cdot \exp \left(q v_{B E} / r k T\right)
$$

The value of $3.3 \times 10^{-17}\left(\mathrm{amp} / \mathrm{cm}^{3} / \mathrm{nvt}\right)$ for $\mathrm{k}_{\mathrm{v}}$ was used, $\mathrm{x}_{\mathrm{m}}\left(\mathrm{V}_{\mathrm{BE}}\right)$ was obtained from the output of the computer program which was used in the impurity profile determination from capacitance-voltage measurements and $\mathrm{n}$ was calculated from equation $(5-27)$.

Three examples are presented (Figures $\mathrm{V}-2, \mathrm{~V}-3$ and $\mathrm{V}-4$ ) which illustrate the utility of the recombination statistical model in prediction the neutron-induced base current component for $n-p-n$ silicon transistors.

\section{Temperature Dependence of the Reciprocal Slope Term (n)}

In the derived recombination statistical model for $n$, temperature (T) has been implicitly included; thus, the dependence of $\mathrm{n}$ on temperature is implicitly studied. Figure V-5 shows the predicted and observed temperature dependence of $\mathrm{n}$, in which $\mathrm{E}_{\mathrm{i}}-\mathrm{E}_{\mathrm{R}}=0.32 \mathrm{eV}, \mathrm{V}_{\mathrm{T}}-\mathrm{V}_{\mathrm{BE}}=0.48 \mathrm{~V}$ and $\sigma_{\mathrm{n}} / \sigma_{\mathrm{p}}$ is a parameter.

Aukerman et al. ${ }^{19}$ point out that the dependence of $n$ on temperature appears to result from the effect of band tailing within the depletion layer region. They also show that the effect of recombination of electrons and holes 
occupying so-called "tail-states" having an exponentially decreasing density of states near the conduction band would lead to equation (5-28), provided the recombination occurs within the depletion layer region. Furthermore, if the recombination centers are rather deep, they have shown that

$$
\mathrm{n}=1+\frac{1}{\mathrm{bkT}}
$$

where $b$ is called the exponential fall-off rate for the density states. Typical values of $b$ for GaAs as presented in their paper lie in the range of $70 i 80 \mathrm{ev}^{-1}$ for doping levels of $2 \times 10^{17} \mathrm{~cm}^{-3}$.

Padovani recently reports ${ }^{53}$ that in the case of Schottky barrier, $\mathrm{n}$ is temperature-dependent and that the forward characteristic is more accurately described by an equation of the form

$$
I=K T^{2} \exp \left[-\frac{\mathrm{qV}_{\mathrm{T}}}{\mathrm{k}\left(\mathrm{T}+\mathrm{T}_{\mathrm{O}}\right)}\right]\left\{\exp \left[\frac{\mathrm{qV} \mathrm{BE}_{\mathrm{BE}}}{\mathrm{k}\left(\mathrm{T}+\mathrm{T}_{\mathrm{O}}\right)}\right]-I\right\}
$$

Comparing equation $(5-30)$ with $(5-28)$, one obtains

$$
\mathrm{n} \simeq 1+\frac{\mathrm{T} \text { 을. }}{\mathrm{T}} \text {. }
$$

By using equations (5-29) and (5-31), the relationship of the exponential fall-off rate for tail density states and $\mathrm{T}_{\mathrm{o}}$ is given by

$$
\mathrm{T}_{0} \simeq \frac{1}{\mathrm{bk}}
$$




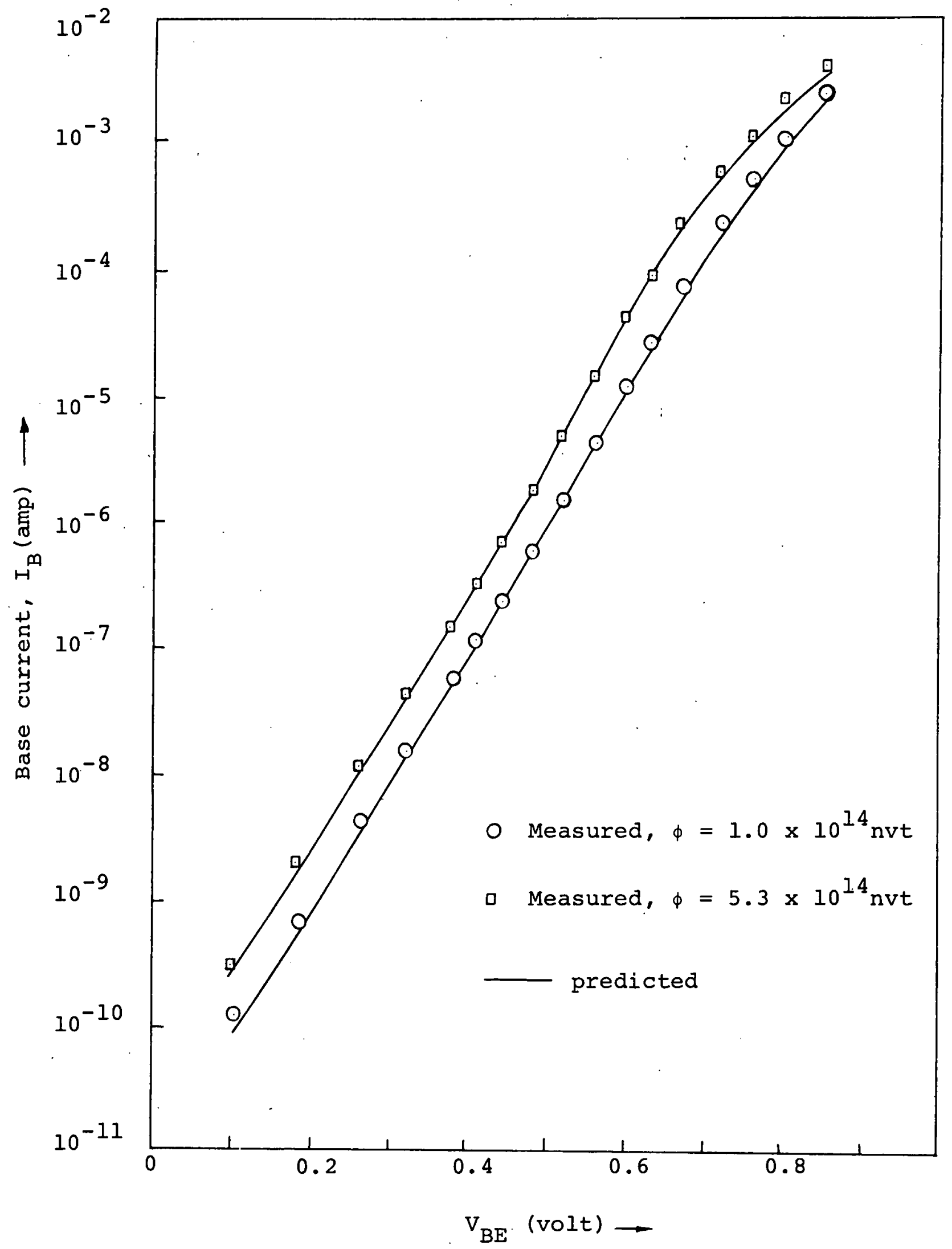

Figure V-2. Predicted and observed base current versus emitter-base bias (Device SF2523 \#40). 


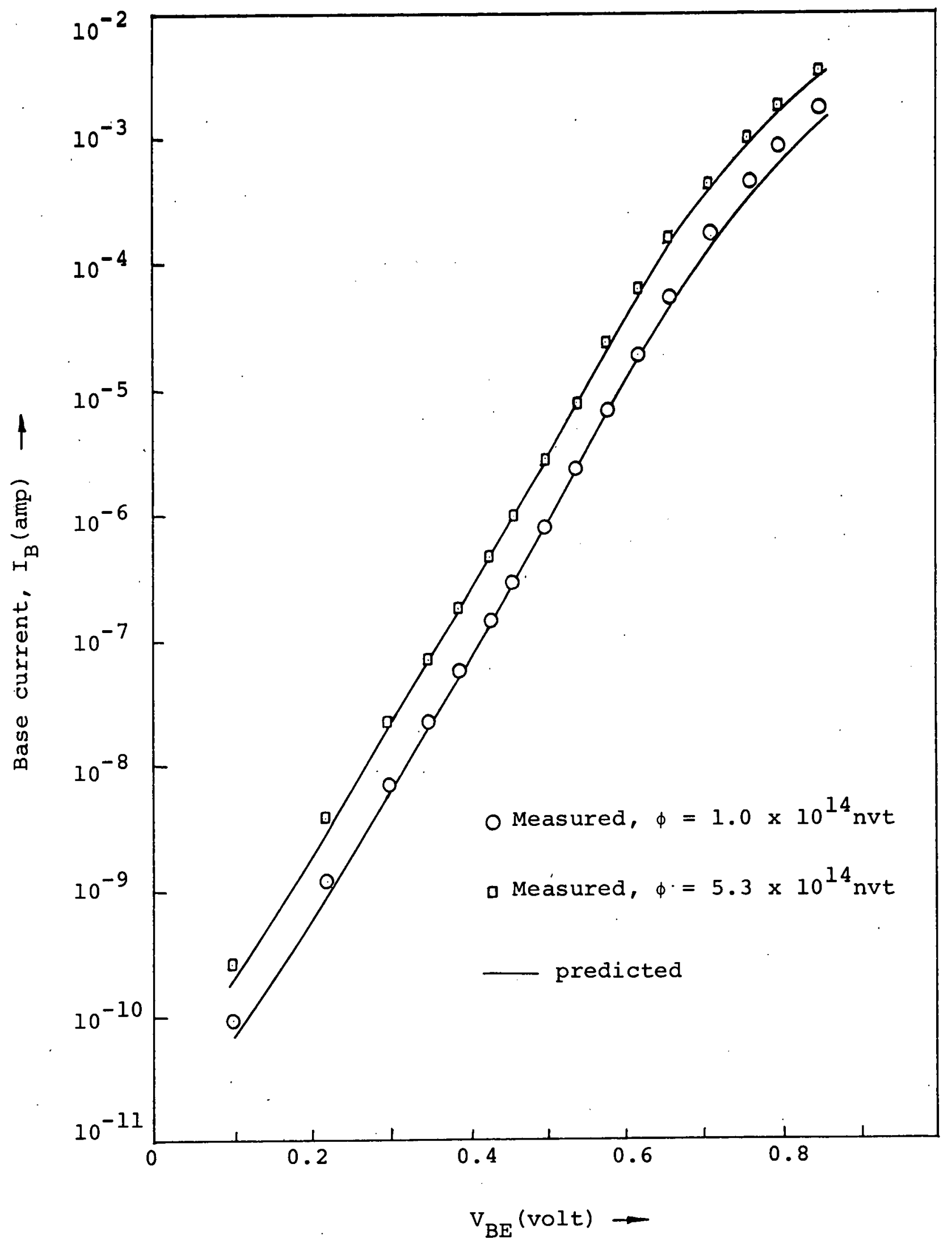

Figure V-3. Predicted and observed base current versus emitter-base bias (Device SF2524 \#68). 


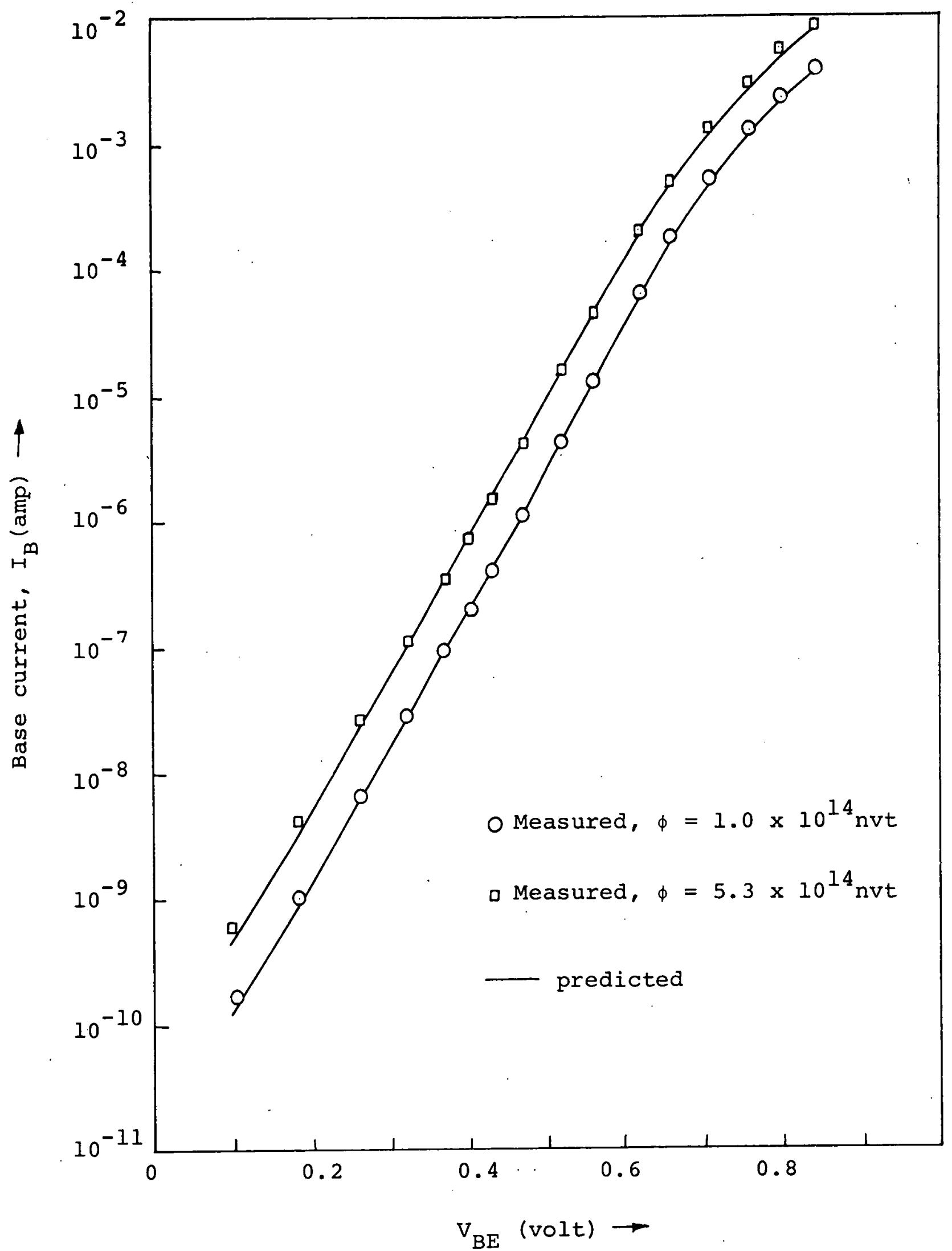

Figure V-4. Predicted and observed base current versus emitter-base bias (Device 2N914 \#7). 


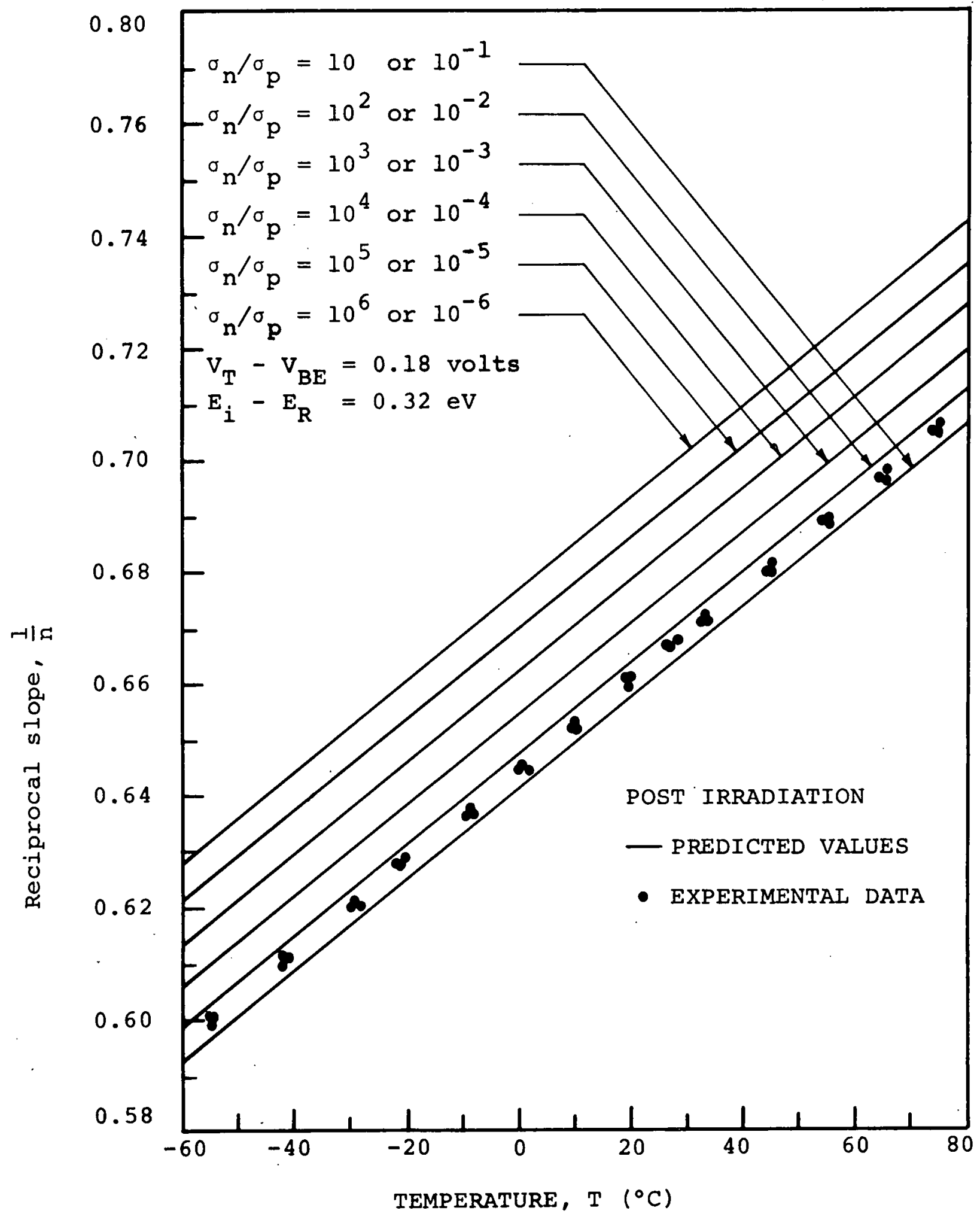

Figure V-5. Predicted and observed temperature dependence of the reciprocal slope term, $n$, for $n-p-n$ silicon transistors. 
From n-T data (shown previously in Figure V-5) the exponential fall-off rate for tail density states was calculated. Typical values of $\mathrm{b}$ which lie in the range from $72 \sim 97 \mathrm{ev}^{-1}$ were obtained. If one assumes that equation $(5-30)$ is also true for a diffused $\mathrm{p}-\mathrm{n}$ junction, the result of $119^{\circ} \mathrm{K}<\mathrm{T}_{0}$ $<161^{\circ} \mathrm{K}$ is obtained, which is in good agreement with those calculated by Padovani ${ }^{53}$ for Schottky barrier diodes. 


\section{SUMMARY AND DISCUSSION}

The neutron-induced base current component was first identified by Goben in 1964. It is of bulk and not of perimeter origin and must be attributed to recombination-generation in the bulk space-charge region. The exact nature of the recombination statistics of this neutron-induced base current component was not studied by any of the previous workers in the area of radiation effects on semiconductors devices. As pointed out by Shockley, Read, Hall, Noyce and Sah, the four parameters $N_{R}, E_{R^{\prime}} \sigma_{p}$ and $\sigma_{n}$ largely describe the electrical properties of a defect state. That is, the recombination process may be decided by a mathematical model, recombination statistics, and these recombination statistics, which depend on the above mentioned parameters, will predict the corrent value for $n$ in $\exp \left(\mathrm{qV}_{\mathrm{BE}} / \mathrm{nkT}\right)$ when the model is accurately fitted to the physical process.

In this work, the impurity profile in the vicinity of metallurgical junctions was determined by forward biased capacitance measurements, and that in the normally "neutral regions" adjacent to junction depletion layers was determined by reverse biased capacitance measurements. The calculated impurity concentration data adjacent to the junctions were then employed in the fitting of $\mathrm{N}(\mathrm{x})=\mathrm{N}_{\mathrm{OE}} \cdot$ $\operatorname{erfc}\left(\mathrm{L}_{\mathrm{E}} \mathrm{x}\right)-\mathrm{N}_{\mathrm{OB}} \exp \left(-\mathrm{L}_{\mathrm{B}}{ }^{2} \mathrm{x}^{2}\right)+\mathrm{N}_{\mathrm{BC}}$, so that the impurity distribution of the transistor could be determined. Computer programs have been written for these purposes. Typical 
values of $\mathrm{N}_{\mathrm{OE}}=2.5 \times 10^{20} \mathrm{~cm}^{-3}, \mathrm{~N}_{\mathrm{OB}}=6.0 \times 10^{18} \mathrm{~cm}^{-3}, \mathrm{~N}_{\mathrm{BC}}=$ $1.1 \times 10^{16} \mathrm{~cm}^{-3}, L_{E}=1.15 \times 10^{6} \mathrm{~cm}^{-1}$ and $\mathrm{L}_{\mathrm{B}}{ }^{2}=0.69 \times 10^{12} \mathrm{~cm}^{-2}$ were obtained in this work. From the determined impurity profile at various neutron fluences, the defect concentration $N_{R}$ was calculated and the carrier removal coefficients for holes and electrons, $\mathrm{k}_{\mathrm{p}}=1.8 \times 10^{8} \times \mathrm{N}_{0}^{0.442}$ and $\mathrm{k}_{\mathrm{n}}=4.0 \times 10^{8} \times \mathrm{N}_{0}^{0.444}$, respectively, were obtained. In the determination of impurity profiles from the capacitance-voltage measurements, correction factors were required; thus, this paper presents a more complete table of these correction factors than that presented by Hilibrand and Gold. The dependence of the diffusion potential, $\mathrm{V}_{\mathrm{T}}$, on neutron fluence was derived as $\mathrm{V}_{\mathrm{T}}=\mathrm{V}_{\mathrm{TO}}-(\mathrm{kT} / \mathrm{q}) \cdot \mathrm{K}_{\mathrm{d}} \cdot \phi$, and $\mathrm{K}_{\mathrm{d}}=2.71 \times 10^{-15}\left(\mathrm{nvt}^{-1}\right)$ was obtained in this work. The activation energy $\left(E_{R}\right)$ determined from current-temperature measurements has the value of $0.235 \mathrm{eV}$. This activation energy was found to be independent of neutron fluence at low to moderate fluences. The values of the activation energies obtained in this work are comparably close to those by other workers.

The minority carrier lifetimes in base and collector regions were calculated from the measured transistor risetime and diode storage time by using a Tektronix 555 Oscilloscope with a Tektronix Type $\mathrm{R}$ risetime and a Type $\mathrm{S}$ recovery time plug-in units. The lifetime damage constants of $\mathrm{K}_{\tau}=2.3 \times 10^{-7}\left(\mathrm{~cm}^{2} / \mathrm{n}\right.$-sec $)$ in the $\mathrm{p}$-type base region and $\mathrm{K}_{\tau}=8.5 \times 10^{-9}\left(\mathrm{~cm}^{2} / \mathrm{n}-\mathrm{sec}\right)$ in the $\mathrm{n}$-type collector region 
were obtained. From the values of $N_{R^{\prime}} \tau_{B^{\prime}} \tau_{C^{\prime}} E_{R}$ and $E_{F}$ ' the capture cross-section for holes has been calculated as $\sigma_{\mathrm{p}}=1.8 \times 10^{-16} \mathrm{~cm}^{-2}$ and $\sigma_{\mathrm{n}}=8.1 \times 10^{-15} \mathrm{~cm}^{-2}$ for electrons. The reciprocal slope term, $n$, in $\exp \left(\mathrm{qV}_{\mathrm{BE}} / \mathrm{nkT}\right)$ was studied in this work, based on the model given for the neutron-induced base component by Goben, on Shockley-Read-Hall statistics and on Sah-Noyce-Shockley statistics. A statistical model of $\mathrm{n}$ was developed and the dependence of $\mathrm{n}$ on temperature is correctly given by the model. From the given example, it can be seen that this statistical model of $n$ gives a good fit to those current densities for $\mathrm{V}_{\mathrm{BE}}<0.75$ volts. Discrepancy between the predicted and observed values in the higher injection level suggests there may be another neutron-induced base current component which dominates the base current in the higher current density range. Additionally emission crowding complicates the study above $0.75 \mathrm{~V}$. Further study on this phenomenon should be made, and techniques for higher accuracy measurements of minority carrier lifetimes should be developed; then a model which will cover the entire current density range could be constructed easily.

The model developed in this investigation was derived for the $n-p-n$ silicon junction transistors and may be extended to a more general model for other types of transistors. There are other plausible alternative extensions or modifications to the model developed which might also give accurate predictions. 
The effect of band tailing within the depletion region has also been studied from $n$ versus temperature characteristics; the exponential fall-off rate has the typical values, $72 \sim 97 \mathrm{ev}^{-1}$, for the devices used in this work. Future work is also needed to study the exact recombination statistics of this tail density effect. 


\section{BIBLIOGRAPHY}

1. Shockley, W. and Read, W. T., "Statistics of the Recombination of Holes and Electrons," Phys. Rev., 87: 835842,1952 .

2. Shockley, W., "Electrons, Holes, and Traps," Proc. IRE, 46: 973-990, 1958 .

3. Shockley, w., "The Theory of $p-n$ Junctions in Semiconductors and $\mathrm{p}-\mathrm{n}$ Junction Devices," Bell System Tech. J., 28: 435-589, 1949 .

4. Hall, R. M., "Electron-Hole Recombination in Germanium," Phys. Rev., 87: 387, 1952.

5. Sah, C. T., Noyce, R. N. and Shockley, W., "Carrier Generation and Recombination in $p-n$ Junctions and $p-n$ Junction Characteristics," Proc. IRE, 45: 1228-1243, 1957.

6. Sah, C. T., "Effect of Recombination and Channel on p-n Junction and Transistor Characteristics," IRE, Trans. on Electron Devices ED-9: 94-108, 1962.

7. Moll, J. L. and Ross, I. M., "The Dependence of Transistor Parameters on the Distribution of Base Layer Resistivity," Proc. IRE, $\underline{44}$ : 72-78, 1956.

8. Goben, C. A., Smits, F. M. and Wirth, J. L., "Neutron Radiation Damage in Silicon Transistors," Sandia Corp. (Albuquerque, N. M.), SC-RR-67-312, 1967.

9. Goben, C. A., and Smits, F. M., "Anomalous Base Current Component in Neutron Irradiated Transistors," Sandia Corp. (Albuquerque, N. M.), SC-R-64-195, 1964.

10. Goben, C. A., "A Study of the Neutron-Induced Base Current Component in Silicon Transistors," Sandia Corp. (Albuquerque, N. M.), SC-R-65-912, 1965.

11. Goben, C. A., "Neutron Bombardment Reduction of Transistor Current Gain," Sandia Corp. (Albuquerque, N. M.), SC-R-64-1373, TID-4500, 1964 .

12. Goben, C. A., "Neutron Bombardment Reduction of Transistor Current Gain," Ph.D. Thesis, Iowa State University Library, Ames., Iowa, 1965.

13. Johson, P. E., Su, L. S., Gassner, G. E., Beckmann, T. D., and Goben, C. A., "Radiation and Annealing Characteristics of Neutron Bombarded Silicon Transistors," to 
be presented in the 1968 IEEE Annual Conference on $\mathrm{Nu}-$ clear and Space Radiation Effects.

14. Loferski, J. K., "Analysis of the Effect of Nuclear Radiation on Transistors," J. Appl. Phys., 29: 35-40, 1958 .

15. Messenger, G. C. and Spratt, J. P., "The Effects of Neutron Irradiation on Germanium and Silicon," Proc. IRE, 46: 1038-1044, 1958.

16. Easley, J. W. and Dooley, J. A., "On the Neutron Bombardment Reduction of Transistor Current Gain," J. Appl. Phys., 31: 1024-1028, 1960.

17. Hood, J. A., "Predicting the Current Gain Degradation in npn Silicon Transistors by High-Energy Neutrons," Sandia Lab. (Albuquerque, N. M.), SC-TM-64-69, 1964.

18. Easley, J. W., "Radiation Damage to Semiconductor Devices," Sandia Lab. (Albuquerque, N. M.), SCR-532, 1962 .

19. Aukerman, L. W., Millea, M. F. and McCall, M., "Effects of Radiation Damage on the Behavior of GaAs p-n Junctions," IEEE Trans. on Nuclear Science, NS-13: 6, 1966.

20. Hood, J. A., "Degradation of npn Silicon Planar Transistors with Bombardment by High-Energy Neutrons," Sandia Corp. (Albuquerque, N. M.), SCTM-261-63 (14), 1963.

21. Hilibrand, J. and Gold, R. D., "Determination of the Impurity Distribution in Junction Diodes from Capacitance-Voltage Measurements," RCA Rev., 21: 245-252, 1960 .

22. Lawrence, H. and Warner, R. M., "Diffused Junction Depletion Layer Calculations," Bell Sys. Tech., 39: 389404,1960 .

23. Stein, H. J. arid Vook, F. L., "Transient Radiation Defects," Sandia Corp. (Albuquerque, N. M.), SC-R-67-. 1048,1967 .

24. Sander, H. $\dot{H}$ and Gregory, B. L., "Transient Annealing in Semiconductor Devices Following Plused Neutron Irradiation," IEEE Trans. on Nuclear Science, NS-13: 531966.

25. Messenger, G. C. and Spratt, J. P., "The Effects of Neutron Irradiation on Germanium and Silicon," Proc. IRE, 46: 1038-1044, 1958. 
26. Messenger, G. C., "Displacement Damage in Silicon and Germanium Transistors," IEEE Trans. on Nuclear Science, NS-12: 2, 53-74, 1965 .

27. Messenger, G. C., "A Two Level Model Lifetime Reduction Processes in Neutron Irradiated Silicon and German," IEEE Trans. on Nuclear Science, NS-14: 6, 88-102, 1967.

28. Meechan, C. J. and Brinkman, J. A., "Electrical Resistivity Study of Lattice Defects Introduced in Copper by 1.25-MeV Electron Irradiated at $80^{\circ} \mathrm{K}, "$ Phys. Rev., 103: $5,1193-1202,1956$.

29. Phillips, A. B., Transistor Engineering, Chapters 4 and 5, MCGraw-Hill N. Y., 1962 .

30. Sckottky, "Ereifacht and Erweiterte Theories der Randschichtgleichrichter," Zeitschrift fur Physik, 118, p. 539, 1942, as cited in Reference \#21.

31. Goldstein, B., "Electron Mobility in the GermaniumSilicon Alloys," RCA Rev., 18: 458, 1957.

32. McAfee, K. B., Shockley, w. and Sparks, M., "Measurement of Diffusion in Semiconductors by a Capacitance Method," Phys. Rev. 1. 86: 137, 1952.

33. Greenberg, L.S., Martowska, Z. A. and Happ, W. W., "A Method of Determining Impurity Diffusion Coefficients and Surface Concentrations of Drift Transistors," IRE Trans. PGED, ED-3: 97, 1956.

34. Frank, M. and Taulbee', C. D., "Handbook for Predicting Semiconductor Device Performance in Neutron Radiation," Technical Report No. AFWL-TR-67-54, The Bendix Corp., 1967.

35. Sander, H. H., "Room Temperature Annealing of Silicon Transistor Parameters Degraded by a Burst of Neutrons," Sandia Corp. (Albuquerque, N. M.), SC-R-64-192, 1964.

36. Stein, H. J., "Introduction Rate of Electrically Active Defects in Silicon by Nuclear Radiations," Sandia Corp. (Albuquerque, N. M.), SC-R-64-193, 1964.

37. Stein, H. J. and Smits, F. M., "Energy Dependence of Neutron Damage in Silicon," Bull Am. Phys. Soc., 9: 289,1964 .

38. Bass, R. F., "Influence of Impurity on Carrier Removal Annealing in Neutron-Irradiated Silicon," IEEE Trans. on Nuclear Science, NS-14: 6, 1967. 
39. Stein, H. J., "Introduction Rate of Electrically Active Defects in n-Type Silicon by Nuclear Radiation," Report SC-R-65-938, Sandia Corp. (Albuquerque, N. M.), 1965.

40. Lindmayer, J. and Wrigley, C. Y., Fundamentals of Semiconductor Devices, D. Van Nostrand Co., Inc., Princetion, N. J., 1966.

41. Bartling, D. I., "An Automatic Data Acquisition System for Semiconductor Device Testing," Master's Thesis, T 1959, University of Missouri-Rolla, 1967.

42. Bartling, D. L., Jenkins, C. R. and Goben, C. A., "An Automatic Data Acquisition System for Semiconductor Device Testing," IEEE Trans. on Instrumentration and Measurement, IM-17: 19-28, 1968.

43. Loferski, J. K., "Analysis of the Effect of Nuclear Radiation on Transistors," J. Appl. Phys., 29: 35-40, 1958 .

44. Messenger, G. C. and Spratt, J. P., "The Effects of Neutron Irradiation on Germanium and Silicon," Proc. IRE, 46: $1038-1044,1958$.

45. Easley, J. W. and Dooley, J. A., "On the Neutron Bombardment Reduction of Transistor Current Gain," J. Appl. Phys., 31: 1024-1028, 1960.

46. Hood, J. A., "Predicting the Current Gain Degradation in npn Silicon Transistors after Irradiation by HighEnergy Neutrons," Sandia Lab. (Albuquerque, N. M.), SCTM-64-69， 1964.

47. Easley, J. W., "Radiation Damage to Semiconductor Devices," Sandia Lab. (Albuquerque, N. M.), SCR-532, 1932 .

48. Landis, D. J., "Some Effects of Gamma Radiation on Silicon and Silicon Devices," Technical Report No. 5110-1, Standford Electronics Lab., Stanford University, 1967.

49. Lederhandler, S. R. and Giacoletto, L. J., "Measurement of Minority Carrier Lifetime and Surface Effects in Junction Devices," IRE, 447-483, 1955.

50. Frank, M., "Development of a Non-Destructive Radiation Effects Prediction Technique," Contract AF 29 (601)7110 , First Quarterly Progress Letter for Period Ended April 30, 1966, Bendix Research Lab., Div. Report 3311, $\mathrm{AD}-378-081,1966$. 
51. Curtis, O. L., Jr., "Effects of Oxygen and Dopant on Lifetime in Neutron Irradiated Silicon," IEEE Trans. on Nuclear Science, NS-13: 33-40, 1966.

52. Curtis, O. L., Jr., Bass, R. F. and Germano, C. A., "Impurity Effects in Neutron-Irradiated Silicon and Germanium," Northrop, Nortronics, NARD-65-20R, AD-476458,1965 .

53. Padavani, F. A., "The Schottky Barrier Space Charge," 20th Annual Southwestern IEEE Conference \& Exhibition Record, Catalog No. 68C16-SWIEEECO, pp. 6C1-6C3, 1968.

54. Bartholemew, C. Y., "Recombination Centers in Silicon Transistor Emitter-Base Junctions," IEEE Trans. On Electron Devices, ED-14:8, 452-453, 1967. 


\section{ACKNOWLEDGEMENTS}

The author wishes to express his appreciation to Dr. Charles A. Goben, his advisor, for suggesting the problem, providing advice and assistance throughout the project, and for his careful and thorough review of this dissertation.

The author also wishes to thank Mr. C. R. Jenkins for his valuable assistance in the operation of test equipment. He would like to thank his colleagues at the University of Missouri-Rolla, Space Sciences Research Center, for their useful discussions and suggestions.

The author is happy to acknowledge Texas Instruments for their fabrication of the special devices used in these experiments. Appreciation also goes to the U. S. Atomic Energy Commission for supporting this research effort, under contract AT (11-1)-1624.

The author is deeply grateful to his wife, Chao-Chu Lin, who, in addition to typing this dissertation, has shown so much consideration and understanding during these years in school. Appreciation is expressed to Mrs. Sally J. Johnson for her help in typing this dissertation. 
VITA

The author, Ming-Chwan Chow, was born on April 12, 1937, in Kaohsiung, Taiwan. He received his primary and secondary education in his home town and graduated from Kaohsiung Senior High School, 1956.

He entered National Taiwan University in 1956 and graduated in 1960 with a B.S. Degree in Electrical Engineering. He served as a communication officer in the Chinese Army Communication Base for one year and three months and was honorably discharged in October, 1961. Since then, he was a teacher of mathematics and physics at Kaohsiung Girls senior High School until August, 1964.

In september 1964, he entered the graduate school of the University of Missouri-Rolla. He received an M.S. Degree in Electrical Engineering in 1966 and continued work toward the Doctor of Philosophy in Electrical Engineering. During his graduate studies, he has held a teaching assistantship in the Mathematics Department from June, 1965 to August, 1966, and a research assistantship from the Electronics Research Center since September, 1966, sponsored by U. S. Atomic Energy Commission.

He is married to the former Chao-Chu Lin of Kaohsiung, Taiwan, and they have a daughter, Hui-Ann. 
APPENDIX A: AUTOMATIC DATA ACQUISITION SYSTEM AND DATA REDUCTION TECHNIQUES

\section{General Description}

The Automatic Data Acquisition system ${ }^{A}$ for the measurement and recording of the voltage versus current characteristics of the test devices used in most of the studies conducted is capable of current and voltage measurement with an overall absolute accuracy of $\pm 1 \%$ of reading and a precision (repeatability) of $\pm 0.3 \%$ of reading in the range from $10^{-10}$ amperes to $2 \times 10^{-1}$ amperes (over 9 decades). Figure A-l shows a block diagram of the complete Data Acquisition System plus the additional facilities necessary for obtaining the $V / I$ Characteristics. Figure $A-1$ also indicates the flow paths for data and control information between the various equipments. Figure $\mathrm{A}-2$ is a photograph of the system as its operation is initiated.

The heart of this system is a Control Center ${ }^{A 2}$, A3 which controls the programming, measurement and recording sequence of the system. A signal is sent to the Programmer ${ }^{\mathrm{A} 2}, \mathrm{~A} 3$ to program the John Fluke 383B Voltage-Current Calibrator which applies an emitter-base bias to the test device which is mounted in a sample holder (see Figure A-3) contained within a Delta Design MK2310 Temperature Control Chamber. The collector-base bias is supplied by a manually controlled Harrison Labs $865 \mathrm{C}$ Power Supply or a digitally controlled John Fluke 383B Voltage/Current Calibrator. The currents 


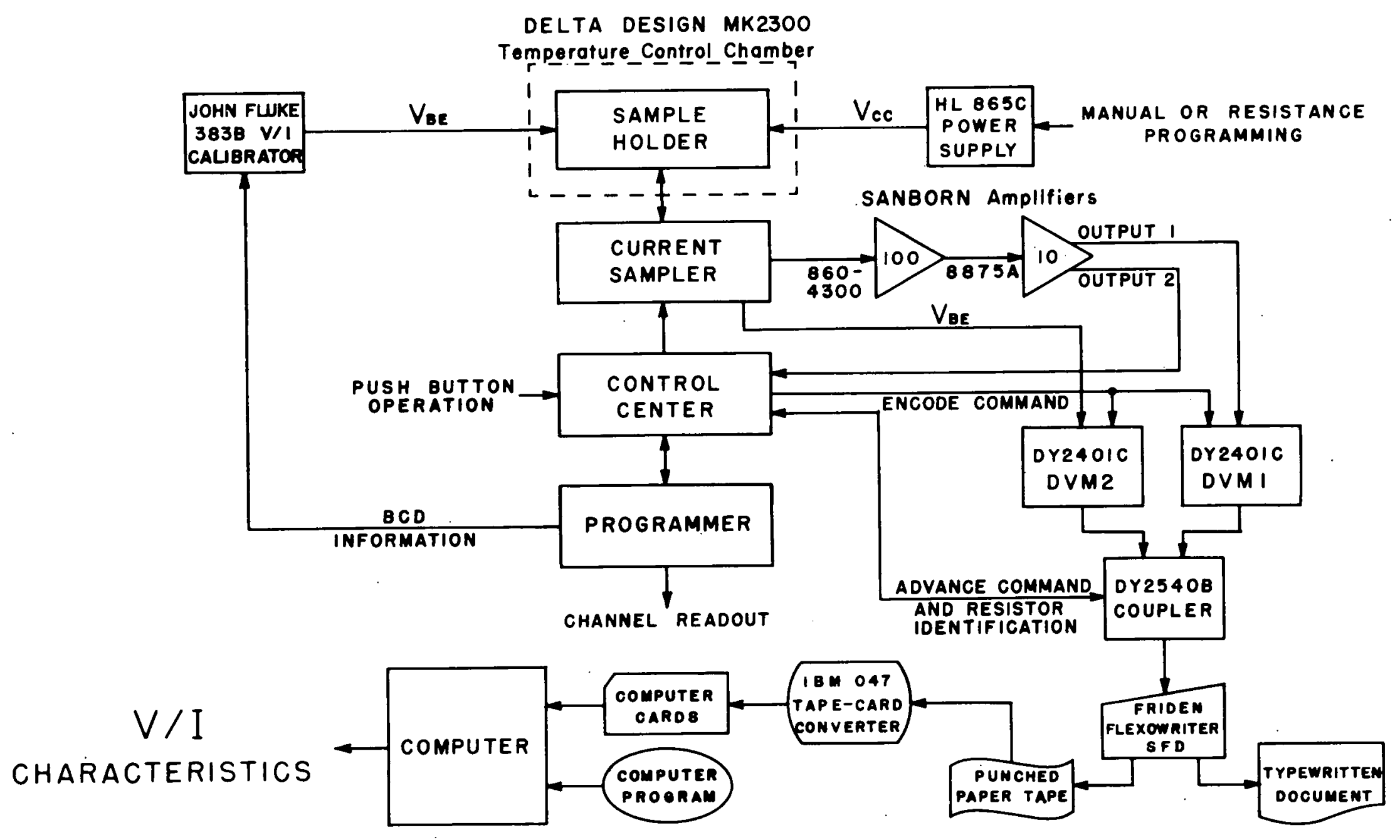

Figure A-1. Block diagram of the Automatic Data Acquisition System. 


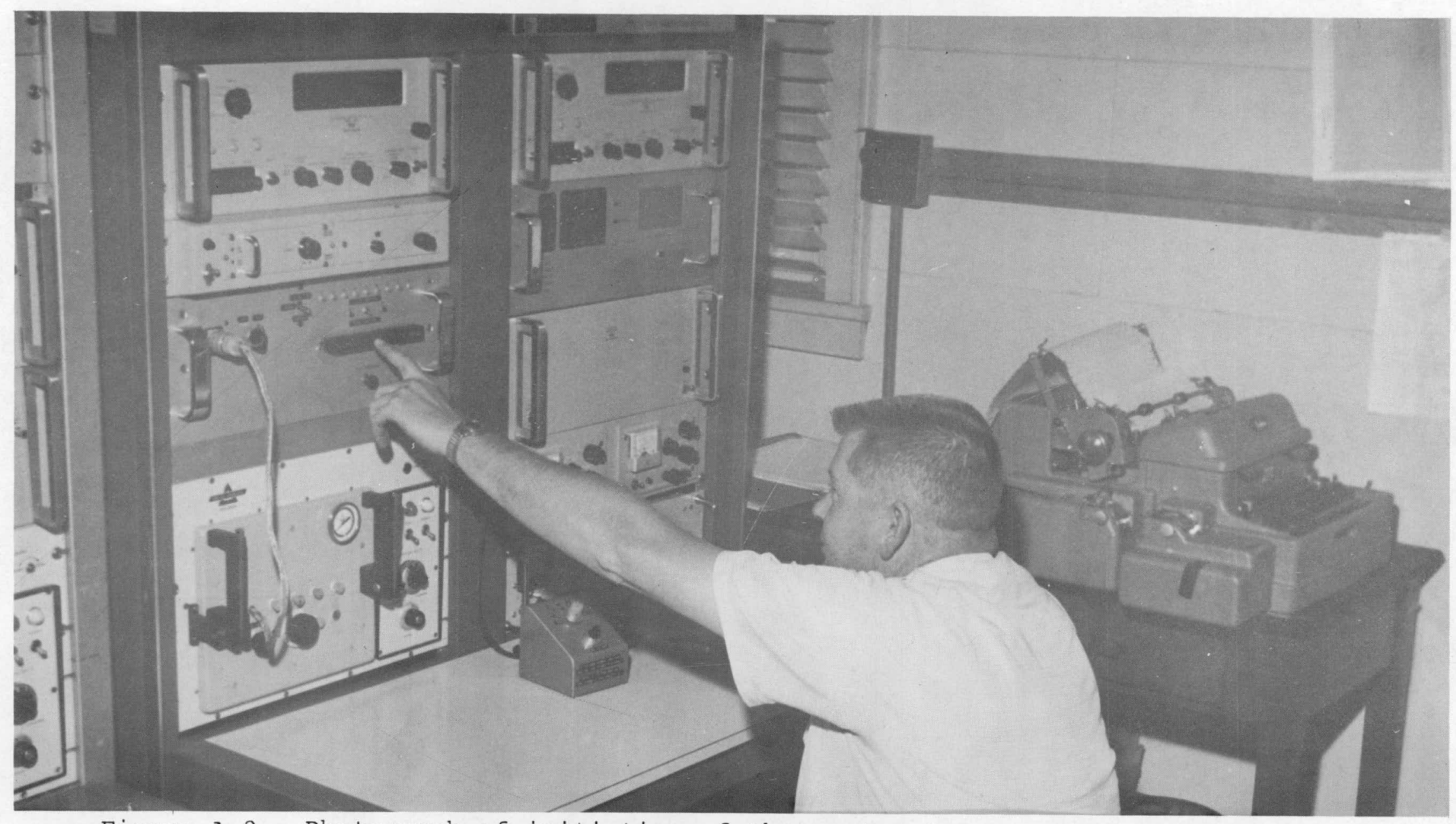

Figure A-2. Photograph of initiation of the system for a typical data run. 


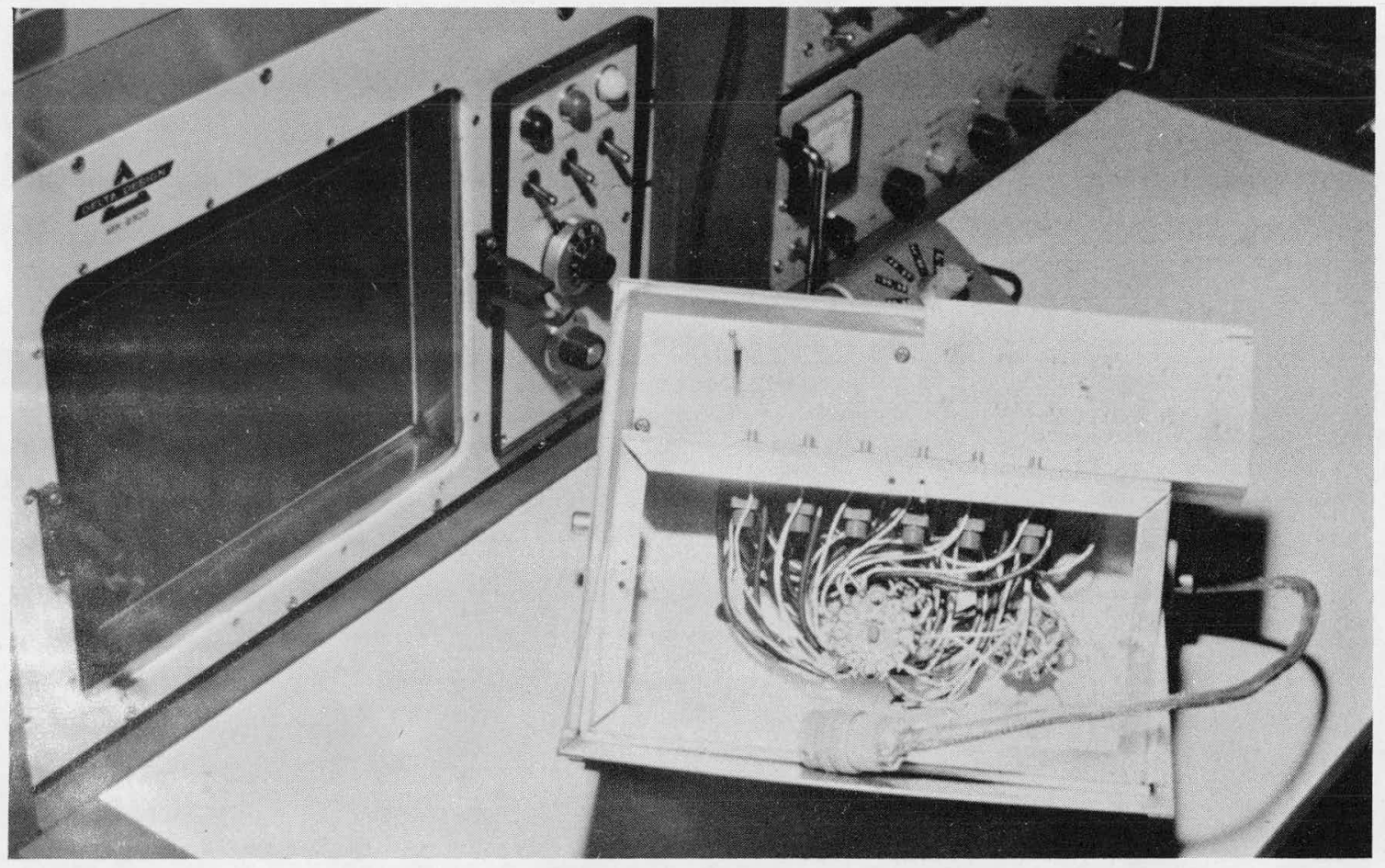

Figure A-3. Photograph of sample holder in its mounting, the heat sink standing behind the devices. 
are sampled by the Current sampler ${ }^{\mathrm{A} 2}, \mathrm{~A} 3$ whose output is amplified by a low noise Sanborn Type 860-4300 amplifier and measured by a Dymec 2401C-M31 Digital Voltmeter. The emitter-base bias voltage is measured by a second Dymec $2401 \mathrm{C}-$ M3l Digital Voltmeter. The voltmeter readings are recorded along with resistor identification information in digital form supplied by the Autoranging Current Sampler ${ }^{\mathrm{A}}$, A3 . This information is serialized by a Dymec $2540 \mathrm{~B}$ Coupler and recorded on a Friden Model SFD Flexowriter in both type-written form and on punched paper tape. The punched paper tape is converted to IBM punched cards on an IBM 047 Tape-to-Card Converter, and the punched cards are processed by an IBM 360-50 Digital Computer. The computer output is the tabulated voltage versus current characteristics and a plot (Calcomp Model 566) of the tabulated values.

To increase the flexibility of the system and to shorten the time required to change programming, a paper tape reader-programmer was added. Since a paper tape reader-programmer capable of performing the desired functions was not available commercially, one has been designed and fabricated. The addition of this paper tape reader-programmer permits the programming of either or both John Fluke 383B Voltage/ Current Calibrators while greatly reducing the time required to change from one set of pre-programmed values to another. A program was written for the processing of the output data from the Automatic Data Acquisition System by the IBM 360-50 Computer. This program performs four major 


\section{functions.}

First, computation of device voltages and currents from the input voltage and resistance data with corrections made for the voltage drop across the current sampling element.

Second, interpolation is made to values of emitter-base voltage which are integral multiples of 10.0 millivolts. This interpolation provides a means of comparing currents and current gains at fixed values of base-emitter voltage.

Third, the applied base-emitter voltage versus base and collector currents and current gain is provided in tabular form together with heading information which includes device identification and measurement conditions.

Fourth, a machine plot (Calcomp Model 566) of input voltage versus logarithm of base current and logarithm of collector current, with printed device identification and neutron fluence, is output for use by the investigator in comparison studies. Each plotted page is a 14 × 10 inch graph of the form $\log (I)$ versus $V_{B E}$. This program will return a plot of the logarithms of $I_{B}$ and $I_{C}$ versus $V_{B E}$ for each device while a second plot program returns one plotted page depicting either $\log \left(I_{C}\right)$ or $\log \left(I_{B}\right)$ versus $V_{B E}$ curves for as many devices as desired.

The run time for the first plot program is approximately $2 \frac{1}{2}$ minutes per device and the run time for the second plot program is approximately one minute per device.

The test device is located in the Sample Holder, as shown at the top of Figure $A-1$ which is, in turn, inside the 
Delta Design MK2300 Temperature Control Chamber. The MK2300 is a precision environmental temperature test chamber capable of maintaining any temperature from $-100^{\circ} \mathrm{F}\left(-73.4^{\circ} \mathrm{C}\right)$ to $600^{\circ} \mathrm{F}\left(+315.6^{\circ} \mathrm{C}\right)$ within $\pm 0.1{ }^{\circ} \mathrm{C}$. The forced air circulation system is closed and powered by a 140 CFM blower. The chamber is heated by applying full wave power to a pair of bobbin wound nichrome 720 watt heating elements controlled by the "heat" solid state switch and is cooled by injecting liquid $\mathrm{CO}_{2}$ into the air stream through an expansion nozzle controlled by the "cool" solid state switch.

Comparing the resistance of a temperature probe to the resistance of a "Temperature Set" potentiometer, the controller senses when to apply heat, coolent, or withold both so as to obtain and maintain a selected temperature in the chamber.

\section{Cyclic Operation}

The data for the base current versus voltage characteristic and collector current versus voltage characteristic is obtained with the device in, respectively, the Base Current Measurement Circuit shown schematically in Figure $\mathrm{A}-4$, and the Collector Current Measurement Circuit shown schematically in Figure $\mathrm{A}-5$. The Sampling Resistance appears in the measurement circuit as a physical resistance having one of nine discrete values, ranging from 17 milliohms to one megohm, each approximately a decade apart from the next. The Sampling Resistance is determined by the parallel combination 


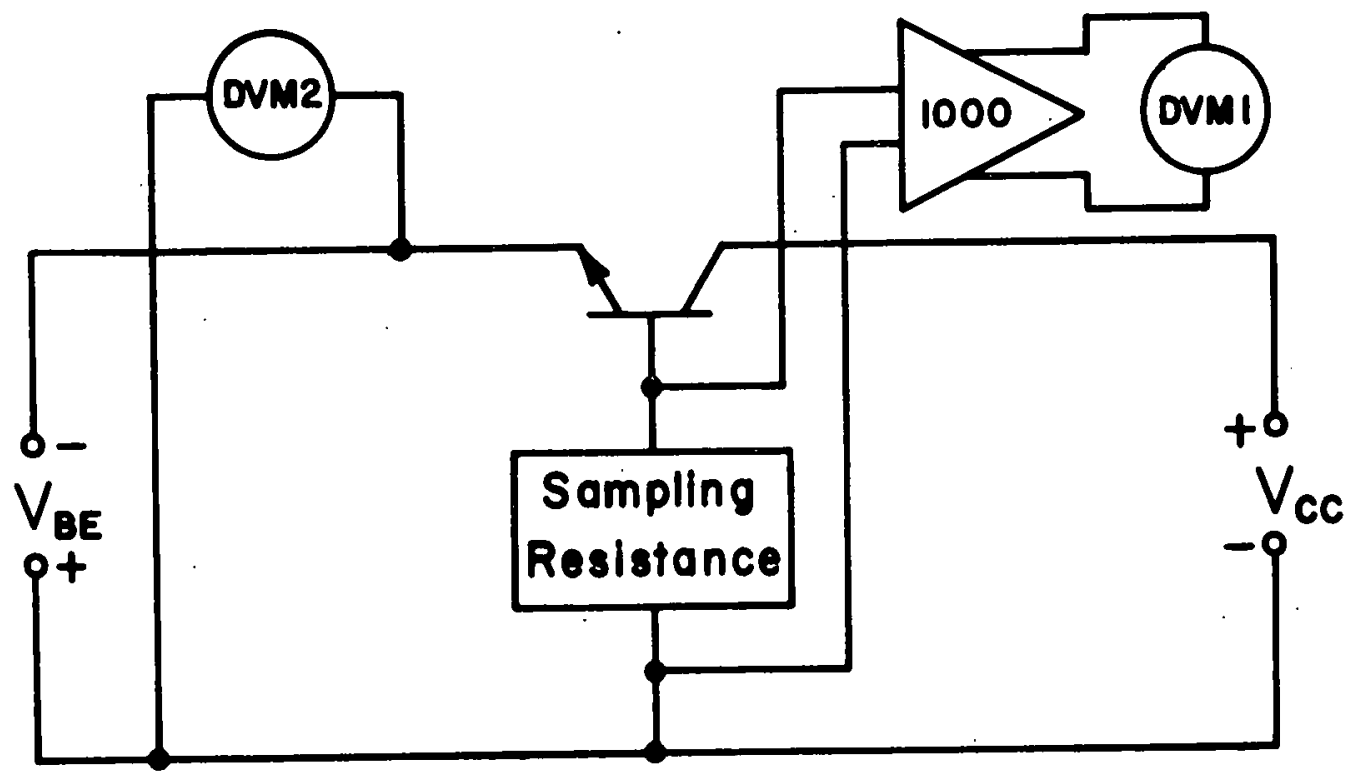

Figure A-4. Base current measurement circuit.

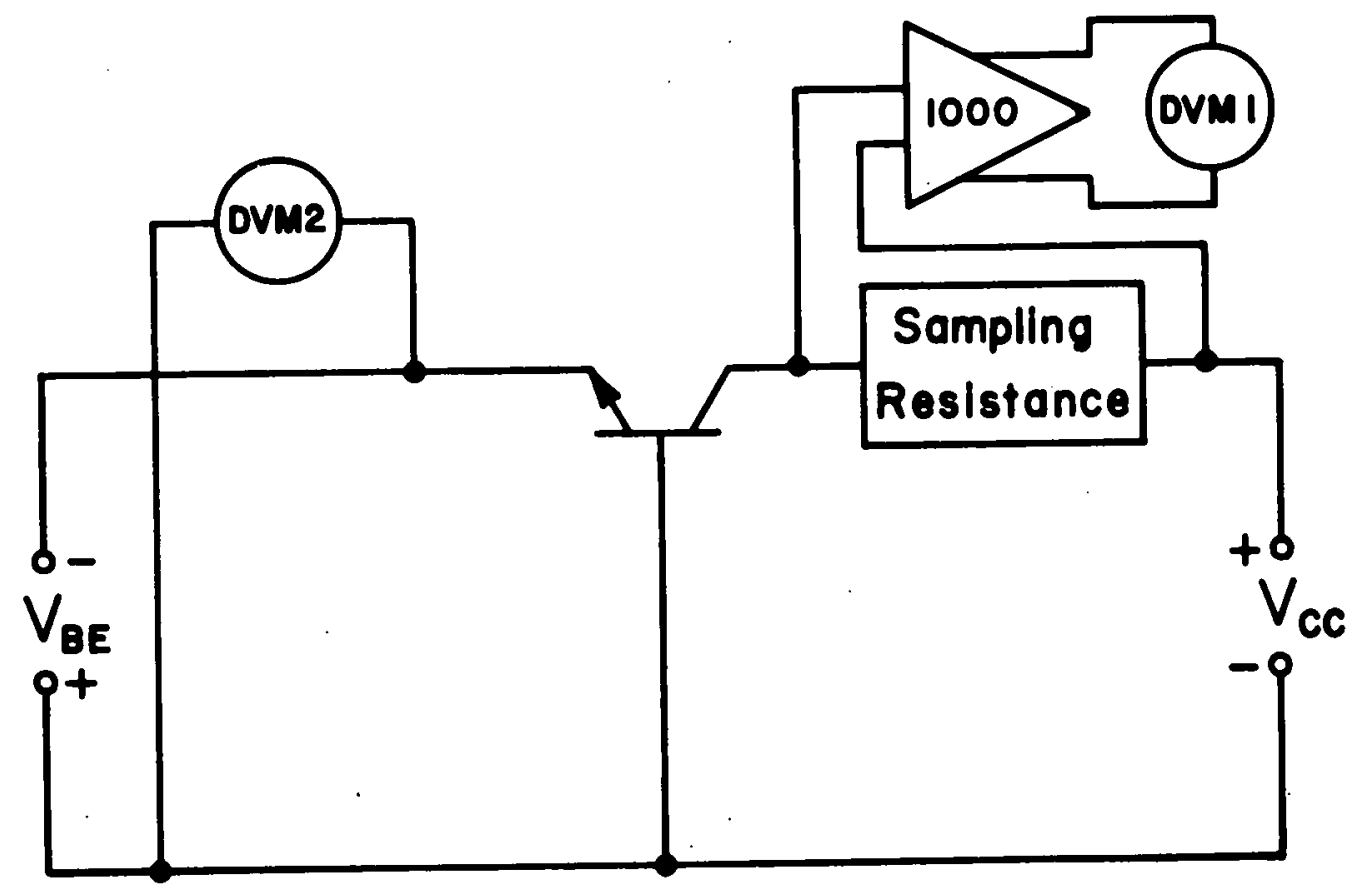

Figure A-5. Collector current measurement circuit. 
of all resistors which are in the measurement circuit after the autoranging procedure is performed. The value of the Sampling Resistance as shown in Figure $A-6$ is, therefore, 17 milliohms.

The system is designed to perform a particular sequence of events in obtaining test data from a semiconductor device. In simplified terms, the sequence of events for one typical cycle of the system is as follows:

1. With the test device initially in the Base current Measurement Circuit (Figure $\mathrm{A}-4$ ) and with a particular value of base-emitter bias and collector supply voltage applied to the device, the system autoranges selecting one of the nine possible values of the Sampling Resistance such that the voltage drop across the Sampling Resistance is normally greater than 0.5 millivolts and less than 5 millivolts. This autoranging procedure has been explained in detail in reference $\mathrm{A} 2$.

2. The digital voltmeters encode and their readings are recorded.

3. The device is switched into the collector Current Measurement Circuit (Figure A-5).

4. The two digital voltmeters again encode and their readings are recorded

5. The device is switched back into the Base Current Measurement Circuit (Figure A-4).

6. A new value of base-emitter bias, $V_{B E^{\prime}}$ is applied 


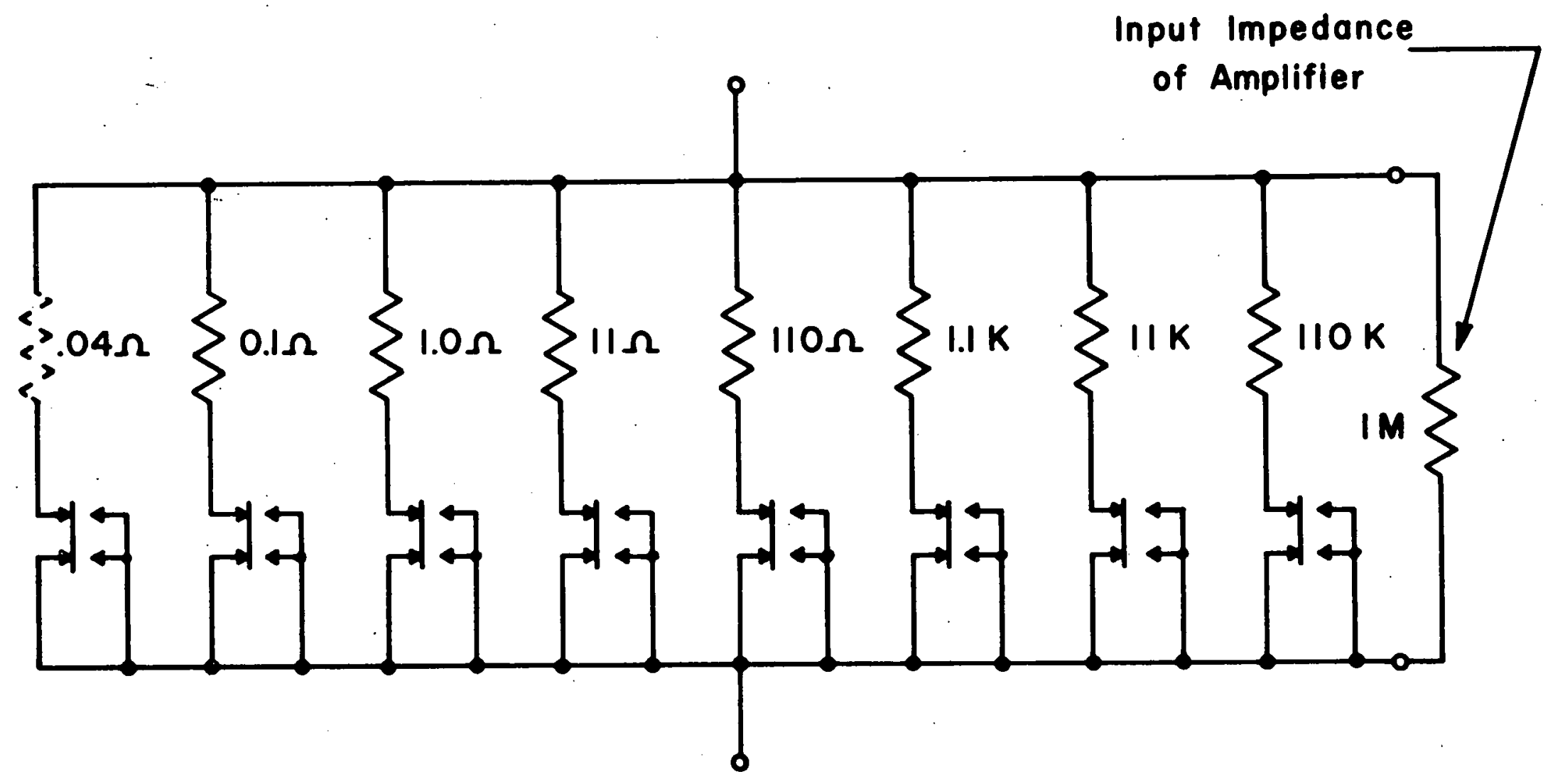

Figure A-6. Sampling resistance. 
to the device and the sequence is repeated.

These steps define one cycle of the system. The system continues cycling in this manner until all of the required pre-programmed values of $\mathrm{v}_{\mathrm{BE}}$ (59 values of $\mathrm{v}_{\mathrm{BE}}$ are available if needed) have been used.

The collector supply voltage, $\mathrm{V}_{\mathrm{CC}}$, $\mathrm{can}$ be set manually before a test run in which case it remains constant during that test run, or a series of voltages can be programmed for a test run. In this second case, the emitter supply voltage, $\mathrm{V}_{\mathrm{BE}}$, is usually held constant.

An additional method of operation allows one to measure base current only or collector current only. This method of operation is selected by the MODE switch on the front panel of the control center. 


\section{REFERENCES}

Al. Goben, C. A., "Nuclear Radiation Effects on Silicon p-n Junctions," Technical Progress Report, Document COO1624-11, Space Sciences Research Center, University of Missouri-Rolla, 1968.

A2. Bartling, D. L., "An Automctic Data Acquisition System for Semiconductor Device Testing," M.S. Thesis, Library, University of Missouri-Rolla, 1967.

A3. Bartling, D. L., Jenkins, C. R. and Goben, C. A., "An Automatic Data Acquisition System for Semiconductor Device Testing," IEEE Trans. on Instrumentation and

Measurement, IM-17: 1, 19-28, 1968 . 


\section{APPENDIX B : CAPACITANCE-VOLTAGE MEASURING SYSTEMS}

Two systems were used for the measurement and recording of capacitance versus voltage data ${ }^{B 1}$. The alternative capacitance measuring systems use a Micro-Instruments Model 1201DS Digital Capacitance Tester as the basic measuring instrument. A Dymec 2901A Master Scanner/Programmer and a Dymec 2902A Slave Scanner/Programmer are used for control and programming. The Dymec 2901A Master Scanner/Programmer and the Dymec 2902A Slave Scanner/Programmer are electronically controlled stepping switches which provide automatic scanning of 25 signal inputs each. The test devices in the alternative systems are mounted in a Delta Design MK2310 Temperature Control Chamber (see Appendix A).

The digital Capacitance Tester is a direct reading high speed instrument for accurate capacitance measurements. A guarded two terminal test jig is permanently attached to the front panel of the instrument. This test jig is guarded with a signal similar to the test signal to neutralize the capacitance effects of the component leads; thus the instrument measures direct capacitance rather than grounded capacitance. Three BNC coaxial connectors for remote or special test jigs are provided on the front panel. The connectors provide for a test signal, a guard signal and a return for use with remote or special jigs. The Coarse zero Control may be used to neutralize up to $100 \mathrm{pF}$ of capacitance added by the cable and jig. 
A digital output connector is provided on the Digital Capacitance Tester. This connector provides a print command signal as well as digital information to operate the HewlettPackard R66-562AR Digital Recorder. The recorder is controlled by means of a "Print" switch located on the front panel of the instrument. The output is BCD 1248 logic.

In the first alternative capacitance measuring system, a start command advances the scanner/programmer which digitally programs a voltage or current on a John Fluke 383B Voltage/Current Calibrator. This voltage or current is applied to the device under test. A capacitance reading is taken by a Micro Instrument Digital Capacitance Tester 1201DS and recorded on a Hewlett-Packard R66-562AR Digttál Recorder together with the applied voltage which is measured by a Dymec 2401C-M31 Digital Voltmeter. The printed record is punched on IBM cards and processed by the IBM 360-50 Digital Computer. The block diagram for the system is shown in Figure $B-1$.

Alternatively, when the Automatic Data Acquisition System described in Appendix $A$ is not in use for voltage-current measurements, the Dymec 2401C-M31 Digital Voltmeters, Dymec 2540B Coupler and Friden SFD Flexowriter may be used as the output medium. For this mode of operation the frequency output (proportional to capacitance) of the Micro-Instruments 1201DS Capacitance Bridge is measured by one of the DVM's in the Automatic Data Acquisition System while the other DVM measures the potential applied to the device under 
DELTA UESIGN MK 2310
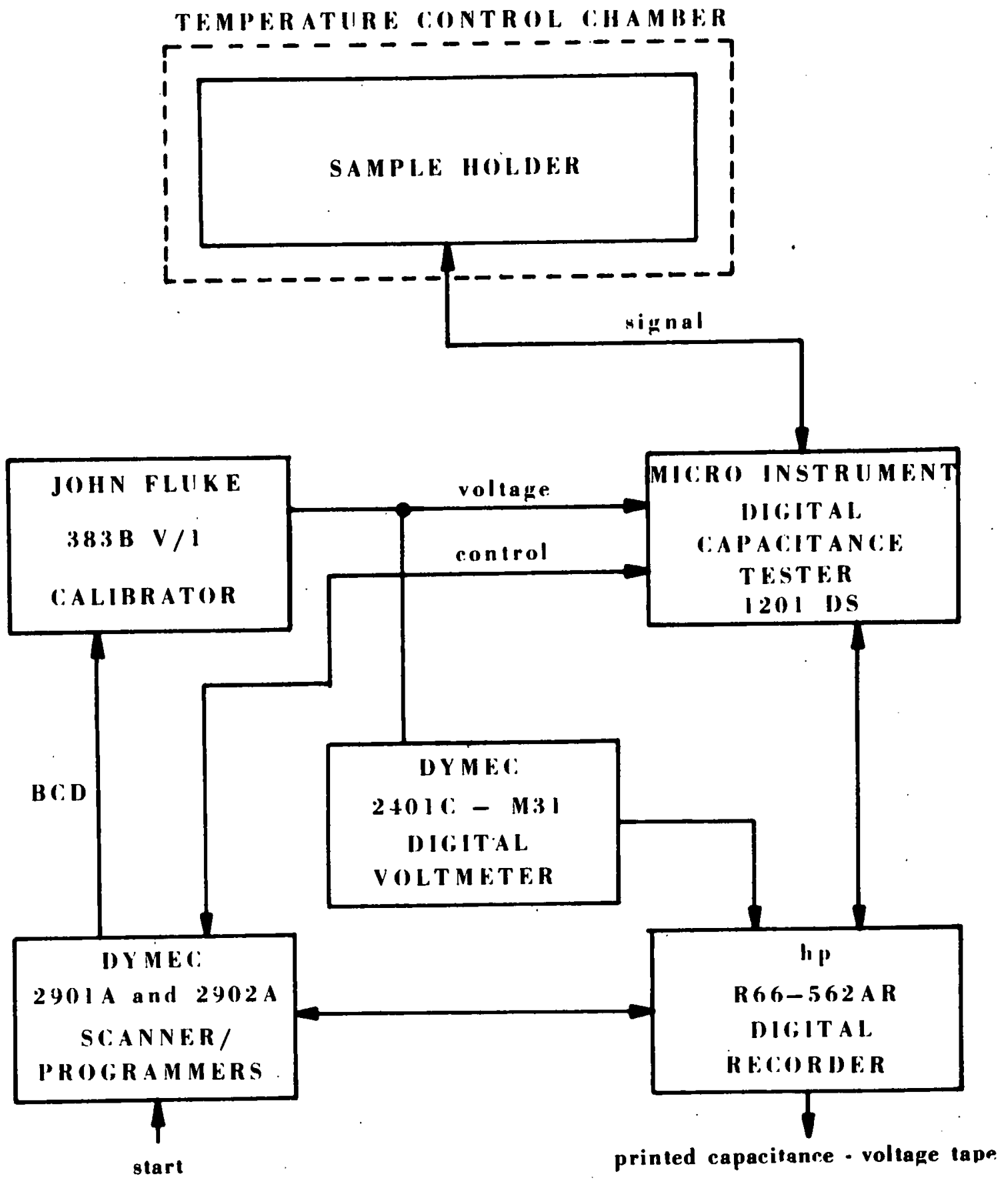

Figure B-1. Capacitance-voltage measurement system. 
test. This information is then serialized by the Dymec 2540B Coupler and then printed as output by the Friden SFD Flexowriter on both punched paper tape and typewritten copy. Data processing is accomplished in a similar manner to that described for the Automatic Data Acquisition System. The block diagram of the alternative system for the capacitancevoltage measurements is shown in Figure B-2.

To facilitate the inter-connection of the Automatic Data Acquisition System and the Capacitance-Voltage System for this alternative mode of operation, a single cable was constructed carrying all data, control and signal lines. When the two systems are used separately, shorting plugs are placed over the chassis connectors on the two systems. 
Delta Design MK.2310 Temperature Control Chamber

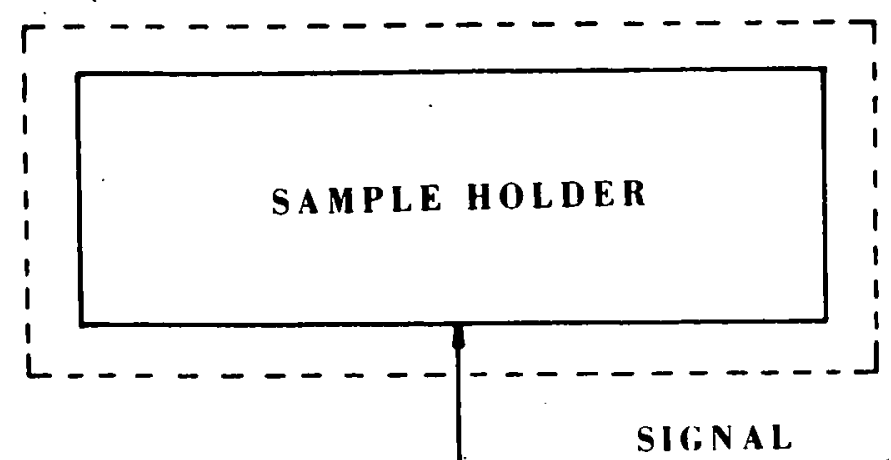

SIGNAL

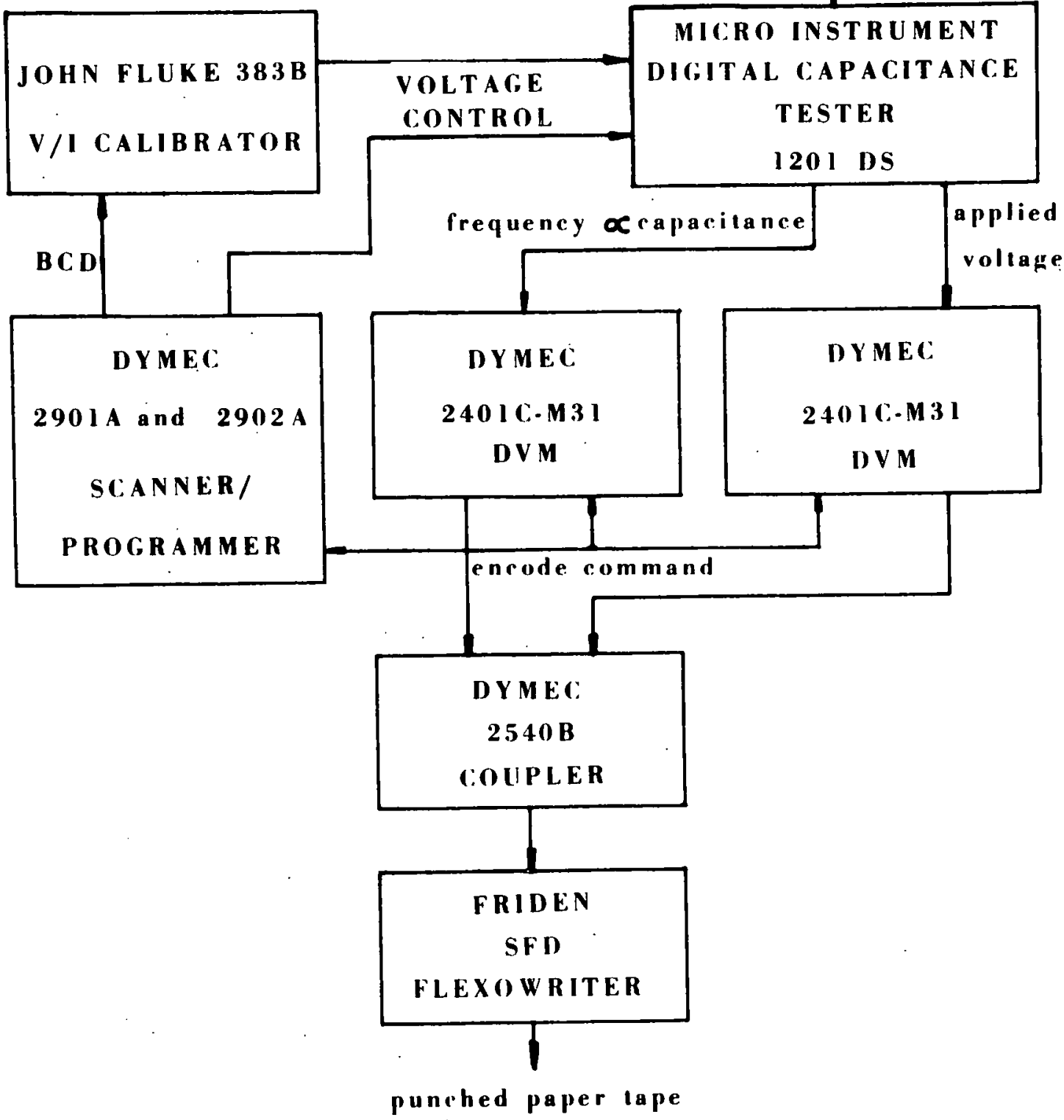

Figure B-2. Capacitance-voltage system block diagram. 
REFERENCE

BI. Goben, C. A., "Nuclear Radiation Effects on Silicon p-n Junctions," Technical Progress Report, Document COO1624-11, Space Sciences Research Center, University of Missouri-Rolla, 1968. 


\section{Reverse Recovery Characteristics of Diodes}

When a diode is switched from conduction in a forward bias to a reverse bias condition, instead of a high impedance immediately appearing across the diode, a momentary low impedance, which is indicated by a very low voltage across the diode, immediately occurs after the switching. This is due to the storage of minority carriers in the semiconductor material.

As the junction is suddenly reverse biased the excess minority carriers must either be swept out of the junction or recombine with excess majority carriers before a high reverse impedance can be obtained.

A typical display of diode reverse recovery characteristics is shown in Figure $\mathrm{C}-1$. In Figure $\mathrm{C}-1$, there are

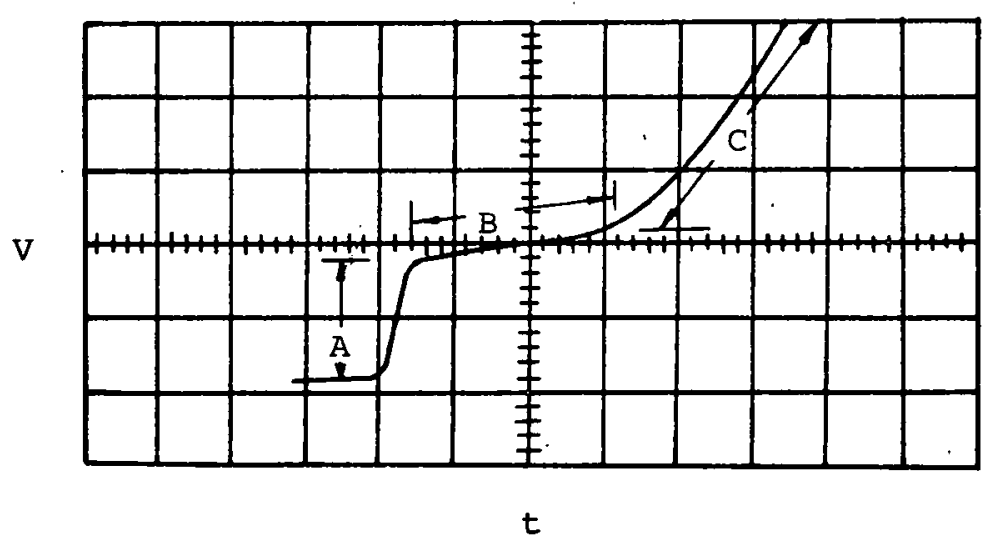
Figure C-1. Typical display of diode reverse recovery
characteristics.

three areas of particular interest. These areas are desig- 
nated by $A, B$ and $C$. The sudden voltage drop at area $A$ occurs at the time when forward conduction ceases. During forward conduction, this voltage drop is produced by the internal series resistance across the diode ${ }^{\mathrm{Cl}}$. When forward current is cut off, this voltage drop disappears, producing the voltage step. Immediately after the sudden drop at area A the voltage decays exponentially for a relatively long period of time (area B). During this interval, minority carriers in the semiconductor material are being swept out by the reverse current. The length of time required for the reverse current to remove the minority carriers gives an indication of the amount of charge stored in the material. The stored charge is found to be proportional to the forward current passing through the junction just before the diode is switched off. If zero reverse current is drawn from the diode, the voltage decay is due entirely to the recombination of minority carriers. By measuring the rate at which the voltage across the diode decays for this case, the effective lifetime can be found.

When the minority carriers in the semiconductor material have either been swept out or have recombined, the depletion region increases at the junction due to the movement of the majority carriers away from the junction. Further reverse current is then required to charge the capacitance of this depletion region (area $C$ ). This accounts for the rise in voltage across the junction. The junction capacitance is also dependent on the voltage. The capacitance does not re- 
main constant, but varies with the voltage across the junction.

\section{The Effective Lifetime of Minority Carriers}

During the period of forward current conduction, excess minority carriers are injected into the semiconductor material. These excess minority carriers are in addition to the normal number of minority carriers present at room temperature due to the formation of electron-hole pairs. The effective lifetime of these excess minority carriers is the time required for the number of the minority carriers to decrease to $36.7 \%(1 / e)$ of the original number after termination of the forward current. The effective lifetime expresses the relative rate at which the minority carriers recombine and is a constant for a given diode at a particular absolute temperature. It does not depend on either the forward or the reverse current drawn from the diode. Effective lifetimes should be specified with the temperature at. which the measurements were made.

When the measured time $(t)$ is small compared to the effective lifetimes $\tau$ and where $\mathrm{kT} / \mathrm{q}$ is much smaller than the voltage across the diode, the approximation for the effective lifetime shown below holds ${ }^{\mathrm{Cl}}$ :

$$
\tau \simeq \frac{\mathrm{kT}}{\mathrm{q}} \cdot \frac{\Delta \mathrm{t}}{\Delta \mathrm{V}}
$$

At room temperature, equation $(\mathrm{C}-1)$ becomes 


$$
\tau\left(300^{\circ} \mathrm{K}\right) \simeq \frac{0.026}{(\Delta \mathrm{V} / \Delta \mathrm{t})}
$$

In equation $(\mathrm{C}-1)$, it is assumed that $t$ is small compared to $\tau$. This means that the decay rate of the voltage across the junction should be measured just after the forward current is switched off. Mathematically stated, $\Delta V / \Delta t$ should be measured as $t \rightarrow t_{0}$, where $t_{0}$ is the time when the forward current is switched off. The assumption that $\mathrm{kT} / \mathrm{q}$ is much smaller than the voltage across the diode also holds quite generally as $t \rightarrow t_{0}$. Therefore, equation $(C-2)$ should be rewritten as:

$$
\tau\left(300^{\circ} \mathrm{K}\right) \simeq \frac{0.026}{(\Delta \mathrm{V} / \Delta t)} t \rightarrow t_{0}
$$

Figure $\mathrm{C}-2$ shows a typical waveform used to measure the effective lifetime of minority carriers. The Tektronix Oscilloscope Type $555^{\mathrm{C} 2}$ with the Tektronix Type S Recoverytime plug-in Unit ${ }^{\mathrm{C} 3}$ is used for the measurements. .

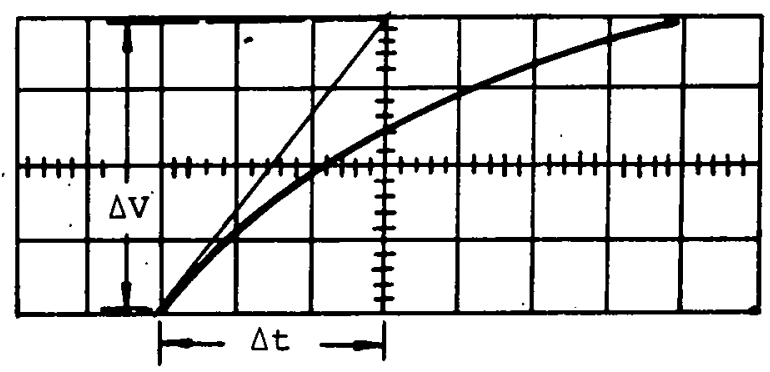

Figure C-2. Tangent line for calculating the voltage decay rate across the diode. 
The waveforms used to measure the effective minority carrier lifetime were photographed by a Tektronix Type 100 camera with a Polaroid back. The pictures for each device at both emitter-base and collector-base junctions have been taken at every irradiation step. Figure C-3 shows two typical pictures which are used to illustrate the decrease in minority carrier lifetimes.

\section{Minority Carrier Lifetimes in the Base and Collector Regions of a Junction Transistor}

For measuring the lifetimes of a transistor, both the emitter-base and collector-base junctions can be treated as diodes. Using the method described above, the values of $\tau_{B E}$ and $\tau_{B C}$ for the emitter-base and collector-base junctions, respectively can be calculated. The minority carrier lifetimes in the base and collector regions are $\tau_{B}$ and $\tau_{C}$ ' respectively, and are related to $\tau_{B E}$ and $\tau_{B C}$ according to:

$$
1 / \tau_{B}+1 / \tau_{C}=1 / \tau_{B C}
$$

and,

$$
1 / \tau_{B} \simeq 1 / \tau_{B E^{\prime}}
$$

or,

$$
\begin{aligned}
& \tau_{B} \simeq \tau_{B E}{ }^{\prime} \\
& \tau_{C} \simeq\left(\tau_{B E}-\tau_{B C}\right) / \tau_{B C} \cdot \tau_{B E} \cdot
\end{aligned}
$$

Equations (C-6) and (C-7) were used to calculate the minority carrier lifetimes of a transistor throughout this investigation. 


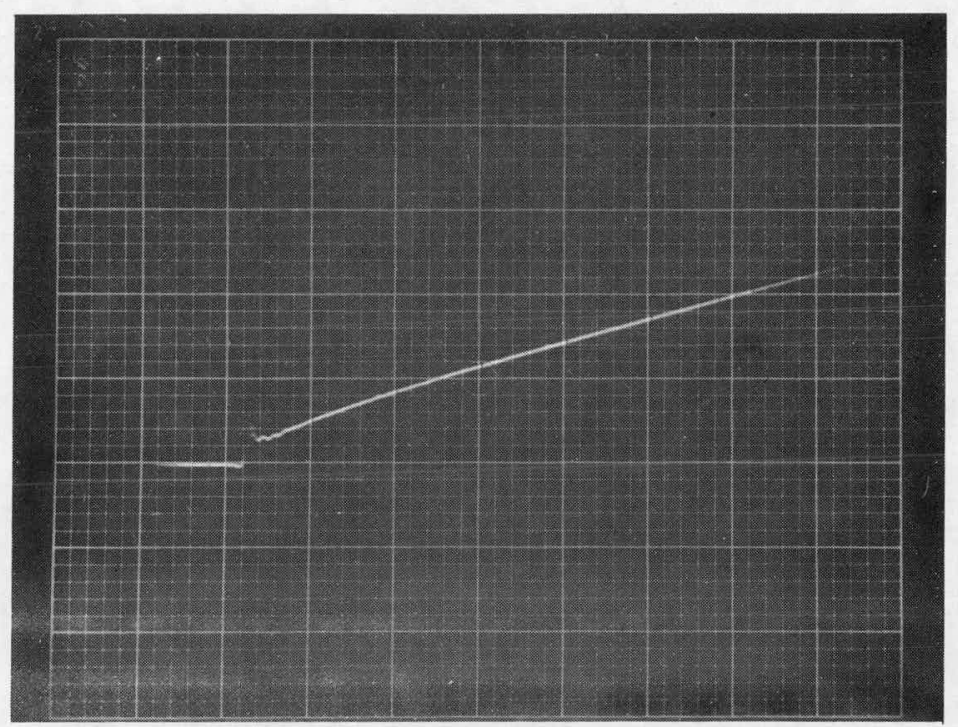

$$
\begin{aligned}
\Phi & =0 \\
\tau & \simeq \frac{0.026}{\frac{(0.05) \cdot(0.6)}{(0.1) \cdot(1.6)}} \\
& \simeq 139.2 \mathrm{~ns}
\end{aligned}
$$

(at $300^{\circ} \mathrm{K}$ )

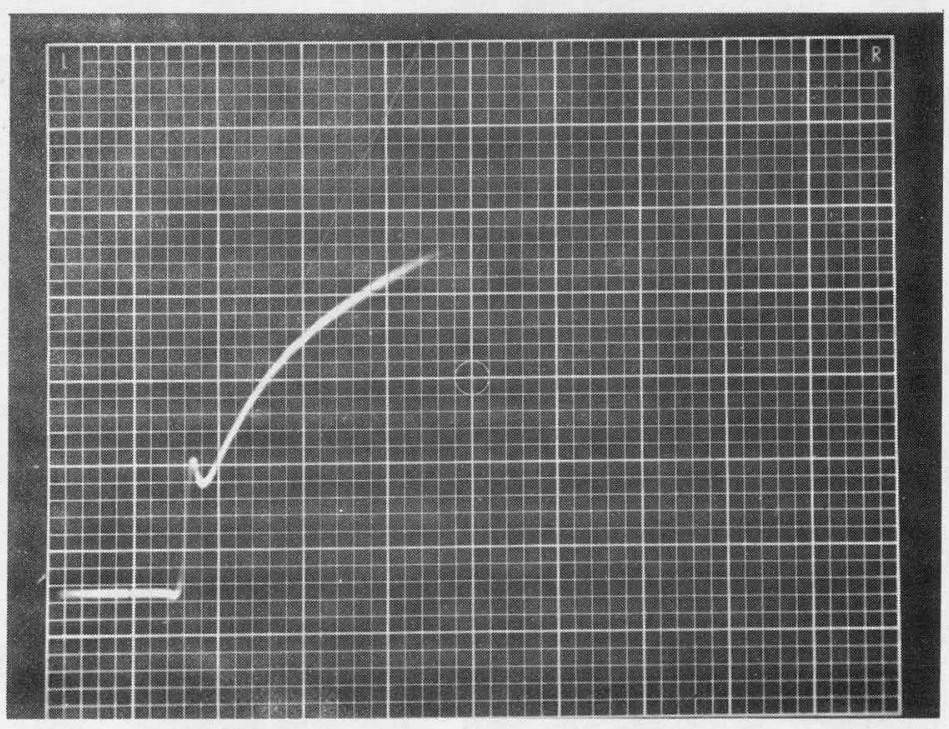

$$
\begin{aligned}
\Phi & =6 \times 10^{13} \mathrm{nvt} \\
\tau & \simeq \frac{0.026}{\frac{(0.05) \cdot(0.4)}{(0.1) \cdot(0.2)}} \\
& \simeq 26 \mathrm{~ns}
\end{aligned}
$$

(at $300^{\circ} \mathrm{K}$ )

Figure C-3. Photographs from which measurements of $\tau_{\mathrm{BE}}$ at two difference fluences are made. 

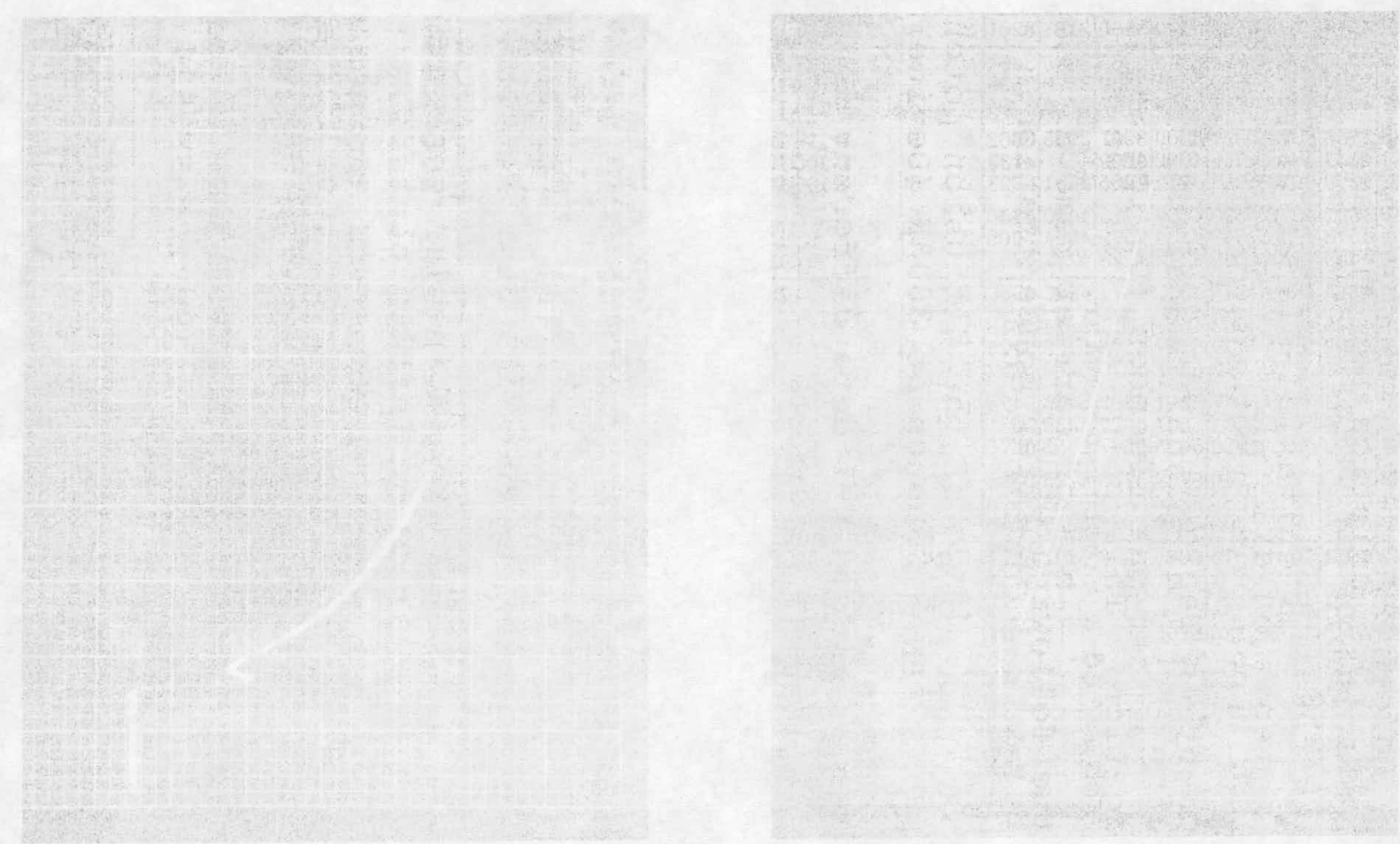


\section{REFERENCES}

Cl. Lederhandler, S. K. and Giacoletto, L. J., "Measurement of Minority Carrier Lifetime and surface Effects in Junction Devices," Proc. IRE, 43: 477-483, 1955.

C2. "Tektronix Type 555 Oscilloscope Manual," Tektronix Inc., Beaverton, Oregon, 1964.

C3. "Tektronix Type S Plug-in Unit Manual," Tektronix Inc., Beaverton, Oregon, 1960 . 
APPENDIX D: NUCLEAR REACTOR FACILITY AND IRRADIATION PROBLEMS

\section{Nuclear Reactor Facility}

The neutron irradiations used in this investigation were performed at the Research Reactor of the University of Missouri-Rolla. This reactor is used both for laboratory training and research by the faculty and students of the University of Missouri-Rolla and other nearby universities. A table of the major reactor characteristics of the Research Reactor of the University of Missouri-Rolla is illustrated in Figure $\mathrm{D}-1$ :

The Research Reactor of the University of MissouriRolla is a "swimming pool" type reactor, installed in a windowless, concrete, brick and steel structure. The pool consists of a thick walled pit, 19 feet long, 9 feet wide and 27 feet deep, containing 32,000 gallons of pure water. The reactor core is suspended near the bottom of the pool and is covered with some 19 feet of shielding water. The water is continuoasly puriftēd by an ion exbhanger, which removes cations and anions, preyenting corrosion and contamination. The reactor grid plate, containing several rows of holes and 22 fuel elements, is a racklike aluminum. tray. Open positions in the grid plate are available as sample holders in experiments. Position B2, (see Figure D-2). which is mapped for fast flux irradiations, was used in this experiment. The maximum fast flux ( $\mathrm{E}>0.01 \mathrm{MeV})$ available 


\section{Type}

Swimming pool type (modified BSR-type), housed in a windowless, concrete, brick and steel structure.

Core Heterogeneous 908 U-235 enriched uranium oxide-Aluminum-water.

Moderator Light water.

Reflector Light water.

Coolant Light water.

Biological shield Light water and normal concrete.

Critical mass Approximately 2.7 kilograms of $\mathrm{U}-235$

Power level Up to $200 \mathrm{kw}$

Maximum thermal flux $1.5 \times 10^{12}$ neutrons $/ \mathrm{cm}^{2}-$ sec.

Maximum fast flux $\left(E>10 \mathrm{keV}\right.$ ) ---: $2.25 \times 10^{11}$ neutrons $/ \mathrm{cm}^{2}-\mathrm{sec}$

Fuel elements MTR type; each fuel element has 10 fuel plates, each plate approximately 17 gms of U-235. Each fuel element is $3^{\prime \prime} x 3^{\prime \prime} x 36^{\prime \prime}$. The reactor has 22 full fuel elements: 1 left hand half elements, 2 right hand half elements, and 4 control rod elements ( 3 shim-safety rod, 1 regulating rod).

Auxiliary equipment

Neutron diffraction multi-channel analyzer, nuclear counting equipment; neutron generator, subcritical assembly, neutron chopper.

Figure D-1. Table of technical data for the UMR Research Reactor. 


\begin{tabular}{|c|c|c|c|c|c|c|c|c|}
\hline Al & A2 & A3 & A4 & A5 & A6 & A7 & A8 & A9 \\
\hline Bl & B2 & B3 & B4 & S & B6 & B7 & B8 & B9 \\
\hline Cl & C2 & C3 & F & F & X & O & C8 & C9 \\
\hline DI & D2 & F & X & F & F & F & F & D9 \\
\hline E1 & E2 & F & X & F & X & F & F & E9 \\
\hline F1 & F2 & PT & F & F & $F$ & PT & F8 & F9 \\
\hline
\end{tabular}

$\mathrm{F}=$ Fuel

$\mathrm{S}=$ Source

0 = Sample Rotator

$\mathrm{x}=$ Control Rods

PT = Pneumatic Transfer Tubes

Figure D-2. Core configuration 31-T. 
at $200 \mathrm{~kW}$ for position $\mathrm{B} 2$ is $2.25 \times 10^{11}$ neutrons $/ \mathrm{cm}^{2}-\mathrm{sec}$. Nickel foils were used to determine the fluence levels for each irradiation. Dosimetric measurements for the neutron irradiations were performed at the reactor.

A photograph of the sample holder which was used for the transistors in all the irradiations is shown in Figure D-3.

\section{Irradiation Problems}

The transistors used in this neutron radiation effects study were irradiated in a double-walled aluminum sample holder having the inner space filled with boron carbide. The boron carbide., shield: is needed to-allow only fast neutrons ( $\mathrm{E}>\mathrm{i} 0 \mathrm{keV}$ ) to bombard the devices. Boron carbide has a high capture cross-section for slow (E < 10keV) neutrons.

The aluminum used in the fabrication of the sample holder contained impurities whose radioactive half-life was long compared with aluminum. As a result, the sample holder could not be removed from the pool until this radioactive decay decreased to a point which was considered safe. A cadmium cylinder was used to shield the sample holder from the thermal neutrons causing this activation. This allowed the samples to be removed from: the pool on the day that they were irradiated.

At higher fluence levels, the temperature inside the sample chamber would tend to increase, requiring a flow of nitrogen through the sample chamber during irradiation to 


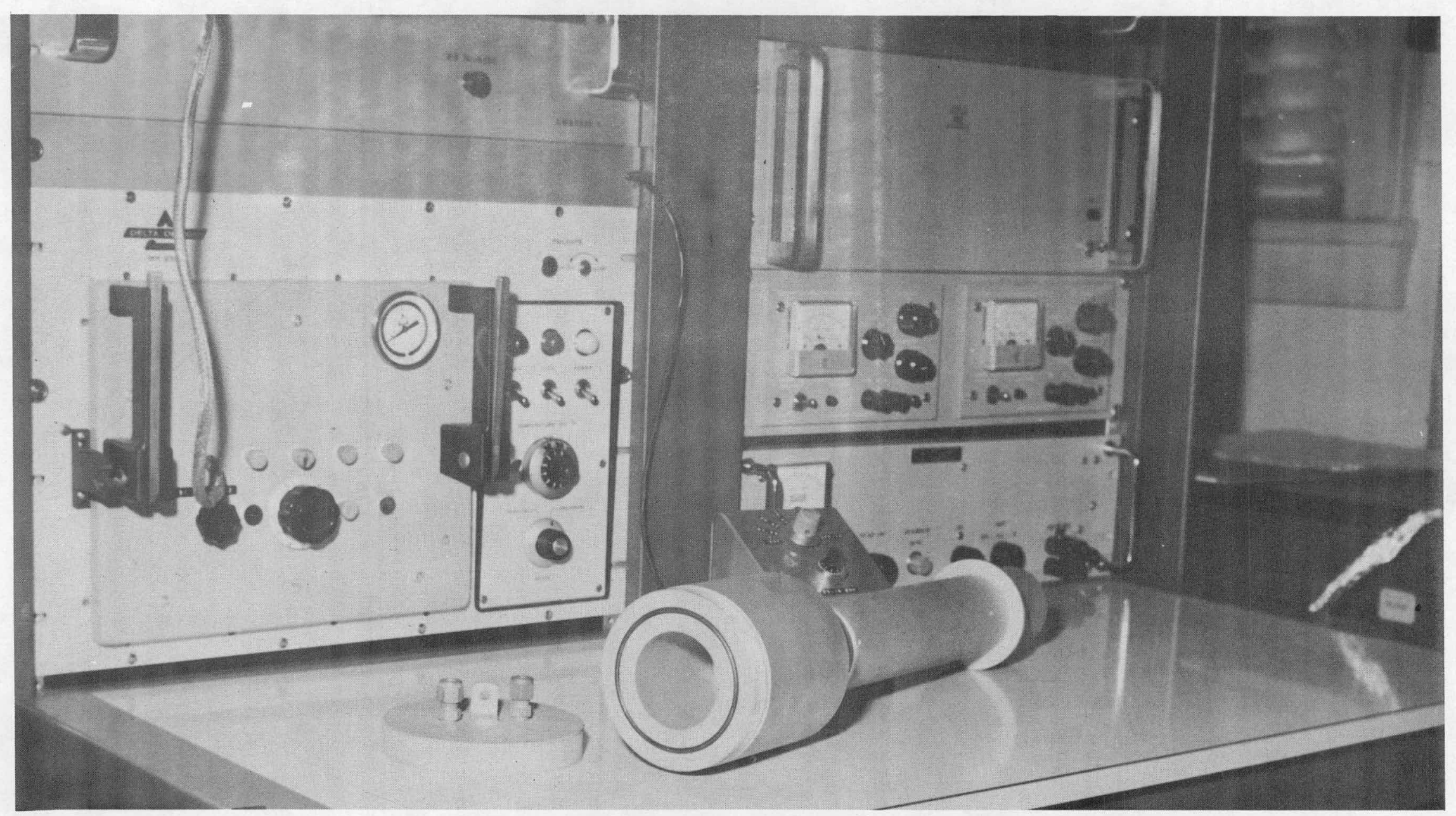

Figure D-3. Photograph of sample holder. 
cool the devices. This coolant was necessary to insure that annealing did not take place during irradiation.

Further complications were presented by the reactor being operated at $200 \mathrm{~kW}$ in other experiments which raised the water temperature at times to as high as $57^{\circ} \mathrm{C}$. This required the use of nitrogen coolent as long as the devices were in the reactor pool, otherwise, annealing would have taken place. 


\section{APPENDIX E: HISTORY OF THE RESEARCH IN THIS AREA}

The observed decrease in transistor current gain resulting from exposure of transistors to neutron irradiation $^{E l}$ had, in the past, been attributed primarily to the neutron-induced reduction in minority carrier lifetime in the base region, that is, to the resultant reduction of the base recombination term ${ }^{\mathrm{E} 2-\mathrm{E} 6}$. Recent investigations ${ }^{\mathrm{E} 7, \mathrm{E} 8}$ have shown that the fall off of the transistor current gain at low currents in non-irradiated transistors is caused by a reduction in the emitter efficiency. This suggested that emitter efficiency was-important in transistor gain changes resulting from irradiation. To ascertain the role of emitter effeciency, a more detailed study of the degradation of transistors in a radiation environment was required. Such a study was reported by Goben and Smits ${ }^{E 9}$ in 1964.

Several components of base current have been identified in non-irradiated transistors. The first of these, the bulk recombination-generation current, or the ideal diffusion current for uniform base transistors was first suggested by Shockley ${ }^{\mathrm{ElO}}$ and later extended to the non-uniform base situation by Moll and Ross ${ }^{E 1 l}$. It has a voltage dependence of $\exp (\mathrm{qV} / \mathrm{kT})$. The second component is a recombination current in the transition (space-charge) region. The voltage dependence of this second component approximates $\exp (\mathrm{qV} / 2 \mathrm{kT})$ at low current densities ${ }^{\mathrm{E} 12}$. A third component, the surfaceperimeter component, has been found to originate at the 
perimeter of the emitter ${ }^{\mathrm{E} 7, \mathrm{E} 8, \mathrm{E} 13}$, that is, where the emitter-base junction intersects the surface. Iwersen et al. E7 suppressed this component by placing a guard ring on the emitter and applying a bias from emitter contact to guard ring. The voltage dependence of this particular component of current is as $\exp (\mathrm{qV} / \mathrm{nkT})$, where $\mathrm{n}$ is approximately

1.5. A fourth component, the surface current, stems from surface channels and varies with voltage as exp (qV/mkT), where $\mathrm{m}$ is usually between two and four for silicon junctions, although values larger than four have been noted for large channels $\mathrm{E} 7, \mathrm{E} 12, \mathrm{E} 13$.

As was shown in the work by Goben and Smits ${ }^{E 9}$, neutron radiation of $\mathrm{p}-\mathrm{n}$ junction devices produces a component of current which varies as $\exp (\mathrm{qV} / \mathrm{nkT})$, where $\mathrm{n}$ is approximately 1.5 at room temperature and varies from 1.3 to 1.7 as the temperature ranges from $100^{\circ} \mathrm{C}$ to $-50^{\circ} \mathrm{C}$. This component of current is induced in the bulk transition region and dominates the transistor current gain over a wide range of current levels. These findings implies, that emitter efficiency played a much more important role in radtation-induced changes in current gain than had been assumed in the past. In 1949, Shockley ${ }^{E 10}$ pointed out that the injected minority carrier current in the base of a transistor depended on the ratio of the minority carrier mobility to the base doping, i.e., the sheet carrier density. Shockley further pointed out that, in the absence of collector multiplication, the collector current is simply the injected minority 


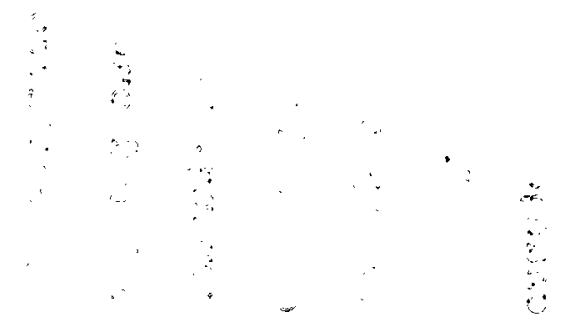

C 
carrier current modified by a recombination term, the base transport factor (base recombination term), which accounts for the carriers which recombine in the base region. The base current is composed of this recombination current, the space-charge recombination current, and the surface recombination current. Shockley then derived an expression for the current gain which ignored these fundamentally different currents.

Ignoring these different components of current apparently led previous researchers in the field of radiation behavior of transistor current gain to erroneous conclusions. From Shockley's work, it may be seen that the best approach for studying the emitter efficiency in a $p-n$ junction device is to ignore the simple expressions for emitter efficiency presented in the literature and instead study the emitter efficiency in terms of the components of current associated with the $p-n$ junction.

Much work has been done on both permanent and transient radiation effects on semiconductor materials and semiconductor devices ${ }^{E 1}$. A very small amount has involved detailed examination of the degradation of transistor current gain ${ }^{\mathrm{E} 2-\mathrm{E} 6}$. Most of the investigations have centered on characterizing parameters at particular bias conditions ${ }^{\text {E14-E23, }}$ or in measuring the effects of radiation on bulk semiconductor materials.

Transient radiation effects in semiconductor materials and devices are associated with the creation, by ionization, 
of excess hole-electron pairs. Transient radiation effects disappear after the exciting radiation is removed in times on the order of the minority carrier lifetime. Permanent radiation effects are associated with damage to the lattice, whether or not the damage anneals out with time and temperature. Sander ${ }^{E 23}$ has recently shown that significant annealing is completed in times of the order of tens of seconds after the irradiation is stopped. Hood ${ }^{\mathrm{2} 25}$ found the remaining damage to be stable at room temperature with less than a three per cent change in 3,000 hours although recent studies $^{\mathrm{E} 26}$ indicate a somewhat larger change. The permanent damage with which this research is concerned is the room temperature stable permanent damage.

Crystal lattice defects caused by radiation damage act as recombination sites and hence decrease the minority carrier lifetime. Crystal lattice defects, through impurity scattering and compensation of shallow impurities, reduce the carrier mobilities and the carrier concentration. Fastneutron irradiation is particularly damaging to crystal lattices because thousands of atoms may be removed from their lattice sites as the result of a single collision ${ }^{\mathrm{E} 24}$. Loferski ${ }^{\mathrm{E} 2}$, in the first investigation (1958) of transistor current gain degradation, employed the simple expression $^{E 27-E 32}$ for emitter efficiency involving only the ratios of the sheet resistivities of the base and emitter regions ${ }^{E 33, E 34}$. He concluded that the emitter efficiency would be negligible. By using a linear dependence of the 
reciprocal lifetime on neutron fluence, Loferski modified Webster's equation ${ }^{E 28}$ to include fluence and concluded that the reciprocal of the common-emitter current gain should vary linearly with fluence. Discrepancies between theory and experiment were attributed to experimental error and the use of incorrect values for the constants in his theoretical expression.

Messenger and Spratt $^{E 3}$, in their analysis (1959) of transistor gain degradation caused by neutron bombardment, again assumed the emitter efficiency to be essentially independent of neutron fluence. The theoretical analysis consisted of applying Shockley-Read ${ }^{\mathrm{E} 35, \mathrm{E} 36}$ statistics to Webster's equation. From this analysis, Messenger and Spratt were able to calculate the energy of an assumed single level for the recombination sites. The recombination sites were assumed to be in the bulk base region and to act only through lifetime degradation. Cross-sections for interaction with the mobile carrier were also calculated. Discrepancies between theoretical and experimental results were attributed to lack of precise knowledge of the lifetime damage constant and to experimental error. Easley and Dooley ${ }^{E 4}$ (1960) assumed the emitter efficiency to be independent of neutron flux, and further assumed that the emitter efficiency and collector multipication factor were equal to unity. Thus, the common-base current gain reflected only the base transport factor (base re-

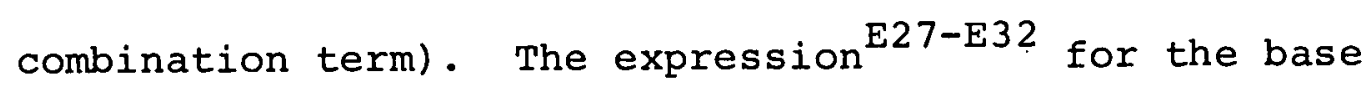


recombination term was modified to exhibit a dependence on neutron flux by assuming a flux dependent lifetime and an electrical base width that varied with irradiation resulting from change in the carrier concentration. The expression which Easley and Dooley derived simplified to a linear dependence on flux for the assumption of fluxes too low to cause appreciable carrier removal. Experiments to verify the theory were carried out in a steady state reactor, with measurements made in-core. Disagreements were attributed to partial annealing of the radiation damage during bombardment.

In a later analysis (1964) of neutron degradation of transistor current gain, Hood ${ }^{\mathrm{E} 5}$ allowed the emitter efficiency to vary with neutron fluence by the inclusion of the back-injection current term and a simplified form of the Sah-Noyce-Shockley ${ }^{E 12}$ expression for the normal bulk spacecharge recombination-generation current term. The back injection into the emitter is normally negligible because of the high doping in the emitter, and the normal bulk spacecharge recombination current is negligible at emitter-base biases greater than 0.3 volts. The discrepancy between Hood's theoretical and experimental results was greatest, where it would be expected to be the least, at low current levels. The discrepancy was attributed to neglecting the collector leakage current in his analysis.

In 1964 , Goben ${ }^{\mathrm{E} 9, \mathrm{E} 37}$ reported a base current with a voltage dependence of $\exp (\mathrm{qV} / \mathrm{nkT}), \mathrm{n} \simeq 1.5$, which was 
observed to increase in proportion to neutron fluence upon exposure to neutron radiation. From a study of the base resistance through which this current component flows, Goben $^{\text {E9,E37 }}$ showed that this component is of bulk and not of perimeter origin and must be attributed to recombination in the bulk space-charge region. This current component dominates transistor gain over a wide range of current density and is primarily responsible for degradation of transistor current gain by decreasing the emitter efficiency. Goben ${ }^{E 38}$, in the analyses of the deviation of the characteristics from an exponential caused by the emission concentration in "ring-dot" structures and the transverse bias dependence of the base current components for a special "tetrode-type" test structure, found that the small " 1.5 component" of current initially present is indeed of surface-perimeter origin while the added " 1.5 component" of current induced by neutron bombardment is of bulk space-charge origin. An investigation was made of many different types of silicon transistors, and all were found to exhibit a similar neutroninduced component. In this work, Goben ${ }^{E 38}$ also found an apparent difference in annealing rates for the neutral base region and the space-charge region of the emitter-base junction.

Recent work by Goben et al. ${ }^{\text {E39 }}$ indicated, from a study of base and collector current as a function of the emitterto-base voltage, that the neutron-induced base current had components originating in the emitter space-charge region as 
well as the neutral base region. At low injection levels the neutron-induced base current was dominated by the spacecharge component, whereas the high injection behavior appeared to be controlled by recombination in the neutral base region. Additional experiments performed in special tetrode transistor and van der Pauw-type sample indicated that changes in collector current were dominated by recombination in the neutral base, while changes in base doping and mobility had only a secondary effect. These conclusions were reached from experiments on transistors with a ring emitter, on tetrode-type test transistors, and on special Hall-effect devices.

Chott and Goben ${ }^{E 40}$ in a recent study (1967) found indications that the origin of the anomalous annealing was one, or a combination, of the following mechanisms: a quasitunneling recombination phenomena in the emitter-base spacecharge region, or a dependence of the neutron-induced defect centers on the $\mathrm{p}-\mathrm{n}$ junction field. A field dependence appeared to be present, but it was not certain whether the quasi-tunneling phenomena occurred, although it was shown that it is possible for such phenomena to occur. The annealing characteristics of the defects causing changes in the collector and base currents were obtained. Three sets of devices were irradiated and then annealed, with one set having a forward bias during annealing, one set having no bias, and one set having a reverse bias. The dependence of the field on annealing was present but appeared quite 
complex. The presence of the externally applied field during annealing appeared to enhance the annealing of neutroninduced defects regardless of whether the junction was forward or reverse biased.

While studying the transient annealing effects in semiconductor devices, Sander and Gregory ${ }^{\mathrm{E} 41}$ recently discovered that p-type material is very sensitive to the minority carrier injection level and the room temperature annealing rate can be increased by the presence of minority carriers. The injection dependence of $n$-type material is very small and is in the opposite sense (i.e., the room temperature annealing rate can be decreased by the presence of minority carriers). This behavior can be correlated on the basis of the hole-toelectron ratios of the different material types and resistivity.

Bass $^{\mathrm{E} 42}$ in his recent work of neutron damage and annealing in silicon found the carrier removal rate and the annealing behavior of n-type semiconductor to depend on the crystal growth method. A slight dependence on the dopant impurity was observed in vacuum-float-zone material, but carrier removal in p-type semiconductor was not influenced by the growth method of the dopant impurity.

Curtis and Germano ${ }^{\mathrm{E} 43}$ recently investigated the dependence of carrier lifetime on excess carrier density for bulk n-type and p-type silicon materials. Their results showed that the lifetime was constant at low excess densities, increased to a value several times larger at excess densities 
near the equilibrium carrier density, and then decreased. In fitting the model for lifetime versus excess carrier, an activation energy of $0.32 \mathrm{eV}$ above the valence band or $0.35 \mathrm{eV}$ below the conduction band was found to give the best fit. Curtis ${ }^{\mathrm{E} 44}$ concluded that recombination was dominated by sites within defect clusters, and that there was no dependence on oxygen concentration or type of defect in $n$-type material. A very small dependence on dopant was noted in heavily doped p-type material. It was also concluded that it was impossible to fit all the experimental data with a single level recombination model. A two level model for recombination processes in neutron irradiated materials and

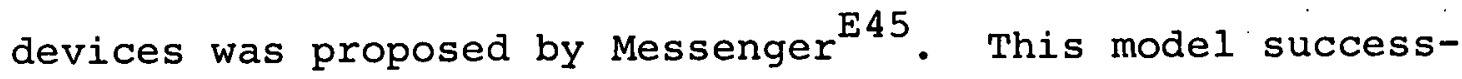
fully explained the previously published experimental data for lifetime, lifetime damage constant as a function of resistivity, lifetime damage constant as a function of injection level and temperature. Two deficiencies in Messenger's model should be noted: 1) the two level model is an approximation to a very complicated defect structure which is known to contain many levels; 2) there are several: plausible alternative extensions and modifications to the one level model which might also resolve its contradictions with the experimental data.

A computer program was written by Gwyn, Scharfetter and Wirth ${ }^{\mathrm{E} 46}$ for the prediction of transient and permanent radiation damage in $\mathrm{p}-\mathrm{n}$ junction devices. The program automatically solved the Poisson's equation and the continuity 
equations over a one-dimensional region. It included nonlinear mobility, lifetime and the Shockley-Read-Hall recombination statistical model ${ }^{E 12, E 35}$. The program should predict the electrical properties of a defect state with considerable accuracy.

Frank and Taulbee ${ }^{\mathrm{E} 26}$ in their recent study of transistor current gain prediction after neutron irradiation found that carrier injection and elevated temperatures in normally biased transistors can produce 20-25 percent less measured damage than in passively irradiated devices. Room temperature annealing ${ }^{\mathrm{E} 46}$ was found to be 15-20 percent over a period of several weeks whereas high carrier injection ${ }^{\mathrm{E} 26}$ was found to produce a temporary 10-15 percent increase in damage. Their work ${ }^{\mathrm{E} 26}$ also shows that silicon junction capacitance at low voltage is frequency dependent after large neutron exposures.

The accumulation of positive charge ${ }^{\mathrm{4} 47}$ has been reported previously as :the dominantimechanism responsible for the surface effect. in oxide passivated devicesi The existence: of the positive charge effect and the introduction of acceptor-like surface recombination states has been demonstrated by Maier ${ }^{\mathrm{E} 48}$ recently, and the additional surface recombination states ${ }^{\mathrm{E} 48}$ are shown to be the dominant mechanism for the surface effect in oxide passivated devices. 
REFERENCES

El. "The Effect of Nuclear Radiation on Semiconductor Devices," Batelle Memorial Institute, Radiation Effects Information Center (Columbus, Ohio) REIC Report No. 10, April 30, 1960, and Addendum, July 15, 1961.

E2. Loferski, J. K., "Analysis of the Effect of Nuclear Radiation on Transistors," J. Appl. Phys., 29: 35-40, 1958.

E3. Messenger, G. C. and Spratt, J. P., "The Effects of Neutron Irradiation on Germanium and Silicon," Proc. IRE, 46: 1038-1044, 1958 .

E4. Easley, J. W. and Dooley, J. A., "On the Neutron Bombardment Reduction of Transistor Current Gain," J. Appl. Phys., 31: 1024-1028, 1960

E5. Hood, J. A., "Predicting the Current Gain Degradation in $n-p-n$ Silicon Transistors after Irradiation by HighEnergy Neutrons," Sandia Lab. (Albuquerque, N.. M.) (Publication) SC-TM-64-69, 1964.

E6. Easley, J. W., "Radiation Damage to Semiconductor Devices," Sandia Lab. (Albuquerque, N. M.) (Publication) SCR-532, 1962 .

E7. Iversen, J. W. , Bray, A. R. and Kleinmack, J. J., "LowCurrent Alpha in Silicon Transistors," IRE Trans. On Electron Devices, ED-9: 474-478, 1962 .

E8. Coppen, P. J. and Matzen, W. T., "Distribution of Recombination Current in Emitter-Base Junctions of Silicon Transistors," IRE Trans.. on Electron Devices, ED-9: 75-81, 1962 .

E9. Goben, C. A. and. Smits, F. M., "Anomalous Base Component in Neutron Irradiated Transistors," IEEE Radiation Effects Conference, Seattle, Washington, 1964.

E10. Shockley, W., "The Theory of $p-n$ Junctions in Semiconductors and p-n Junction Devices," Bell System Tech. J., 38: 435-589, 1949.

E11. Moll, J. L. and Ross, L. M., "The Dependence of Transistor Parameters on the Distribution of Base Layer Resistivity," Proc. IRE, 44: 72-76, 1956.

E12. Sah, C. T., Noyce, R. N. and Shockley, W., "Carrier Generation and Recombination in $p-n$ Junctions and $p-n$ Junction Characteristics," Proc. IRE, 45: 1228-1243, 1957. 
E13. Sah, C. T., "Effect of Recombination and Channel on $\mathrm{p}-\mathrm{n}$ Junction and Transistor Characteristics," IRE Trans. on Electron Devices, ED-9: 94-108, 1962 .

E14. DeNure, D. G., "Effect of Fast Neutron Bombardment on Type 2N559 and 2N559E Epitaxial p-n Germanium Switching Transistors," Bell Telephone Lab. (Murray Hill, N. J.) (Publication) MM-61-4252-33, 1.961.

E15. Hood, J. A., "Degradation of $n-p-n$ Silicon Planar Tran'sistors with Bombardment by High-Energy Neutron," Sandia Lab. (Albuquerque, N. M.) (Publication) SC-TM$261-73(14), 1963$.

E16. Hood, J. A., "Neutron-Induced Degradation of Commercial Transistors," Sandia Lab. (Albuquerque, N. M.) (Publication) SC-TM-129-63(14), 1963.

E17. Westmark, C. I. and Rice, W. H., "Radiation-Induced Degradation of DC Current Gain and Collector-ToEmitter Saturation Voltage for Selected Power Transistors," Sandia Lab. (Albuquerque, N. M.) (Publication) SC-TM-223-63(14), 1963.

E18. Sanders, H. H., "Neutron Permanent Damage Data for the 2N1675 Transistor," Sandia Lab. (Albuquerque, N. M.) (Publication) SC-RR-65-550, 1964.

E19. Manlief, S. K., "A Method of Measuring the Minority Carrier Base Transit Time in a Junction Transistor Exposed to a Neutron Environment," Sandia Lab.

(Albuquerque, N. M.) (Publication) SC-TM-314-63(14), 1963.

E20. Levy, G. F., Fouse, R. R. and Castner; S. V., "The Effects of Nuclear Radiation on Some Selected Semiconductor Devices," Proc, of the 2nd Conf. on Nuclear Radiation Effects on Semiconductor Devices, Materials and Circuits, 76-81, 1959

E21. Loferski, J. J., "A Brief Resume of Radiation Effects on Semiconductor Materials and Devices," Proc. of the 2nd Conf. on Nuclear Radiation Effects on Semiconductor Devices, Materials and Circuits, 8-10, 1959 .

E22. Smits, F. M., "On the Energy Dependence of Neutron Damage to Silicon Transistors," Sandia Lab. (Albuquerque, N. M.) (Publication) SC-R-64-196, 1964.

E23. Sander, H. H., "Room Temperature Annealing of Silicon Transistor Parameters Degraded by a Burst of Neutrons," Sandia Lab. (Albuquerque, N. M.) (Publication) SC-R64-192, 1964 . 
E24. Billington, D. S. and Crawford, J. H., Jr., Radiation Damage in Solids, Princeton, N. J., Princeton University Press, 1961.

E25. Hood, J. A., "Predicting the Current Gain Degradation in $n-p-n$ Silicon Transistors after Irradiation by High-Energy Neutrons," Sandia Lab. (Albuquerque, N. M.) (Publication) SC-TM-64-69, 1964.

E26. Frank, M. and Taulbee, C. D., "Factors Influencing Prediction of Transistor Current Gain in Neutron Radiation," IEEE Trans. on Nuclear Science, NS-14: 6, 127$133,1967$.

E27. Shockley, w., "The Theory of $p-n$ Junctions in Semiconductors and $\mathrm{p}-\mathrm{n}$ Junction Devices," Bell System Tech. J., 28: 435-589, 1949 .

E28. Webster, W. M., "On the Variation of Junction-Transistor Current-Amplification Factor with Emitter Current," Proc. IRE, 42: 914-920, 1954 .

E29. Rittner, E. S., "Extension of the Theory of the Junction Transistor," Phys. Rev., 94: 1161-1171, 1954.

E30. Fletcher, N. H., Note on, "The Variation of Junction Transistor Current-Amplification Factor with Emitter Current," Proc. IRE, 44: 1475-1476, 1956.

E31. Matz, A. W., "Variation of Junction Transistor Current Amplification Factor with Emitter Current," Proc. IRE, 46: $616-617,1958$.

E32. Jakits, O. H., "Some Comments on Webster's Equation," IEEE Trans. on Electron Devices, ED-10: 292-294, 1962.

E33. Tanenbaum, M. and Thomas, D. E., "Diffused Emitter and Base Silicon Transistors," Bell System Tech. J., 35: $1-22$, 1956.

E34. Boothroyd, A. R. and Trofimenkoff, F. N., "Determination of the Physical parameters of Transistors of Single and Double-Diffused Structure," IEEE Trans. on Electron Devices, ED-10: 149-163, 1963 .

E35. Shockley, W. and Read, W. T., Jr., "Statistics of the Recombinations of Holes and Electrons," Phys. Rev.' 87: $835-842,1952$.

E36. Shockley, W., "Electrons, Holes and Traps," Proc. IRE, 46: $973-990,1958$.

E37. Goben, C. A., "Neutron Bombardment Reduction of 
Transistor Current Gain," Ph.D. Thesis, Iowa State University Library, Ames, Iowa, 1965.

E38. Goben, C. A., "A Study of the Neutron-Induced Base Current Component in Silicon Transistors," IEEE Radiation Effects Conference, Ann Arbor, Michigan, 1965. IEEE. Trans. on Nuclear Science, NS-12: 5. 134-146, 1965 .

E39. Goben, C. A., Smits, F. M. and Wirth, J. L., "Neutron Radiation Damage in Silicon Transistors," IEEE Trans. on Nuclear Science, to be published April, 1968 .

E40. Chott, J. R. and Goben, C. A., "Annealing Characteristics of Neutron Irradiation Silicon Transistors," IEEE Trans. On Nuclear Science, NS-14: 6, 134-146, 1967 .

E41. Sander, H. H. and Gregory, B. L., "Transient Annealing in Semiconductor Devices Following Pulsed Neutron Irradiation," IEEE Trans. on Nuclear Science, NS-13: 6 , $53-62,1966$.

E42. Bass, R. F., "Influence of Impurities on Carrier Removal and Annealing in Neutron-Irradiated Silicon," IEEE Trans. on Nuclear Science, NS-14: 6, 78-81, 1967.

E43. Curtis, O. L., Jr. and Germano, C. A. "InjectionLevel Studies in Neutron-Irradiated Silicon," IEEE Trans. on Nuclear Science, NS-14:6, 68-77, $19 \overline{67 .}$

E44. Curtis, O. L., Jr., "Effects of Oxygen and Dopant on Lifetime in Neutron-Irradiated Silicon," IEEE Trans. on Nuclear Science, NS-13: 6, 33-40, 1966 .

E45. Messenger, G. C., "A Two Level Model for Lifetime Reduction Processes in Neutron Irradiated Silicon and Germanium," IEEE Trans. On Nuclear Science, NS-14: 6 , $88-102,1967$.

E46. Gwyn, C. W., Scharfetter, D. L. and Wirth, J. L. "The Analysis of Radiation Effects in Semiconductor Junction Devices," IEEE Trans. on Nuclear Science', NS-14: $6,153-169,1967$.

E47. Hughes, H. I., "Comparative Study of Ionizing Radiation Surface Effects, Utilizing MOS Device Fabricated with Various Dielectrics," IEEE Annual Conference on Nuclear and Space Radiation Effects, Palo Alto, Calif., July, 1966. 
E48. Maier, R. J., "Radiation Induced Surface Recombination in Oxide Passivated Transistors," IEEE Trans. on Nuclear Science, NS-14: 6, 252-259, 1967 . 


\section{APPENDIX F: BACKGROUND OF THE PROBLEM}

One important limitation of transistors operated in a neutron environment is the decrease in transistor current gain observed upon exposure to neutron irradiation. This reduction in current gain results from the degradation of minority carrier lifetime ${ }^{F 1-F 5}$ in the base region (that is, to the resultant reduction of the base recombination term $^{\mathrm{Fl}-\mathrm{F5}}$, and to the reduction in the emitter efficien$\mathrm{CY}^{\mathrm{F6}-\mathrm{F9}}$. In Goben's work ${ }^{\mathrm{F} 8, \mathrm{F9}}$, it was shown that the emitter efficiency is indeed a very sharply decreasing function of neutron fluence and is responsible for a large fraction of the neutron degradation of transistor current gain. Several facts have been concluded from Goben's work. They are:

1. Degradation of parameters in the base region due to neutron bombardment is similar to that of parameters in bulk material.

2. The base recombination term did degrade with neutron fluence, but not as substantially as had been assumed in the past ${ }^{1-F 5}$.

3. A base current component is induced when the transistor is exposed upon neutron bombardment.

4. This neutron-induced base current component has an emitter-to-base voltage dependence of $\exp \left(\mathrm{qV}_{\mathrm{BE}} / \mathrm{nkT}\right)$; $\mathrm{n}$ is approximately 1.5 .

5. This neutron-induced component is of bulk origin rather than surface origin, as may have been 
assumed from its voltage dependence.

6. The effect of this neutron-induced component of base current is the degradation of the emitter efficiency.

The analytical relationship between the increase in base current and neutron fluence, $\phi$, is given ${ }^{\mathrm{B}}$. by the equation below ${ }^{\text {I }}$,

$$
I_{B N}=K_{V} \cdot A_{E} \cdot x_{m}\left(V_{B E}\right) \cdot \phi \cdot \exp \left(\frac{q}{n k T} V_{B E}\right),
$$

where $x_{m}\left(V_{B E}\right)=$ depletion layer width $(\mathrm{cm})$,

$$
\begin{aligned}
\mathrm{K}_{\mathrm{V}} & \simeq \text { damage constant }\left(3.3 \times 10^{-17} \mathrm{amp} / \mathrm{cm}^{3} / \mathrm{nvt}\right), \\
\mathrm{A}_{\mathrm{E}} & =\text { emitter area }\left(\mathrm{cm}^{2}\right), \\
\phi & =\text { neutron fluence }(\mathrm{nvt}), \\
\mathrm{V}_{\mathrm{BE}} & =\text { emitter-to-base voltage (volt), } \\
\mathrm{n} & \simeq 1.5 \text { at } \mathrm{T}=300^{\circ} \mathrm{K} .
\end{aligned}
$$

This neutron-induced base current component has been observed $^{F 8}$ over several decades in current and dominates transistor gain over a wide range of current density (e.g., from $10^{-9}$ to $10^{-4}$ amp for epitaxial-planar transistor 2N914). It is primarily responsible for degradation of the transistor current gain by decreasing the emitter efficiency.

Steady-state recombination statistics of electrons and holes have been developed by Shockley, Read and Hall, and are called Shockley-Read-Hall statistics Fl0,Fll. It is assumed that the recombination-generation of electrons and holes in semiconductors may take place at some type of recombination centers or traps. These sites may be lattice 
dislocations, impurity atoms located interstitially or substitutionally in the crystal lattice, or surface defects. Recombination may also occur directly with the emission of light or by the three particle process : (Auger process) Fl0 with the third carrier carrying away the energy. There is insufficient information ${ }^{\mathrm{F} 12}$ about the Auger process in semiconductors. There are four basic processes ${ }^{\mathrm{FlO}}$ involved in the carrier recombination-generation through the recombination, centers: 1) electron capture; 2) hole emission; 3) electron emission; and 4) hole capture. Under steady-state conditions, a single energy level recombination center is largely described by three parameters ${ }^{\mathrm{Fl0}}$ : the capture crosssection for holes, the capture cross-section for electrons, and the energy involved in these transitions.

Sah, Noyce and Shockley. ${ }^{\text {F12,13 }}$ pointed out that the measured $p-n$ junction current-voltage characteristics deviated from the ideal case of the diffusion model ${ }^{F 10}$. Sah et al. have derived ${ }^{\mathrm{F} 12}$ a physical theory for $\mathrm{p}-\mathrm{n}$ junctions taking into account. the recombination and generation of the carriers in the space-charge (or transition) region. This model accounts for the nonsaturable reverse current and also predicts an apparent exp(qV/nkT) dependence of forward current in a $\mathrm{p}-\mathrm{n}$ junction. The increase of the emitter efficiency of silicon transistors with emitter current was explained by the relative importance of the diffusion current outside the space-charge region and the recombination current inside the space-charge region ${ }^{\mathrm{F} 12}$. They also found ${ }^{\mathrm{F} 12}$ 
that the most effective energy level for the recombination centers is a few kT from the intrinsic Fermi energy level. Based on the Shockley-Read-Hall statistics, Messenger ${ }^{\text {Fl4 }}$ proposed a model for neutron-radiated germanium; the position in the forbidden band of the recombination site was $E_{C}$ - $E_{R}=0.23 \mathrm{eV}$, and the capture cross sections of the site for electron and hole capture were $\sigma_{\mathrm{n}} \simeq 4.0 \times 10^{-15}\left(\mathrm{~cm}^{2}\right)$ and $\sigma_{\mathrm{p}} \simeq 1.0 \times 10^{-15}\left(\mathrm{~cm}^{2}\right)$, respectively: This model predicted that the interstitial atom acted as a donor, and the vacancy as an acceptor. There are many "radiation-induced energy levels" in the forbidden band in silicon ${ }^{\mathrm{F} 15}$; the recombination levels are known to exist at the center of the band and were found $\mathrm{Fll}^{15}$ to be $0.37 \mathrm{eV}$ above the valence band. At low bias levels recombination centers present in the emitter diode field region cause a very large decrease in current gain. At higher levels of emitter bias current, recombination centers present in the base region cause a reduction in current gain ${ }^{F 15}$. Messenger ${ }^{\text {Fl6 }}$ proposed a two level model which resolved the contradictions inherent in fitting experimental data for neutron irradiated silicon to the one level models previously used. But the two level model has two substantial deficiencies: I) it is an arbitrarily chosen approximation to a very complicated defect structure which is known to contain many levels; 2) there are certainly several other plausible alternative extensions or modifications to the one level model which might also resolve its contradictions with experimental data. 


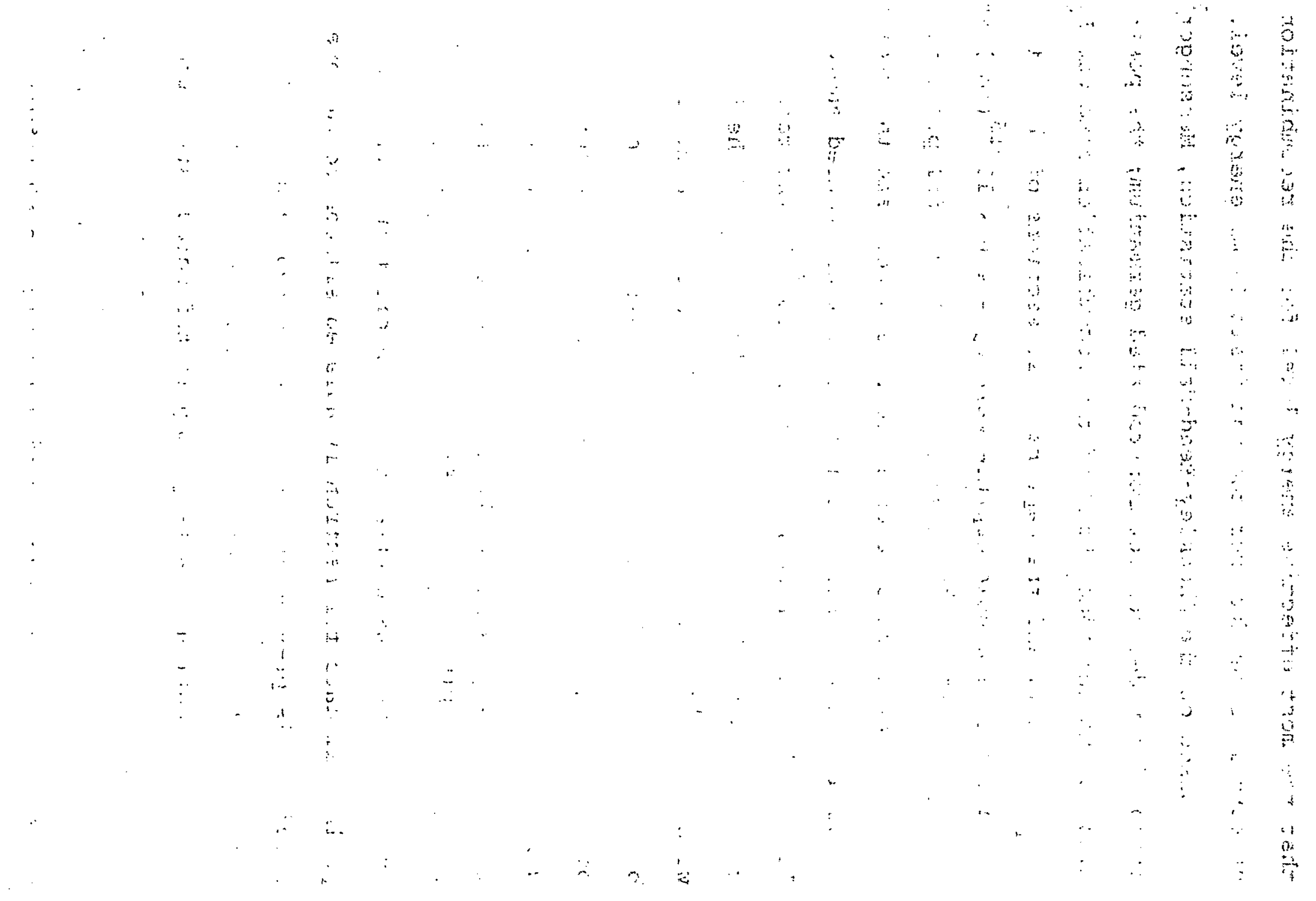




\section{REFERENCES}

F1. Loferski, J. K., "Analysis of the Effect of Nuclear Radiation on Transistors," J. Appl. Phys., 29: 35-40, 1958.

F2. Messenger, G. C. and Spratt, J. P., "The Effects of Neutron Irradiation on Germanium and Silicon," Proc. IRE, 46: 1938-1044, 1958 .

F3. Easley, J. W. and Dooley, J. A., "On the Neutron Bombardment Reduction of Transistor Current Gain," J. Appl. Phys., 31: 1024-1028, 1960.

F4. Hood, J...A., "Predicting the Current Gain Degradation in npn Silicon Transistors by High-Energy Neutrons," Sandia Lab. (Albuquerque, N. M.), SC-TM-64-69, 1964.

F5. Easley, J. W., "Radiation Damage to Semiconductor Devices," Sandia Lab. (Albuquerque, N. M:), SCR-532, 1962 .

F6. Goben, C. A. and Smits, F. M., "Anomalous Base Current Component in Neutron Irradiated Transistors," Sandia Corp. (Albuquerque, N. M.) , SC-R-64-195, 1964.

F7. Goben, C. A., Smits, F. M. and Wirth, J. L., "Neutron Radiation Damage in Silicon Transistors," Sandia Corp. (Albuquerque, N. M.) , SC-RR-67-312, 1967.

F8. Goben, C. A., "A Study of the Neutron-Induced Base Current Component in Silicon Transistors," IEEE Radiation Effects Conference, Ann Arbor, Michigan, 1965. IEEE Trans. on Nuclear Science, NS-12: 5, 134-146, 1965 .

F9. Johson, P. E., Su, L. S., Gassner, G. E., Beckmann, T. D. and Goben, C. A., "Radiation and Annealing Characteristics of Neutron Bombarded Silicon Transistors," to be presented in the 1968 IEEE Annual Conference on Nuclear and Space Radiation Effects.

F10. Shockley, W. and Read, W. T., "Statistics of the Recombination of Holes and Electrons," Phys. Rev., 87: 835-842, 1952 .

Fll. Hall, R. N., "Electron-Hole Recombination in Germanium," Phys. Rev., 87: 387-393, 1952. 
F12. Sah, C. T., Noyce, R. N. and Shockley, W., "Carrier Generation and Recombination in $p-n$ Junctions and $p-n$ Junction Characteristics," Proc. IRE, 45: 1228-1243, 1957.

F13. Sah, C. T., "Effect of Surface Recombination and Channel on $\mathrm{p}-\mathrm{n}$ Junction and Transistor Characteristics," IRE Trans. on Electron Devices, ED-9: 94-108, 1962.

F14. Messenger, G. C. and Spratt, J. P., "The Effects of Neutron Irradiation on Germanium and Silicon," Proc. IRE, 46: 1038-1044, 1958 .

F15. Messenger, G. C., "Displacement Damage in Silicon and Germanium Transistors," IEEE Trans. on Nuclear Science, NS-12: $2,53-74,1965$.

F16. Messenger, G. C., "A Two Level Model for Lifetime Reduction Processes in Neutron Irradiated Silicon and German," IEEE Trans. on Nuclear Science, NS-14: 6, 88102,1967 . 
APPENDIX G: A SHORT REVIEW OF STATISTICS REGRESSION MODELS - LEAST-SQUARES FITTING

In a system in which variable quantities change, it is of interest to examine the effects that some variables exert (or appear to exert) on others. There may in fact be a simple functional relationship between variables; in most physical processes this is the exception rather than the rule. Often there exists a functional relationship which is too complicated to grasp or to describe in simple terms. In this case we may wish to approximate to this functional relationship by some simple mathematical function, such as a polynomial, which contains the appropriate variables and which graduates or approximates to the true function over some limited ranges of the variables involved. By examining such a graduating function one may be able to learn more about the under lying true relationship and to appreciate the separate and joint effects produced by changes in certain important variables.

Two types of variables are used in a statistical model. They are independent variables and response variables, or dependent variables. If the model is in the form:

$$
y=p_{0}+p_{1}+p_{1} x+\varepsilon,
$$

where $y$ and $x$ are the dependent and independent variables, respectively and they are observable quantities, $p_{0}$ and $p_{1}$ are called paremeters which are to be estimated by 
statistical least-squared fitting, and $\varepsilon$ is the random error.

When someone says that a model is linear or nonlinear, he is referring to linearity or nonlinearity in the parameters. The value of the highest power of an independent variable in the model is called the order of the model. For example,

$$
y=p_{0}+p_{1} x+p_{2} x^{2}+\varepsilon
$$

is a second-order linear regression model. The methods used for both linear and nonlinear parameters estimations are discussed briefly in the following sections.

\section{Least-Sguares Fitting to Linear Regression}

One defines $\mathrm{Y}$ to be the vector of observations $\mathrm{y}, \mathrm{X}$ to be the matrix of independent variables, $p$ to be the vector of parameters to be estimated, and $\mathrm{E}$ to be the vector of errors. Thus the model in matrix form can be written as:

$$
Y=X P+E,
$$

so that the sum of squares of deviation is:

$$
S=\sum_{i=1}^{m} \varepsilon_{i}^{2}=\sum_{i=1}^{m}\left(y_{i}-\sum_{i=1}^{m} x_{i j} p_{j}\right)^{2},
$$

where $\mathrm{m}=$ number of observations,

$\mathrm{n}=$ number of parameters.

It is desirable to choose the estimates $B$ (a Vector) to have 
the values which result in the least possible value for $s$. One can determine B by differentiating equation (G-4) with respect to $\mathrm{p}^{\prime} \mathrm{s}$, respectively, and setting the results equal. to zero. This yields

$$
X^{\prime} X B=X^{\prime} Y
$$

These are called the normal equations ( $X^{\prime}$ is the transpose of matrix $\mathrm{X}$ ).

The least-squares estimates of $\mathrm{p}^{\prime} \mathrm{s}$ are given by

$$
B=\left(X^{\prime} X\right)^{-1} X^{\prime} Y
$$

if $X^{\prime} X$ is a non-singular matrix. The function used for prediction is in the form

$$
\mathrm{Y}=\mathrm{XB}
$$

\section{Non-Linear Estimation}

Suppose the nonlinear model is of the form

$$
y=f\left(x_{1}, x_{2}, \cdots x_{k} ; p_{1}, p_{2}, \cdots p_{n}\right)+\varepsilon, \quad(G-8)
$$

or in a shorter form

$$
y=f(X, P)+\varepsilon .
$$

If one has $m$ observations, the sum of the squares of the errors is

$$
S(p)=\sum_{i=1}^{m} \varepsilon_{i}^{2}=\sum_{i=1}^{m}\left[y_{i}-f\left(x_{i}, P\right)\right]^{2}
$$


To find the least squares estimate, $B$, one needs to differentiate equation (G-10) with respect to P. This provides the normal equations, which must be solved for $B$. The normal equations take the form:

$$
\sum_{i=1}^{m}\left[y_{i}-f\left(x_{i}, B\right)\right]\left[\frac{\partial f\left(x_{i}, P\right)}{\partial p_{r}}\right]_{p=b}=0 .
$$

In some nonlinear problems it is most convenient to write down the normal equations (G-11) and develop an iterative technique for solving them. Whether this works satisfactorily or not depends on the form of the equations and the $i$ terative method used. In addition to this approach there are several currently employed methods available for obtaining the parameter estimates, by a routine computer calculation. Three of these are: 1) linearization (or Taylor series), 2) steepest descent, and 3) Marquardt's compromise.

The nonlinear estimates used in this paper are the linearization method which requires the initial guesses of the parameters and the analytical derivatives ${ }^{\mathrm{Gl}}$.

Both the linear and nonlinear least-squares parameters estimating programs used to obtain the models in this research were written in Fortran IV language and ran on the IBM system 360 (Mod 50) computer. 
Example - Derivation of equation (5-27)

In the derivation, $\log f(b)$ was treated as the dependent variable, that is, $y$ in equation $(G-8)$, and $E_{R^{\prime}} E_{i},\left(\sigma_{p} / \sigma_{n}\right)$, $\mathrm{V}_{\mathrm{T}}$ and $\mathrm{V}_{\mathrm{BE}}$ were the independent variables as $\mathrm{x}_{\mathrm{i}}$ in equation. $(G-8)$. The $m$ sets of data $\left(Y_{j}, x_{1 j}, x_{2 j}, x_{3 j}\right.$ and $x_{4 j}$; $j=1, \mathrm{~m})$ were generated, as follows, by

1. assuming values for $E_{R^{\prime}} E_{i},\left(\sigma_{p} / \sigma_{n}\right), V_{T}$ and $V_{B E}$, and calculating $z_{1}, z_{2}$ and $b$ by equations (5-22) and $(5-21)$,

2. calculating $f(b)$ by either equation $(5-24)$ or (5-25) or (5-26), decided by the calculated value of $\mathrm{b}$ from step 1 ,

3. calculating $\log _{e} f(b)$ for a set of $E_{R^{\prime}} E_{i},\left(\sigma_{p} / \sigma_{n}\right)$, $\mathrm{V}_{\mathrm{T}}$ and $\mathrm{V}_{\mathrm{BE}}$.

The assumed values for $E_{R}, E_{i},\left(\sigma_{p} / \sigma_{n}\right), V_{T}$ and $V_{B E}$ are listed below

$$
\begin{aligned}
& \mathrm{E}_{\mathrm{R}}=0.15,0.23,0.36,0.8 \\
& \mathrm{E}_{\mathrm{i}}=0.55, \\
& \left(\sigma_{\mathrm{p}} / \sigma_{\mathrm{n}}\right)=30,120,180,300, \\
& \mathrm{~V}_{\mathrm{T}}=0.98,0.68,0.63,0.54, \\
& \mathrm{~V}_{\mathrm{BE}}=0.3,0.4,0.5,0.55,0.6,0.70,0.75 .
\end{aligned}
$$
Therefore, $\mathrm{m}$ was equal to $448\left(=\begin{array}{llllllll}4 & \times & 1 & \times & 4 & 4 & \times & 7\end{array}\right)$. With $m$ sets of data, $\left(y_{j}, x_{i j}\right)$, the following model was assumed, 


$$
\begin{aligned}
y= & V_{B E}+B \log _{e}\left(V_{T}-V_{B E}\right)+\gamma \cdot \frac{V_{B E}}{E_{i}-E_{R}} \\
& \left.+\delta \cdot V_{B E} \cdot \log _{e}\left[\sigma_{p} / \sigma_{n}\right)^{1 / 2}+\left(\sigma_{n} / \sigma_{p}\right)^{1 / 2}\right], \quad(G-12)
\end{aligned}
$$

then the multivariate least-squares fitting technique was used to determine $\alpha, \beta, \gamma$ and $\delta$ in equation (G-12). Finally, equation (G-12) was substituted into equation (5-19) to yield equation (5-27).

\section{REFERENCE}

Gl. Draper, N. R. and Smith, H. Applied Regression Analysis, New York, John Wiley \& Sons, Inc., 1966. 
1. General Consideration of Minority Carrier Lifetimes ${ }^{\mathrm{HI}}$

From Shockley-Read-Hall statistics ${ }^{\mathrm{H} 2, \mathrm{H} 3}$, it can be assumed that the density $\mathrm{N}_{\mathrm{R}}$ of the recombination centers is small compared to the equilibrium concentrations of carriers, $\mathrm{n}$ and p. Furthermore, it is assumed that the centers all lie at a dominant single energy value $E_{R}$ in the forbidden band. The net recombination rate $R$, which is equal to the capture rate of the centers less the emission rate, of the centers is determined as indicated in the following paragraphs.

First, consider the case of the electron. The FermiDirac function $f(E)$ represents the probability that a state at energy $E$ is occupied and $[1-f(E)]$ is the probability that the state: is empty. The net electron-recombination rate is

$$
R_{n}=n C_{n} N_{R}\left[1-f\left(E_{R}\right)\right]-e_{n} N_{R} f\left(E_{R}\right),
$$

where $N_{R}\left[1-f\left(E_{R}\right)\right]$ = number of empty centers $\left(\mathrm{cm}^{-3}\right)$,

$$
\begin{aligned}
\mathrm{N}_{\mathrm{R}} \mathrm{f}\left(\mathrm{E}_{\mathrm{R}}\right)= & \text { number of occupied centers }\left(\mathrm{cm}^{-3}\right), \\
\mathrm{R}_{\mathrm{n}}= & \text { net electron-recombination rate } \\
& \left(\mathrm{cm}^{-3}-\mathrm{sec}^{-1}\right), \\
\mathrm{C}_{\mathrm{n}}= & \text { the capture probability of the centers } \\
& \text { for electrons }\left(\mathrm{cm}^{3} / \mathrm{sec}\right), \\
\mathrm{n}= & \text { the electron concentration }\left(\mathrm{cm}^{-3}\right), \\
\mathrm{e}_{\mathrm{n}}= & \text { the thermal emission rate for }
\end{aligned}
$$




$$
\text { electrons }\left(\sec ^{-1}\right) \text {. }
$$

Similar results can be obtained for the case of the hole, with the exception that the capture rate is proportional to the number of filled centers. Likewise, the emission rate for holes is proportional to the number of empty centers. Thus, the net hole-recombination rate is given by

$$
R_{p}=p C_{p} N_{p} f\left(E_{R}\right)-e_{p} N_{R}\left[1-f\left(E_{R}\right)\right],
$$

where the notations have their definitions corresponding to those for the electron in equation ( $H-1)$.

Under the nonequilibrium condition, the net recombination rate for the electrons and that for the holes must be equal to each other, that is,

$$
\begin{aligned}
R & =R_{n}=R_{p} \\
& =n C_{n} N_{R}\left[1-f\left(E_{R}\right)\right]-e_{n} N_{R} f\left(E_{R}\right) \\
& =p C_{p} N_{R} f\left(E_{R}\right)-e_{p} N_{R}\left[1-f\left(E_{R}\right)\right] .
\end{aligned}
$$

Solving equation $(H-3)$ for $f\left(E_{R}\right)$, one obtains the probability factor for filled centers as follows

$$
f\left(E_{R}\right)=\frac{n C_{n} N_{R}+e_{p} \dot{N}_{R}}{n C_{n} N_{R}+e_{p} N_{R}+p C_{p} N_{R}+e_{n} N_{R}}
$$

or

$$
f\left(E_{R}\right)=\frac{1}{1+\left(p C_{p}+e_{n}\right) /\left(n C_{n}+e_{p}\right)} .
$$


In the final expression of the net recombination rate R, one would like to eliminate the emission-rate parameters, $e_{n}$ and $e_{p}$. This can be achieved by considering the condition at equilibrium.

At equilibrium, the net recombination rate must be zero. Therefore, if the Fermi level is adjusted such that $E_{F}=E_{R^{\prime}}$, the emission rates for electrons must equal the free-electron concentration $\mathrm{n}_{r}$ times their capture probability $C_{n}$, that is,

$$
e_{n}=n_{r} C_{n}
$$

The emission rate for holes is given by

$$
e_{p}=p_{r} c_{p}
$$

where $\mathrm{p}_{r}$ is the hole concentration that would exist if the Fermi level coincided with the energy level $E_{R}$ of the recombination centers. In other words,

$$
\begin{aligned}
& \mathrm{n}_{r}=\mathrm{N}_{C} \cdot \exp \left(-\frac{\mathrm{E}_{\mathrm{C}}-\mathrm{E}_{\mathrm{R}}}{\mathrm{kT}}\right), \\
& \mathrm{p}_{r}=\mathrm{N}_{V} \cdot \exp \left(-\frac{\mathrm{E}_{\mathrm{R}}-\mathrm{E}_{\mathrm{V}}}{\mathrm{kT}}\right) .
\end{aligned}
$$

Substituting equations $(\mathrm{H}-6)$ and $(\mathrm{H}-7)$ into $(\mathrm{H}-4)$, and then $(\mathrm{H}-4)$ into equation $(\mathrm{H}-5)$, and after some algebra, one obtains 


$$
R=\frac{\mathrm{N}_{R} c_{n} c_{p}\left(n p-n_{r} p_{r}\right)}{c_{n}\left(n+n_{r}\right)+c_{p}\left(p+p_{r}\right)^{\prime}}
$$

with the definitions for limiting lifetimes, viz.,

$$
\tau_{\mathrm{pr}}=\frac{1}{\mathrm{~N}_{\mathrm{R}} \mathrm{C}_{\mathrm{p}}} ; \quad \tau_{\mathrm{nr}}=\frac{1}{\mathrm{~N}_{\mathrm{R}} \mathrm{C}_{\mathrm{n}}}
$$

and the relationship of $n_{r} \cdot p_{r}=n_{i}^{2}$, equation $(H-10)$ can be rewritten as follows

$$
R=\frac{n p-n_{i}^{2}}{\tau_{p r}\left(n+n_{r}\right)+\tau_{n r}\left(p+p_{r}\right)}
$$

The lifetime has been defined as

$$
\tau=\frac{\Delta c}{R},
$$

where $\Delta \mathrm{c}=\Delta \mathrm{p}=\Delta \mathrm{n}$ (due to charge neutrality), and represents small departures from the equilibrium value. Performing the differentiation by considering

$$
\begin{aligned}
& n \rightarrow n+\Delta n(o r, \mathrm{n}+\Delta c), \\
& p \rightarrow p+\Delta p(\text { or, } \mathrm{p}+\Delta c),
\end{aligned}
$$

where $\mathrm{n}$ and $\mathrm{p}$ on the right hand sides are the equilibrium values, from equation $(\mathrm{H}-13)$ one can write

$$
\frac{l}{\tau}=\lim _{\Delta c \rightarrow 0} \frac{R(n+\Delta c, p+\Delta c)-R(n, p)}{\Delta c} .
$$

Substituting equation $(\mathrm{H}-12)$ into $(\mathrm{H}-15)$, one can obtain the 
final expression for the minority carrier lifetime as

$$
\tau=\frac{\tau_{p r}\left(n+n_{r}\right)+\tau_{n r}\left(p+p_{r}\right)}{n+p} \text {. }
$$

2. The Limiting Lifetimes and the Capture Probabilities of the Centers for Holes and Electrons

The electron and the hole concentrations are given ${ }^{\mathrm{Hl}}$ by the following equations,

$$
\begin{aligned}
& \mathrm{n}=\mathrm{N}_{\mathrm{C}} \cdot \exp \left(-\frac{\mathrm{E}_{\mathrm{C}}-\mathrm{E}_{\mathrm{F}}}{\mathrm{kT}}\right), \\
& \mathrm{p}=\mathrm{N}_{\mathrm{V}} \cdot \exp \left(-\frac{\mathrm{E}_{\mathrm{F}}-\mathrm{E}_{\mathrm{V}}}{\mathrm{kT}}\right),
\end{aligned}
$$

where $E_{F}$ is the Fermi energy level for the thermal equilibrium conditions. Let $\mathrm{E}_{i}$ represent the intrinsic Fermi energy, from equations $(\mathrm{H}-8),(\mathrm{H}-9),(\mathrm{H}-17)$ and $(\mathrm{H}-18)$, the following relationships can be easily obtained, under the assumption that $\mathrm{N}_{\mathrm{C}}=\mathrm{N}_{\mathrm{V}}$,

$$
\frac{\mathrm{n}_{r}}{\mathrm{n}}=\exp \left(\frac{\mathrm{E}_{\mathrm{R}}-\mathrm{E}_{\mathrm{F}}}{\mathrm{kT}}\right) \text {, }
$$

$$
\frac{\mathrm{n}_{r}}{\mathrm{p}}=\exp \left(\frac{\mathrm{E}_{\mathrm{R}}+\mathrm{E}_{\mathrm{F}}-2 \mathrm{E}_{i}}{k T}\right)
$$

$$
\frac{p_{r}}{p}=\exp \left(\frac{E_{F}-E_{R}}{k T}\right) \text {, }
$$

and, $\quad \frac{p_{r}}{n}=\exp \left(\frac{2 E_{i}-E_{R}-E_{F}}{k T}\right)$. 
Consider the case of heavily doped n-type material, with $E_{F}$ $>E_{i}$ and $n \gg p$ (or, $\left.n+p \simeq n\right)$, by equations $(H-9)$ and $(\mathrm{H}-22)$, equation $(\mathrm{H}-16)$ becomes

$$
\tau \simeq \tau_{p r}\left[1+\exp \left(\frac{E_{R}-E_{F}}{k T}\right)\right] .
$$

Similarly, for the case of heavily doped p-type material, the following equation holds,

$$
\tau=\tau_{n r}+\tau_{p r} \cdot \exp \left(\frac{E_{R}+E_{F}-2 E_{i}}{k T}\right)
$$

Equations $(\mathrm{H}-23)$ and $(\mathrm{H}-24)$ are assumed to be true also for npn transistors, that is, if $\tau_{B}$ and $\tau_{C}$ represent the minority carriers lifetimes in the base and the collector regions, - respectively, then one has the following relationships

$$
\begin{aligned}
& \tau_{C} \simeq \tau_{p r}\left[1+\exp \left(\frac{E_{R}-E_{F}}{k T}\right)\right], \\
& \tau_{B} \simeq \tau_{n r}+\tau_{p r} \cdot \exp \left(\frac{E_{R}+E_{F}-2 E_{i}}{k T}\right) .
\end{aligned}
$$

The limiting lifetimes are those of holes in highly ntype material and those of electrons in heavily p-type material; they are defined as

$$
\tau_{p r}=\frac{1}{N_{R} C_{n}} ; \quad \tau_{n r}=\frac{1}{N_{R} C_{p}}
$$


where $\mathrm{N}_{\mathrm{R}}$ is the concentration of recombination centers $\left(\mathrm{cm}^{-3}\right)$, and $\mathrm{C}_{\mathrm{p}}$ and $\mathrm{c}_{\mathrm{n}}$ are the capture probabilities of the centers for holes and electrons, respectively, $\left(\mathrm{cm}^{3}-\mathrm{sec}^{-1}\right)$. $C_{p}$ and $C_{n}$ differ from each other due to the differences in the effective mass values for holes and electrons.

\section{REFERENCES}

H1. Phillips, A. B., Transistor Engineering, Chapters 4 \& 5 and Appendix, New York, McGraw-Hill, 1962.

H2. Shockley, W. and Read, W. T., "Statistics of the Recombination of Holes and Electrons," Phys. Rev., 87: 835842,1952 .

H3. Hall, R. N., "Electron-Hole Recombination in Germanium," Phys. Rev., 87: 387-393, 1952. 
8 